(x)

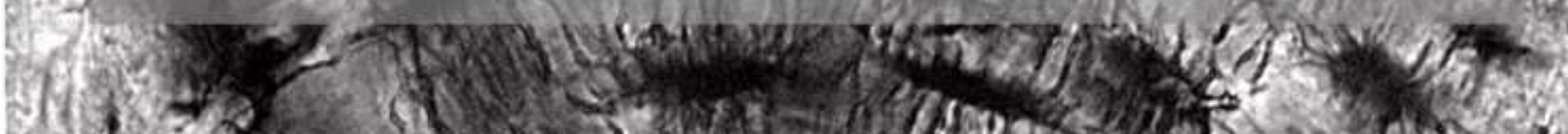
18 (1)

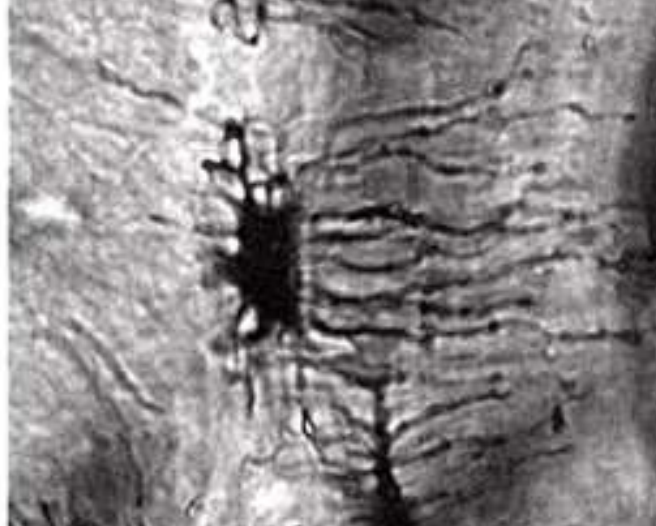

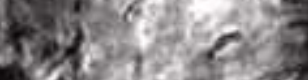

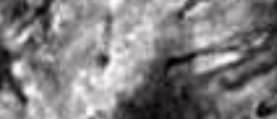


Trabajo de Tesis para optar al título de Doctor en

Ciencias de la Salud

Facultad de Ciencias Médicas

Universidad Nacional de La Plata

\section{"Validación metodológica para la estimación de edad en restos óseos humanos adultos: análisis histomorfométrico"}

Lic. Bárbara Desántolo

Director: Dra. Susana A. Salceda

Co-director: Dra. Ana M. Inda 
A mis padres, Mandy y Faby 
En primer lugar, quiero agradecer a mi directora Dra. Susana Salceda, en lo profesional por su guía permanente no sólo en este trabajo en particular sino en toda mi formación, por su confianza, por su estímulo constante y por no dejarme claudicar, por su mirada crítica. En lo personal, por todos estos años compartidos, por los kilómetros recorridos, por estar en los momentos que fue necesario, por su contención y por sobre todo por su amistad.....Gracias Su!

A mi Co-Directora, Dra. Ana María Inda y Directora del Proyecto "Análisis macro y microscópico de restos óseos humanos. Aporte a la investigación forense y antropológica" por su confianza, su contención y su total apoyo tanto en lo profesional como en lo personal.

A la Dra. Ana Lía Errecalde, Titular de la Cátedra de Citología, Histología y Embriología " $A$ " (FCM-UNLP) por abrirme las puertas de su cátedra y brindarme un lugar de trabajo con todo lo que ello implica, por darme la oportunidad de iniciarme y transitar el camino de la docencia y la investigación, por creer en este proyecto.

A las "chicas" de la cátedra Marce, Laurita, Ceci, Adri, Aye y Su.

A Javiera por prepararme los primeros vidrios y a Maite por ayudarme con el desgaste de los huesitos.

A "Mari" por darme una mano con el retoque final del manuscrito.

A las autoridades y personal del Cementerio Municipal La Plata, sin cuya desinteresada labor este proyecto no hubiese sido posible.

Al Decano de la Facultad de Ciencias Médicas, Dr. Jorge Martínez por su respaldo académico. 
Al Director del Laboratorio de Investigaciones Morfológicas Aplicadas, Dr. Guillermo Prat, por haberme brindado un espacio físico en la primera etapa de este proyecto y al Dr. David Costi.

A la Facultad de Ciencias Naturales y Museo, en donde realicé mi formación de grado.

Al Lic. Calandra "Hora" por estar presente a lo largo de mi carrera, por estar ahí cuando fue necesario..." por la mirada constante y la palabra precisa"....

Al Lic. De Feo "Carlitos" por su amistad y por brindarme su ayuda que resultó indispensable para poder hoy lograr esta meta.

A Rocío y Marcos mis compañeros de cruzadas, mis amigos, pilares fundamentales de este proyecto sin ellos esto no hubiera sido posible.

Un especial agradecimiento a la Lic. Maliandi "Puchi" y al Dr. Paggi "Richar" quien realizó todos los cortes. Ambos me enseñaron los secretos de la histomorfometría, por su generosidad absoluta, por las tardes enteras dedicadas al microscopio y el ansiado aperitivo de las siete, por ser grandes amigos, mil gracias!

A mis colegas y grandes amigos, los de aquí y los de allá....Celes, Marian, Marien, Faby (por la edición de la tapa), Maruja, las Gabys, Vero, Guille, Gabo y Hilton, gracias a todos por estar siempre!

A mi querido Lean, por el camino recorrido juntos....

A mis amigos de "Histo" Pablo, Pame, Ceci, Dami, Juani y Andres gracias por el aguante sobre todo en estos últimos meses.

A Vero, mi compañera de rutas... 
A mi familia extensa....

A Mandy, mi madre a quien le debo lo que soy...

A Faby Murane, mi padre de la vida, por su amor incondicional...

A mis hermanos "larvas" Fede, Facu y Charo de quienes aprendo día a día.

A Nestin y María Lofrano, a mis bellas sobrinas Elena y Emilia...

A mi tía Mirta, mi segunda madre.

Por último, no quiero dejar de mencionar que mi formación de grado y posgrado fue posible gracias a la UNIVERSIDAD PÚBLICA!!!! 


\section{ÍNDICE GENERAL}

INDICE

- de figuras

IX

- de gráficos

IX

- de tablas

$X$

RESUMEN

INTRODUCCIÓN 3

- Objetivos e hipótesis de la investigación 9

$\begin{array}{lr}\text { CAPÍTULO I } & 10\end{array}$

I.1- Estimación de la edad: aproximaciones teóricas 11

$\begin{array}{ll}\text { I.2- Histomorfología ósea } & 17\end{array}$

I.2.1- Componentes celulares y matriz ósea 19

- Células Osteoprogenitoras

- Osteoblastos y osteocitos

- Osteoclastos

- Matriz extracelular

I.3- Clasificación del tejido óseo

I.3.1- Hueso no laminar, primario o plexiforme

I.3.2- Hueso laminar, secundario o adulto

I.4- Histogénesis ósea

I.4.1- Osificación intramembranosa

I.4.2- Osificación endocondral

I.4.3- Crecimiento, modelado y remodelado óseo 
II.1- Estimación histomorfométrica de la edad

li.2- Un repaso histórico

Capítulo III: Material y Métodos

III.1- La colección Lambre

III.1.1- Acondicionamiento

III.1.2- Relevamiento documental

III.1.3- Composición de la colección

III.2.1- Preparación de la muestra

III.2.2- Procesamiento de la muestra

50

- Técnica de desgaste

50

- Técnica en inclusión en resina

III.3- Evaluación histomorfométrica de la muestra

III.3.1- Procesamiento de imágenes

III.3.2- Cuantificación de las variables

III.4- Procesamiento estadístico 
V.2.1- Obtención y preparación de las secciones histológicas

V.2.2- Observación y cuantificación de las variables

V.2.3- Preservación, procesos tafonómicos y diagénesis

V.4- A propósito de los resultados estadísticos y modelos resultantes

V.5- A propósito de la validación de otros métodos en la colección Lambre

I- Ordenanza municipal 7638/90

II- Ordenanza municipal 9471/02

III- Acuerdo de cooperación entre Facultad de Ciencias Médicas y Facultad de Ciencias Naturales y Museo (UNLP) 146 
V- Declaración de la Asociación de Antropología Biológica Argentina

VI- Código deontológico para el estudio, conservación y

Gestión de restos humanos de poblaciones del pasado

(Asociación de Antropología Biológica Argentina).

VII- Resolución n³76/12 Reconocimiento de la colección osteológica

Rómulo Lambre por la Facultad de Ciencias Médicas (UNLP). 158

VIII- Acta de aprobación del Comité de Biótica de la Facultad

161

de Ciencias Médicas del Protocolo “Integración y análisis de la

colección osteológica Rómulo Lambre"(Exp.: 0800-013812/12-000)

Tablas Anexo de Resultados

Tabla I- Matriz básica de datos

Tabla II- Comparaciones múltiples - HSD de Tukey (N.On.Fg.)

Tabla III- Resumen del modelo

Tabla IV- Análisis de la varianza

Tabla V-Coeficientes de la ecuación de regresión

Tabla VI- Resumen del modelo

Tabla VII- Análisis de la varianza ANOVA

Tabla VIII- Coeficientes de la ecuación de regresión

Tabla IX- Edades estimadas a partir de los diferentes métodos 


\section{Índice de Figuras}

Figura 1- Hueso cortical y esponjoso

Figura 2- Sección transversal y longitudinal de un hueso largo

Figura 3- Vista longitudinal de la unidad multicelular básica (BMU) 26

Figura 4 -Remodelación ósea en una unidad multicelular básica (BMU).

Figura 5- Remodelación del hueso cortical y trabecular en fémur. 28

\section{Índice de Gráficos}

Gráfico 1- Distribución de edad y sexo de la colección Lambre

Gráfico 2- Nacionalidad de los individuos adultos

Gráfico 3- Distribución de edad y sexo de la muestra

Gráfico 4- Diagramas de dispersión entre la edad y las variables

Histomorfométricas

Gráfico 5- Gráfico de medias por rangos de edad para la variable N.On.Fg

Gráfico 6- Edad documentada vs edad estimada por el método de Singh y Gunberg

Gráfico 7- Sesgo e inexactitud del método de Singh y Gunberg

Gráfico 8- Edad documentada vs edad estimada por el

método de Kerley

Gráfico 9- Sesgo e inexactitud del método de Kerley 
Gráfico 10- Edad documentada vs edad estimada por el método de Vasallo y col.

Gráfico 11- Sesgo e inexactitud del método de Vasallo y col.

Gráfico 12- Sesgo e inexactitud del método de Vasallo y col.

para individuos menores de 49 años.

Gráfico 13- Sesgo e inexactitud del método de Vasallo y col.

para individuos mayores de 50 años.

\section{Índice de Tablas}

Tabla 1- Conformación de la muestra

Tabla 2- Distribución de edad y sexo

Tabla 3- Variables histomorfométricas

Tabla 4- Distribución de la muestra por rangos de edad

Tabla 5- Estadísticos descriptivos de las variables

histomorfométricas

Tabla 6- Prueba de Kolmogorov-Smirnov para una muestra

Tabla 7- Prueba de homogeneidad de varianza

Tabla 8- Estadísticos de grupo del procedimiento de la prueba de t 73

Tabla 9- Prueba de t para muestras independientes

Tabla 10- Matriz de correlaciones parciales

Tabla 11- Resumen del modelo de regresión líneas múltiple 
Tabla 13- Coeficientes de regresión parcial

Tabla 14- Estadística descriptiva N.On.Fg por rangos de edad

Tabla 15- ANOVA de un factor

Tabla 16- Subconjuntos homogéneos (N.On.Fg) HSD de Tukey

Tabla 17- Ecuaciones de predicción obtenidas a partir del análisis de regresión

Tabla 18- Métodos validados

85 


\section{RESUMEN}

El presente trabajo de tesis consiste en el desarrollo de una ecuación predictiva para la estimación de edad a la muerte en restos óseos humanos adultos. Dicho trabajo fue desarrollado sobre la base del análisis de la validez y el ajuste de diferentes metodologías microscópicas. La originalidad de la propuesta radica en la utilización del análisis microscópico que facilitará las estimaciones en restos óseos fragmentarios procedentes de contextos arqueológicos y/o forenses.

La muestra estudiada estuvo conformada por restos óseos pertenecientes a la Colección Osteológica "Prof. Dr. Rómulo Lambre" alojada en la Facultad de Ciencias Médicas de la Universidad Nacional de La Plata. Para llevar a cabo este estudio se examinaron 150 fémures de individuos adultos, 54 femeninos y 89 masculinos, entre 22 y 91 años con una media de 69,86. Las secciones histológicas analizadas se obtuvieron a partir de la remoción de tejido cortical de la mitad anterior de la diáfisis femoral tal y como sugiere la bibliografía especifica.

Se identificaron y cuantificaron cinco variables microestructurales según criterios previamente publicados por varios autores: no total de osteonas completas (N.On), número de osteonas fragmentarias (N.On.Fg), diámetro promedio de los conductos de Havers (Can.Hav), porcentaje de osteonas fragmentarias (\%On.Fg) y la densidad poblacional osteonal (OPD). Para el análisis microscópico se empleó un Fotomicroscopio Trinocular Nikon (Mod. Eclipse E200) con objetivo 10X y ocular 10X, equipado con cámara digital Nikon (Mod. Coolpix S10).

La observación e identificación de las variables se realizó a través de un programa analizador de imágenes, Image Pro Plus 4.5 (Media Cybernetics). Este permitió efectuar las mediciones y conteo sobre cada microfotografía, cuatro por preparado histológico.

La mayoría de las variables demostraron una asociación significativa con la edad. El N. On. Fg presentó una alta correlación positiva con la edad $(R=0,779)$ seguida por la OPD $(R=0,741)$ y el \% On.Fg $(R=0,646)$, a diferencia del N.On ( $R=$ 
0,330) que presentó una correlación positiva baja. Contrariamente, el Can.Hav no presentó relación lineal con la edad $(R=0,158 ; P>0,187)$, y por lo tanto dicha variable fue excluida del modelo dada su ineficacia como predictora de la edad.

Los análisis estadísticos multivariados nos permiten aseverar que la variable predictiva de la edad para adultos de entre 22 a 91 años es el número de osteonas fragmentarias. Sin embargo, dividiendo la muestra en dos grupos de edad se encontró que: 1) para adultos medios (menores de 49 años) las variables predictivas son el número de osteonas completas y la densidad poblacional osteonal; 2) para adultos mayores (más de 50 años) la variable predictiva es el número de osteonas fragmentarias.

Finalmente, la histomorfometría o histología cuantitativa, ofrece estimaciones precisas y efectivas para adultos mayores de 50 años, en contraste con la mayoría de los métodos basados en la morfología macroscópica del esqueleto, en donde el límite de las estimaciones es, precisamente, los 50 años de edad cronológica. La histomorfometría cobra relevancia en aquellos casos en los cuales los restos se encuentran fragmentados o incompletos, y resulta imposible la aplicación de métodos macroscópicos para la estimación de edad. Si bien la utilización de las técnicas histológicas de estimación de edad han presentado cierta incertidumbre respecto de su exactitud y fiabilidad, concordamos con Stout y Crowder (2012) que la identificación de cuestiones metodológicas específicas así como la mejora de los protocolos, harán de la histomorfometría una herramienta útil para el análisis bioantropológico y forense. 
INTRODUCCIÓN 
En el campo multidisciplinar de la osteología humana, las investigaciones involucran a un conjunto de disciplinas (e.g. antropología biológica/ bioantropología, anatomía, biología, paleontología, entre otras) que comparten el interés en conocer las características biológicas individuales y poblacionales, en todo tiempo y espacio, a través del análisis e interpretación de los huesos (Verano y Ubelaker 1992, Reichs 1998, Katzenberg y Saunders 2008, White y Folkens 2005).

En este marco, la bioantropología en particular, no sólo ha desarrollado una serie de técnicas macroscópicas estandarizadas que permiten la caracterización de los restos óseos, sino que también ha incorporado técnicas histológicas que aportan y complementan dicha caracterización a partir de la observación de la microestructura del tejido óseo humano (Kerley 1965, Sing y Gumberg 1970, Stout 1989, Vasallo et al. 2001).

En ambos casos, el nivel de aproximación que se puede lograr es variable, dependiendo la estimación de muchos factores, entre los cuales el estado de conservación de los restos y la información de contexto a la que se pueda acceder constituyen los más destacables.

Existen dos importantes áreas de conocimiento en las cuales los resultados de las investigaciones osteológicas son frecuentemente aplicados. En primer lugar nos referimos a la osteología forense -una de las ramas de la antropología forensequehacer requerido por los sistemas de seguridad y justicia, para la identificación de individuos no documentados, en acciones que pertenecen a foros públicos y que generalmente se dirimen en una corte de leyes.

En segundo lugar y en el mismo sentido, los conocimientos sobre osteología son comúnmente aplicados tanto en la investigación bioarqueológica como en la paleontológica (White y Folkens 2005, Ubelaker 2008).

En ambos casos, la información que los huesos humanos proveen resulta de suma importancia pues el esqueleto frecuentemente preserva evidencias de los modos de vida individuales y de las adaptaciones que los individuos, como integrantes de un grupo humano, sufren en los distintos ambientes naturales y culturales (Ubelaker 2008). 
En particular para las poblaciones del pasado, la inferencia llegará hasta diagnosticar las características biológicas de los individuos, sus patologías detectables en el esqueleto, el estado nutricional y, en algunos casos, hasta pautas de comportamiento que hayan dejado su huella en los tejidos duros (hueso y diente).

En el caso de poblaciones contemporáneas y en el marco de un pedido judicial, podría llegarse incluso a la identificación positiva de los restos óseos de un determinado individuo sobre el cual se conocen una serie de rasgos característicos de su perfil biológico (Katzenberg y Saunders 2008, White y Folkens 2005).

Particular y tradicionalmente, la antropología ha sido requerida para aplicar en el campo forense, el resultado de los avances metodológicos en biología ósea producidos por los bioantropólogos (Cattaneo 2007). En este sentido, los más significativos resultan de investigaciones realizadas sobre colecciones osteológicas institucionalmente custodiadas. Dichas colecciones originadas históricamente a partir de restos óseos humanos procedentes de excavaciones arqueológicas (Kemkes-Grotternthaler 2002), se han ido complementando como consecuencia de los requerimientos propios de la validación y adecuación metodológica (Cattaneo 2007, Budowle et al., 2009) con otras integradas por restos esqueletarios acompañados de información documental que, en general, procedían de hospitales o cementerios históricos.

Las series esqueléticas más reconocidas y estudiadas en América, aun hoy usadas como referencia, son la "Colección Terry" depositada en el Museo Nacional de Historia Natural del Instituto Smithsoniano en la ciudad de Washington y la "Colección Hamman-Todd" alojada en el Museo de Historia Natural de Cleveland, Ohio (Hoyme e Iscan 1989; Usher 2002, Hunt y Albanese 2005). Estas colecciones están integradas por esqueletos que provienen de autopsias y están acompañados por información documental que incluye edad, sexo, ancestría, estatura, causa de muerte y, en algunos casos, antropometría cadavérica (Hunt y Albanese 2005). Otras muestras documentadas de gran valor en USA son la "Colección Huntington", perteneciente a la Universidad de Columbia; la "Colección Grant", situada en la 
Universidad de Toronto; la "Colección Cobb" de la Universidad de Howard (Hoyme e Iscan 1989, Walker 2000), entre otras.

En Europa, las colecciones de mayor relevancia son portuguesas: la "Colección Luís Lopes" (Universidad de Lisboa) y la "Colección Coimbra" (Universidad de Coimbra) (Cardoso 2006). En un grado menor de importancia por su integración se encuentran las colecciones Saint Bride's (Huda y Bowman 1995) y Christ's Church (Spitalfields) (Cox et al. 1990), ambas inglesas y compuestas por individuos fallecidos durante los siglos XVIII y XIX, inhumados en iglesias locales.

Las colecciones mencionadas up supra se encuentran alojadas en instituciones norteamericanas y europeas, dificultando el acceso para la realización de investigaciones que requieren de material esqueletario documentado fehacientemente.

Todas ellas, en mayor o menor medida, han servido de base para la generación de métodos estandarizados que permiten hoy el diagnóstico de características biológicas individuales (i.e edad, sexo, estatura, ancestría, entre otras) a partir de los restos esqueletarios, resultando de suma importancia tanto en contextos arqueológicos como forenses (Todd 1920, Ferembach et al. 1980, Lovejoy et al. 1985, Meindl y Lovejoy 1985, Brooks y Suchey 1990).

Sin embargo, estos estudios han demostrado la presencia de gran variabilidad entre individuos de una misma población y entre poblaciones (Ubelaker 2005) como producto de la interacción entre el material genético y el medio, así como también debido a la influencia del sexo y la nutrición, y de factores ambientales y socioeconómicos, entre otros (Krenzer 2006).

De este modo, la heterogeneidad poblacional constituye el límite principal de los métodos de estimación de edad y sexo aplicados a restos esqueletales no documentados (Schmitt 2002) y por lo tanto, su aplicación resultaría más confiable en grupos humanos con una misma ancestría. Esta razón justifica, para la mayoría de los investigadores, la necesidad de crear colecciones de referencias documentadas de carácter regional (Brothwell 1987, Ubelaker 2000, Schmitt 2002, Usher 2002, White y Folkens 2005, Frankling 2010). 
Esta situación reconocida y generalizada ha sido el motor principal, en los últimos 20 años, de la conformación de colecciones regionales en diferentes lugares del mundo. En Grecia, "Wiener Lab Collection” (Eliopoulos et al. 2007); en Sudáfrica, "Raymond Dart Collection" (Dayal et al. 2009) y "Pretorian Bone Collection" (L'Abbé et al. 2005); en Tailandia, “Colección osteológica de de la Facultad de Medicina" (Universidad de Chiang Mai) (Ongkana y Sudwan 2009) y en India Central, "Colección del Instituto Médico Legal de Bhopal” (Purkait 2003) entre otras.

En Sudamérica se integraron, en Chile la "Colección Cementerio General" (Paredes et al. 1997), en Brasil la "Colección del Museo de la Universidad Federal de Sao Pablo" (Zavando Matamala et al. 2009) y en Colombia se iniciaron acciones para concretar una colección osteológica contemporánea (Rojas Alfonso y Quintero Pardo 2011).

En Argentina se han realizado diversos emprendimientos, con distinto grado de desarrollo, en la integración de colecciones osteológicas documentadas. Caben mencionar, entre ellos, el "Proyecto Chacarita" (Universidad de Buenos Aires) (Bosio et al. 2009, 2012), y otros en Necochea (Segura com. pers. 2009) y San Martín (Cáceres com. pers. 2008) ambos en provincia de Buenos Aires.

En este mismo sentido y con el interés último y compartido de lograr aproximaciones más ajustadas en el diagnóstico individual y colectivo de restos óseos humanos procedentes de contextos arqueológicos y forenses, es que hemos integrado una importante colección contemporánea, sobre la cual actualmente se están desarrollando significativas investigaciones (García Mancuso 2008; Plischuk 2012), con restos óseos procedentes del cementerio histórico de La Plata (Sempé y Flores 2011). La denominada "Colección Prof. Dr. Rómulo Lambre" (Desántolo et al. 2007, García Mancuso 2008, Desántolo et al. 2009, Salceda et al. 2009) ha sido reconocida y avalada por la Universidad Nacional de La Plata y se encuentra alojada en la Facultad de Ciencias Médicas.

Es así que, en este contexto, los estándares internacionales utilizados como referencia para las estimaciones adquieren un rol protagónico y por lo tanto su 
aplicación en análisis comparativo debe ajustarse a grupos humanos de la misma ancestría otorgándole mayor confiabilidad al diagnóstico (Brothwell 1987, Rodríguez Cuenca 1994). Sin embargo las referencias más usadas en la actualidad, basadas en estudios de poblaciones norteamericanas y europeas, muestran una gran variación interpoblacional lo cual justifica ampliamente la realización de investigaciones regionales que, en este sentido y en consecuencia, acrecienten la confiabilidad de los métodos de caracterización (Meindl y Russell 1998, Ubelaker 2000). Además la incorporación de técnicas desarrolladas por otras disciplinas científicas, como la histología en nuestro caso, complementan el abordaje otorgando mayor precisión a las estimaciones.

Respondiendo a esta problemática, y en consonancia con programas de investigación similares en el resto del mundo, es que nos propusimos indagar sobre la validez de los métodos histológicos para estimar edad en restos óseos humanos adultos. El tema propuesto apunta a lograr mayor precisión en la estimación de la edad en restos esqueletales no documentados a partir de la generación de una base de datos regional y representativa que actúe como control en el análisis comparativo. Todo ello considerando que, disponer de esta información permitiría hacer inferencias más ajustadas en el estudio de poblaciones extintas, así como contribuir a la identificación individual en casos forenses. 


\section{OBJETIVO GENERAL}

Analizar la validez y ajuste de diferentes métodos microscópicos para estimar edad a la muerte en restos óseos humanos adultos documentados del Cementerio Municipal de La Plata.

\section{OBJETIVOS ESPECÍFICOS}

- Identificar las variables microestructurales del tejido óseo cortical del fémur de adultos correlacionadas con la edad de muerte.

- Aplicar diferentes métodos histomorfométricos de estimación de edad a la muestra documentada.

- Comparar los resultados obtenidos con la documentación obrante en los archivos del Cementerio Municipal de La Plata.

- Analizar la congruencia entre los resultados obtenidos y la información de edad documentada.

- Desarrollar una ecuación predictiva para estimar edad a la muerte a partir de la microestructura ósea del fémur de individuos adultos.

\section{HIPÓTESIS}

Las modificaciones microestructurales ocurridas durante el proceso de remodelación ósea en el tejido cortical en individuos adultos, permiten inferir la edad biológica en grupos humanos en condiciones homogéneas de ambiente y ancestría. 
CAPÍTULO I 


\section{I.1- ESTIMACIÓN DE LA EDAD: APROXIMACIONES TEORICAS}

La mineralización de los tejidos duros -huesos y dientes- durante la vida de un individuo permite la conservación de partes del esqueleto después de la muerte del organismo, y se convierten en una de las mayores fuentes de información tanto para la bioantropología, como para la osteología forense así como para la paleodemografía, la biología ósea, entre otras disciplinas.

Lejos de su concepción tradicional como un elemento estático, el hueso es un tejido extremadamente dinámico y complejo que crece durante toda la vida de un organismo, cambia de tamaño, forma y posición (Enlow 1982) en respuesta a una multiplicidad de estímulos ambientales, genéticos, nutricionales, metabólicos, hormonales y mecánicos (Kemkes-Grottenthaler 2002).

Por tal razón y debido a su plasticidad, su estructura se modifica en el tiempo y en el espacio de acuerdo al principio de variabilidad filogenética (evolutiva), sexual, ontogénetica (durante el crecimiento y desarrollo), individual (según la intensidad y tipo de actividad física) y cultural (de acuerdo a las prácticas culturales) (Rodríguez Cuenca 1994). De esta manera se convierte en un documento persistente de los cambios que se producen durante la vida del individuo (White y Folkens 2005).

Así, una de las principales problemáticas a dilucidar en la reconstrucción bioantropológica de individuos o grupos humanos no documentados, es la estimación de edad a la muerte a partir de sus restos óseos (Lynnerup et al. 2006). Estimación que se fundamenta en las sucesivas transformaciones experimentadas por el sistema esqueletal en su evolución ontogénetica, i.e durante su crecimiento y desarrollo (Scheuer 2002).

Entendemos por crecimiento al cambio incremental, progresivo, en tamaño y forma, que ocurre en un individuo a lo largo de su vida (Scheuer y Black 2000). Es un proceso medible y cuantitativo. Complementariamente, entendemos al desarrollo como el cambio progresivo, sea cuanti o cualitativo, que conduce de un 
estado indiferenciado o inmaduro a otro organizado, especializado y maduro (Bogin 1999).

Así, y aunque el crecimiento y el desarrollo ocurren simultáneamente, son dos procesos biológicos diferentes. Ambos tienen un fuerte componente genético, pero también se encuentran influenciados por una amplia variedad de factores ambientales, principalmente nutricionales, del estado salud-enfermedad, del sexo de los individuos y de la variabilidad intra e interpoblacional (White y Folkens 2005).

La edad biológica estimada a partir de tejidos duros se fundamenta en el análisis de indicadores que se manifiestan a través del grado de desarrollo y maduración tanto ósea como dental. Por lo tanto la edad biológica comprende la edad dental y la edad ósea.

La edad dental se basa en el grado de mineralización y erupción dentaria. Es el indicador más importante de madurez en individuos jóvenes (subadultos) y está fuertemente controlada por factores genéticos, con influencia mínima del ambiente (Scheuer 2002). La edad ósea se basa en la aparición y fusión de los centros de osificación, y en el tamaño y morfología ósea en subadultos y en cambios degenerativos en adultos. Está controlada genéticamente pero, a diferencia de la edad dental, manifiesta una fuerte influencia ambiental (Scheuer y Black 2000, Cunha et al. 2009).

Entonces, la estimación de la edad biológica en restos no documentados implica la observación de una multiplicidad de rasgos morfológicos que se expresan durante los sucesivos estados de formación, maduración y consolidación del tejido óseo y dental. La información obtenida se compara con los cambios registrados en poblaciones recientes de edad conocida (Ferembach et al. 1980, Ubelaker 2000). En otras palabras, la estimación de la edad biológica se infiere a partir de variables correlacionadas con la edad cronológica ${ }^{1}$.

\footnotetext{
1 Es la edad del individuo en función del tiempo transcurrido desde el nacimiento, es la edad en
} años. 
Sin embargo, la relación entre edad biológica y cronológica no es constante ni lineal dado que los cambios biológicos no son uniformes y están influenciados, además, por diferentes factores intrínsecos (e.g. genes, sexo, ancestría) y extrínsecos (e.g. ambiente, stress, alimentación, patologías y actividad física) que provocan una gran variación dentro y entre poblaciones.

Por lo tanto, la variabilidad en las poblaciones humanas conlleva un cierto margen de error en la estimación de la edad biológica y se expresa en los distintos grados de precisión ${ }^{2}$ y exactitud ${ }^{3}$ (Schmitt et al. 2002, Krenzer 2006).

Según White y Folkens (2005) la precisión y exactitud en esta problemática dependen de:

Los elementos esqueletales disponibles. Precisión y exactitud dependerán del/los elementos esqueletales particulares del cuerpo que se encuentren presentes y de su estado de preservación dado que los distintos huesos proporcionan información diferencial en las distintas etapas de la ontogenia (Sheuer 2002, Franklin 2010). Por ejemplo, el estado dentario provee resultados más precisos en la estimación de la edad desde el nacimiento hasta la adolescencia (Sheuer y Black 2000), mientras que la longitud de los huesos largos es menos confiable y puede llevar a errores. En el caso de los adultos, la estimación de la edad a través de la sínfisis púbica arroja resultados más fiables que otros atributos morfológicos, como por ejemplo, las suturas craneales (Meindl y Lovejoy 1985).

Las categorías de edad. Precisión y exactitud varían en función de la etapa de la ontogenia en la que se encuentra el/los individuos. Es así que la determinación de edad en subadultos se considera más precisa que en adultos pues los indicadores biológicos de crecimiento y desarrollo son relativamente predecibles provocando una correlación positiva entre edad biológica y cronológica (Franklin 2010).

2 La precisión se refiere al conjunto de medidas de una misma magnitud realizadas en las mismas condiciones. Es la medida de dispersión de los datos (Santo y Lecumberry 2005)

3 La exactitud es la distancia entre el valor medido y el valor real (Ferrante y Cameriere 2009), está relacionada con el sesgo de una estimación. Cuanto menor es el sesgo más exacta es una estimación (Christensen et al. 2009). 
En adultos, por el contrario, la estimación de edad sólo se basa en los cambios degenerativos ocurridos durante el envejecimiento humano (i.e. a nivel óseo, dental y de remodelación ósea) y por lo tanto se hace necesario un análisis minucioso de todos aquellos indicadores biológicos que caracterizan dicho proceso.

El envejecimiento es progresivo, irreversible, universal, multifactorial y se caracteriza por la disminución progresiva de la capacidad funcional en tejidos y órganos del cuerpo para ajustarse a estímulos ambientales (Schmitt 2002, Bernis 2004). Además, es altamente variable entre los individuos en diferentes circunstancias ambientales pudiendo el control genético, el sexo y los estilos de vida, afectar la velocidad del proceso degenerativo (Franklin 2010).

Por lo tanto, a mayor edad, mayor es la discrepancia entre la edad biológica y la edad cronológica, el desarrollo esqueletal y dental ha finalizado, con el consiguiente aumento del margen de error en la estimación (Cunha et al. 2009).

La composición de la muestra. Se obtienen resultados más precisos y exactos cuando se trabaja con series esqueletales y no con individuos aislados (White y Folkens 2005), situación frecuente en contextos arqueológicos y no en contextos forenses. De esta manera se obtiene una muestra representativa de la variabilidad interindividual efectiva para el desarrollo de nuevos métodos de estimación de edad (Schmitt 2002).

\section{La aplicabilidad de los métodos analíticos a una muestra o individuo no}

documentado. La exactitud y la precisión varían en función de los estándares de referencia utilizados, en su mayoría formulados en base a series esqueletales estadounidenses y europeas. Sin embargo, como estos métodos son específicos y dependientes del perfil demográfico y cronológico de la serie sobre la cual fueron desarrollados (Schmitt 2002, Baccino y Schmitt 2006), además de la consiguiente variación interpoblacional e interindividual, cuando se aplican a muestras de otras partes del mundo los resultados no son tan fiables.

Los métodos utilizados. La precisión y exactitud dependerán de la elección de métodos adecuados según las categorías de edad y los elementos esqueletales 
disponibles. En el caso de subadultos ${ }^{4}$, desde el nacimiento hasta la adolescencia, la edad se puede diagnosticar a través de la observación de la forma y el estado de metamorfosis de los centros de osificación (Fazekas y Kosa 1978, Kosa 1989, Schmeling et al. 2007), la formación y erupción dental (Hillson 2005), la progresión en el cierre epifisial, como también, la longitud de los huesos largos (Sheuer y Black 2000, Shaefer et al. 2009), fusión de la sincondrosis esfeno-occipital/basilar (Madeline y Elster 1995) y la fusión clavícula- esternón (Schulz et al. 2005).

En adultos ${ }^{5}$, la estimación de la edad se realiza a través de métodos macroscópicos y microscópicos. Las técnicas macroscópicas -morfoscópicas y morfométricas- consisten en la observación directa de indicadores sobre el material óseo y dental. Son más rápidas y no implican destrucción del material pero su principal desventaja es que requieren de elementos esqueletales completos en la mayoría de los casos. Los principales métodos en orden de importancia son: los cambios degenerativos de la sínfisis púbica (Todd 1920, Meindl y Lovejoy 1989, Brooks y Suchey 1990), los de la superficie auricular del ilion (Lovejoy et al. 1985; Buckberry y Chamberlain 2002, Osborne et al. 2004), cambios en la extremidad esternal de la IV costilla (Iscan et al. 1984, 1985, Yoder et al. 2001), el grado de sinostosis de las suturas craneales (Ferembach et al. 1980, Meindl y Lovejoy 1985), el desgaste dental (Lovejoy 1985) y las patologías degenerativas que afectan a la estructura ósea (columna vertebral, articulaciones, etc).

En cuanto a los métodos microscópicos, la histomorfometría o histología cuantitativa (Robling y Stout 2008), ofrece estimaciones más precisas que son efectivas para adultos mayores, en contraste con la mayoría de los métodos basados en la morfología esqueletal (Ubelaker, 1996; Franklin, 2010). Además, son de gran utilidad aun cuando los restos se encuentren fragmentados o incompletos,

${ }^{4}$ Fetos (incluye recién nacidos), infantes (0-3 años), niños (3-12 años), adolescentes (12-20 años) (Buikstra y Ubelaker 2004).

5 Adulto joven (20-35 años), Adulto medio (35-50 años), Adulto mayor (50+ años) (Buikstra y Ubelaker 2004). 
ya que por su estado de conservación resulta difícil estimar la edad macroscópicamente (Bednarek 2008, Franklin 2010).

La técnica consiste en la cuantificación de características o variables microestructurales en secciones delgadas de hueso, como por ejemplo, número de osteonas completas y fragmentarias, diámetro de conductos de Havers, entre otras.

Estos métodos, sin embargo, presentan ciertas desventajas con respecto a los macroscópicos, requiere de más tiempo, equipamiento, conocimiento específico de técnicas histológicas e implica destrucción parcial del material (Ubelaker 2008). Por consiguiente, la interpretación de la información codificada en la microestructura ósea requiere un conocimiento básico de la biología que subyace a la creación de estructuras histomorfológicas (Stout y Crowder 2012). Esta información es crucial para la estimación histológica de la edad que constituye el aporte más común de la histología a la investigación antropológica y forense. 


\section{I.2- HISTOMORFOLOGÍA ÓSEA}

El tejido óseo es una variedad de tejido conectivo especializado en la función de sostén y protección, pues su matriz extracelular está calcificada confiriéndole rigidez, dureza y resistencia (Eynard et al. 2008). Es el componente estructural de los elementos que conforman el sistema esqueletario, los huesos. Además de las funciones mecánicas, juega un rol importante a nivel metabólico como en el depósito de calcio, la reserva de fósforo, magnesio y manganeso.

Macroscópicamente, al observar una superficie de corte de un hueso se pueden identificar dos organizaciones estructurales distintas del tejido óseo (Ross y Pawlina 2007): el tejido esponjoso o trabecular, formado por una red tridimensional de trabéculas y espículas formando un reticulado, que delimita espacios interconectados en donde se encuentra la médula ósea, y el tejido compacto o cortical, que constituye una masa compacta, densa y sin espacios (Figura 1).

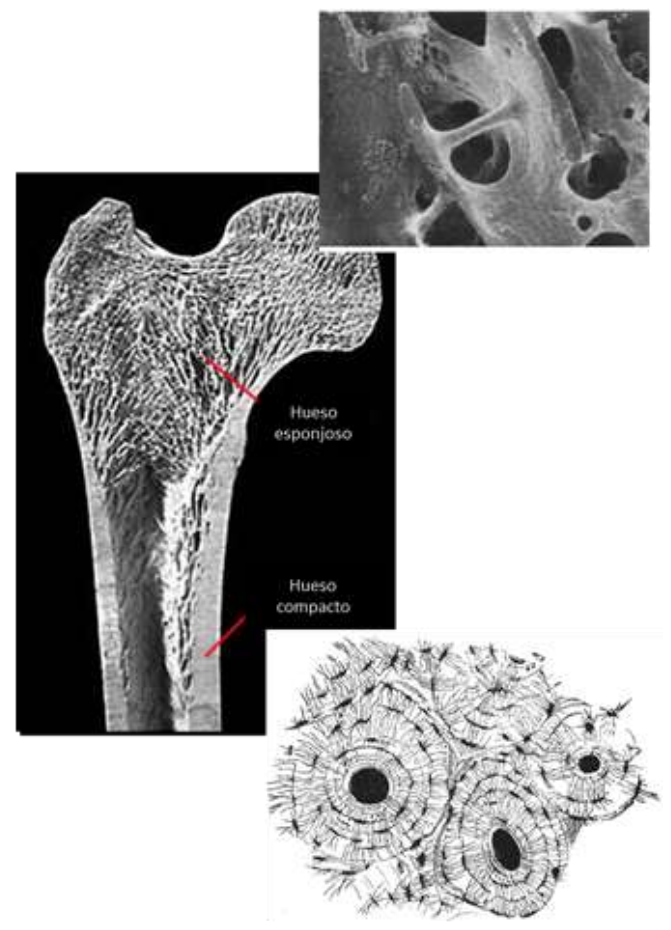

Figura 1. Hueso cortical y esponjoso (Ortner 2003, White y Folkens 2005) 
Además, según su forma y estructura anatómica, los huesos se clasifican en largos, cortos, planos, irregulares y sesamoideos (Gartner y Hiatt 2001). En los huesos largos (e.g. fémur, tibia, húmero) predomina la longitud por sobre otras dimensiones, presentan un cuerpo o diáfisis y dos extremos o epífisis; en los huesos cortos (e.g. carpos, tarsos) la longitud, ancho y alto son aproximadamente iguales, a diferencia de los huesos planos (e.g. huesos del cráneo) en los que predominan la longitud y el ancho sobre su espesor; los huesos con forma irregular (e.g. vértebras, esfenoides, etmoides) o que no presentan algunas de las características antes mencionadas, se denominan irregulares y por último los sesamoideos (e.g. rótula) se definen en relación con los tendones a través de las articulaciones.

A su vez, cada tipo de hueso presenta una distribución diferencial del tejido compacto y esponjoso. El tejido esponjoso o trabecular se encuentra en las epífisis de los huesos largos, en los huesos cortos (vértebras) y en el diploe de los huesos planos, en tanto que el compacto o cortical se localiza en la diáfisis de los huesos largos (rodeando al canal medular) y formando la cubierta externa de los huesos planos (costillas, huesos del cráneo).

Todos los huesos están recubiertos por una capa externa de tejido conectivo denso, vascularizado, el periostio; y una capa interna de tejido conectivo laxo, que recubre la cavidad medular de los huesos largos y la superficie trabecular del hueso esponjoso, el endostio. Tanto el periostio como el endostio tienen capacidad osteogénica, es decir, la propiedad de diferenciarse a osteoblastos para formar hueso. 


\section{I.2.1- COMPONENTES CELULARES Y MATRIZ ÓSEA}

Microscópicamente, al igual que otros tejidos conectivos, el óseo está compuesto por células y matriz extracelular. Los componentes celulares del tejido óseo son cuatro: células osteoprogenitoras, osteoblastos, osteocitos y osteoclastos, los tres primeros de origen mesenquimático y el cuarto de la médula ósea.

\section{Células Osteoprogenitoras}

También llamadas células madres, son células indiferenciadas que persisten tras el nacimiento. Se encuentran en el mesénquima del feto próximas a los centros de osificación, en el endostio y en la capa profunda del periostio. Durante la formación del hueso se dividen por mitosis y se diferencian en células formadoras de hueso u osteoblastos (Ross y Paulina 2007), proceso que ocurre durante la vida fetal y en la etapa de crecimiento. En la etapa adulta se observan en la reparación ósea.

Existen dos tipos de células osteoprogenitoras, los preosteoblastos que darán origen a los osteoblastos, y los preosteoclastos que darán origen a los osteoclastos (Ross y Paulina op. cit.).

\section{Osteoblastos y Osteocitos}

Los osteoblastos son células formadoras de hueso, responsables de la síntesis y secreción del componente orgánico de la matriz ósea no mineralizada, el osteoide, formado por colágeno Tipo I (90\%), glicoproteínas y proteoglucanos. Son mononucleares, poligonales, intercomunicados a través de prolongaciones citoplasmática y se localizan en la superficie del hueso en formación, en una sola capa, semejante a un epitelio. Una vez que dejan de sintetizar matriz algunos de ellos mueren por muerte celular, otros se revierten a un estado de inactividad formando las células de revestimiento óseo (Gartner y Hiatt 2001) o bien quedan atrapados dentro de la matriz ósea transformándose en osteocitos. 
Los osteocitos son las verdaderas células óseas se originan de los osteoblastos atrapados en la matriz ósea durante la formación del hueso. Se ubican en cavidades llamadas lagunas y se comunican entre sí a través de finas prolongaciones, los canalículos. Son células metabólicamente activas, degradan matriz ósea a través del proceso denominado osteólisis osteocítica (Ross y Pawlina op. cit.), permitiendo la reabsorción del mineral óseo, por lo tanto tienen un papel fundamental en la homeostasis fosfocálcica y en la transducción de señales biomecánicas para que se inicien los procesos de recambio y remodelación ósea cuando estos sean necesarios (Eynard et al. 2008).

\section{Osteoclastos}

Los osteoclastos son células que reabsorben hueso (Bruce et al. 1998) multinucleadas de forma y tamaño variable y se localizan en depresiones huecas de la superficie ósea, las lagunas de Howship. Se originan de células precursoras de la médula ósea que están emparentadas con las células precursoras de los monocitos y macrófagos (Welsch 2008). Estudios realizados con microscopia electrónica han permitido observar, en la superficie de contacto de los osteoclastos con la trabécula ósea, un área rugosa (borde fruncido) formada por numerosos pliegues de la membrana plasmática. Esta es la porción de la célula que participa directamente en la resorción ósea, degradando activamente la matriz calcificada y liberando iones fosfato y calcio.

\section{Matriz Ósea}

La matriz extracelular está compuesta por dos componentes: orgánico e inorgánico.

El componente orgánico está formado por fibras de colágeno tipo I (90\%) inmersas en una sustancia fundamental de carácter proteico compuesta principalmente por glucosaminoglucanos (aminoazúcares) y proteínas específicas elaboradas por los osteoblastos (osteocalcina, osteopontina y osteonectina) de fundamental interés en el proceso de mineralización ósea (Welsch 2008). 
El componente inorgánico representa el $65 \%$ del peso seco del hueso adulto; está formado por sales minerales, predominando el calcio y el fósforo en forma de cristales de hidroxiapatita cálcica, $\left[\mathrm{Ca}_{10}\left(\mathrm{PO}_{4}\right)_{6}(\mathrm{OH})_{2}\right]$. Están dispuestos en forma ordenada a lo largo de las fibras de colágeno tipo I. Además, el mineral óseo contiene diferentes iones, entre ellos, magnesio $\left(\mathrm{Mg}^{2}+\right)$, potasio $(\mathrm{K}+)$, sodio $(\mathrm{Na}+)$, carbonato (CO32-) y citrato ( 6 $6 \mathrm{H} 5073)$. Por lo tanto, la dureza del hueso se debe a su contenido de sales inorgánicas, mientras que su resistencia y elasticidad depende del colágeno.

\section{I.3- CLASIFICACIÓN DEL TEJIDO ÓSEO}

Microscópicamente el tejido óseo se clasifica en: hueso no laminar, primario o plexiforme y en laminar, secundario o adulto.

\section{I.3.1- Hueso no laminar, primario o plexiforme}

Este tipo de hueso se encuentra en el esqueleto embrionario y del neonato, que de manera progresiva será reemplazado por hueso laminar hasta alcanzar, hacia los cuatro años de edad, su total madurez (Nolla 1997). El colágeno se distribuye al azar, los osteocitos no tienen una distribución regular y el grado de mineralización es bajo. En el adulto aparecerá en circunstancias reparadoras o patológicas, que impliquen estados de crecimiento rápido, reposición o alto recambio óseo o turnover ${ }^{6}$.

\section{I.3.2- Hueso laminar, secundario o adulto}

Es el hueso maduro que se forma durante el resto de la vida de un individuo (Eynard et al. 2008). Las fibras de colágeno se disponen formando laminillas óseas de manera organizada, paralelas o concéntricas. Los osteocitos en sus lagunas se disponen en forma regular entre las láminas o dentro de ellas y se comunican entre

\footnotetext{
${ }^{6}$ Volumen de hueso preexistente que es cambiado por hueso nuevo, por unidad de tiempo.
} 
sí a través de prolongaciones citoplasmáticas, los canalículos. Estos forman una red de conductos que facilitan el flujo de nutrientes, hormonas, iones y productos de desecho hacia y desde los osteocitos con el torrente sanguíneo.

En el hueso compacto las láminas están dispuestas concéntricamente rodeando canales longitudinales denominados conductos de Havers, por lo que se forman los denominados sistemas de Havers u osteona. Los conductos varían entre 20 y $100 \mu \mathrm{m}$ de diámetro promediando los $50 \mu \mathrm{m}$ y en su interior discurren vasos sanguíneos, linfáticos y nervios de los que depende el metabolismo del hueso (Gartner y Hiatt 2001). Los sistemas de Havers contienen de 8 a 15 laminillas y se comunican con otros sistemas, con el endostio y periostio a través de conductos cortos y transversales, los conductos de Volkmann. Además, se observan, los sistemas circunferenciales internos y externos compuestos por laminillas paralelas por debajo del periostio y del endostio. (Figura 2).

Entre los sistemas circunferenciales y las osteonas se encuentran las laminillas intersticiales.

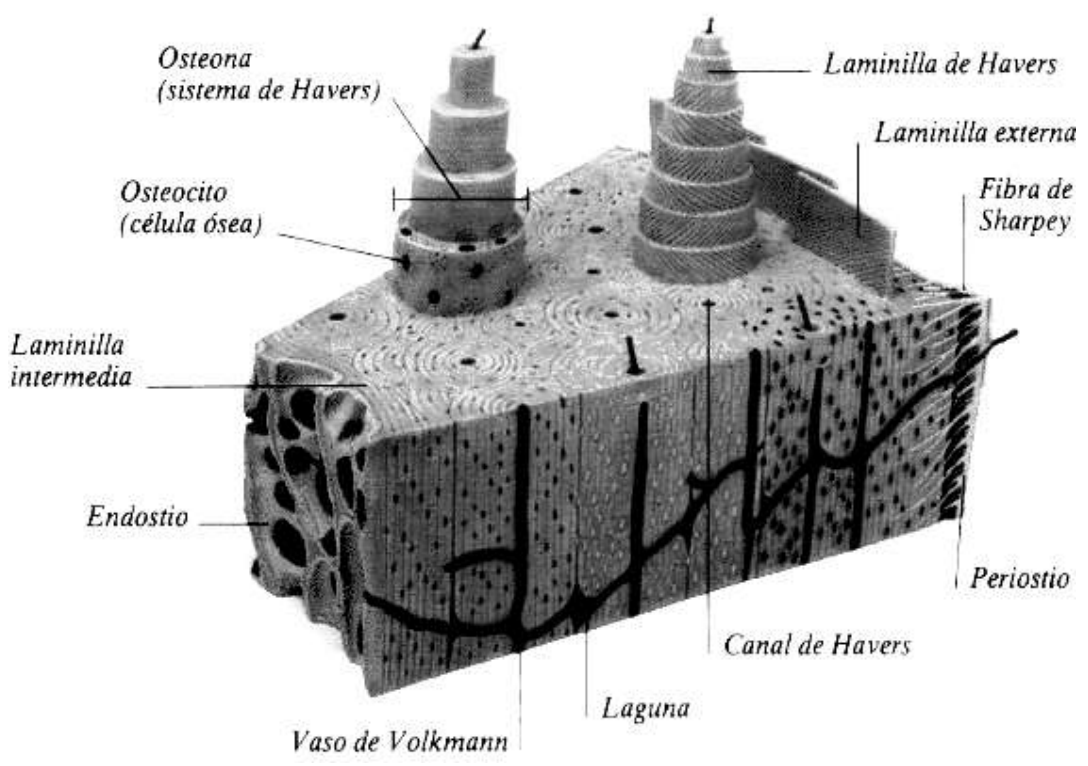

Figura 2. Sección transversal y longitudinal de un hueso largo 


\section{I.4- HISTOGÉNESIS ÓSEA}

La histogénesis, osteogénesis u osificación es la formación del hueso a partir del tejido conectivo embrionario, el mesénquima (Eynard et al. 2008). Puede ser de dos tipos: osificación intramembranosa, a partir del mesénquima y osificación endocondral, a partir de un molde de cartílago.

El primer hueso que se forma es el primario, que luego se resorbe y sustituye por hueso secundario, que continua resorbiéndose durante toda la vida a ritmo más lento.

\section{I.4.1- Osificación intramembranosa}

Este tipo de osificación comienza dentro de una placa mesenquimática, membranosa. Las células del mesénquima proliferan, el tejido se condensa y aumenta su vascularización. Algunas células se diferencian en osteoblastos, las cuales secretan matriz ósea orgánica u osteoide formando el centro primario de osificación. El osteoide se calcifica por depósito de fosfato de calcio, atrapando a los osteoblastos, que se transforman en osteocitos o células óseas maduras. El centro de osificación así formado queda rodeado por mesénquima compacto que constituye el periostio. En la parte profunda del periostio se diferencian osteoblastos, que formaran laminillas óseas superpuestas (hueso compacto perióstico). Los huesos planos del cráneo, parte del maxilar inferior entre otros, se desarrollan por este tipo de osificación.

\section{I.4.2- Osificación Endocondral}

Los huesos largos, cortos e irregulares se forman por osificación endocondral. A los fines explicativos se tomará como modelo la osificación de un hueso largo, por ejemplo el fémur.

La osificación se realiza sobre un molde de cartílago hialino rodeado de pericondrio. El modelo cartilaginoso, al nivel de la futura diáfisis, sufre la invasión de un brote vascular que erosiona al tejido originando el centro primario de osificación. Se hipertrofian los condrocitos, aumentan las superficies de las lagunas 
y se reduce la matriz cartilaginosa a finos tabiques. Tras el depósito de calcio (calcificación) los condrocitos se degeneran y mueren.

Simultáneamente las células del pericondrio, en la parte central de la diáfisis, adquieren propiedades osteogénicas transformándose en periostio. A través de osificación intramembranosa se forma el collarete diafisiario o perióstico (Eynard et al. 2008), permitiendo la entrada de una yema osteogénica o brote perióstico, compuesto por células osteoprogenitoras y hemopoyéticas. Los vasos de este brote se ramifican y envían capilares a los extremos del molde; las células osteoprogenitoras se diferencian a osteoblastos los cuales depositan matriz.

La matriz ósea se calcifica y se forma un complejo de cartílago y hueso calcificado. A medida que el hueso subperióstico crece, desde la diáfisis hacia la epífisis, los osteoclastos comienzan a resorber formando la cavidad medular, finalmente el cartílago es remplazado por el hueso de la diáfisis.

El centro secundario de osificación se inicia en las epífisis por un proceso similar al de la diáfisis. Un brote proveniente del pericondrio invade el cartílago iniciando el depósito de tejido óseo y la eliminación del tejido cartilaginoso, excepto en la superficie articular que permanece cartilaginosa durante toda la vida y en la placa epifisiaria que controla el crecimiento en longitud del hueso.

Durante el crecimiento en longitud de los huesos largos, los condrocitos de la placa epifisiaria proliferan e intervienen en la osificación endocondral del hueso. La zona en que la diáfisis pasa a ser epífisis se llama metáfisis y es la zona donde se produce la eliminación de cartílago y el depósito óseo.

A nivel histológico, la metáfisis se divide en cinco zonas, comenzando del lado epifisiario (Gartner y Hiatt 2001) : Zona de cartílago de reserva (condrocitos mitóticamente activos); Zona de proliferación (los condrocitos proliferan y forman hileras paralelas al eje del crecimiento); Zona de hipertrofia (las células aumentan de tamaño contribuyendo al aumento longitudinal del cartílago); Zona de calcificación (depósito de sales de calcio) y Zona de osificación (depósito y calcificación de la matriz ósea). A esto le sigue la resorción por actividad osteoclástica. 
Alrededor de los veinte años de edad disminuye el ritmo de mitosis en la zona de proliferación y la zona de osificación alcanza la zona de proliferación y reserva. Se sustituye el cartílago de la placa por un complejo mixto de cartílago y hueso que posteriormente se resorberá, como consecuencia, la cavidad medular de la diáfisis y epífisis confluyen. Una vez resorbida la placa epifisiaria el crecimiento longitudinal se detiene, a diferencia del crecimiento circunferencial o aposicional de la diáfisis que ocurre a lo largo de toda la vida, por actividad osteogénica del periostio y resorción del endostio (Eynard et al. 2008).

\subsection{3- Crecimiento, Modelado y Remodelación ósea}

Desde el inicio del desarrollo óseo en el feto hasta el final del crecimiento en el adulto los huesos conservan en gran parte su forma estructural (Gartner y Hiatt 2001) esto se debe a la acción conjunta del crecimiento, modelado y remodelado óseo.

El crecimiento y el modelado son dos procesos que actúan conjuntamente en el individuo durante la infancia y la adolescencia. Mientras el crecimiento produce un incremento en la masa ósea, el modelado modifica el tamaño y la forma del hueso completo; además y de acuerdo con el modelo Wolff (1982), la forma y la estructura interna de un hueso se adapta a la función y a las necesidades mecánicas (Stout y Crowder 2012).

Una vez alcanzada la madurez esquelética el proceso de modelado disminuye en comparación con el grado de actividad ocurrida en el transcurso del crecimiento.

La remodelación ósea es un proceso que ocurre durante toda la vida a través del cual se remueve y reemplaza "packets" de hueso (Robling y Stout 2008) entre un 7 y $10 \%$ del volumen total del esqueleto por año. Sin embargo, la intensidad del proceso es mayor en el hueso trabecular (25\%) que en el compacto (3\%) (Riancho y Gutiérrez 2003). La reabsorción y formación ósea es llevada a cabo por la acción sucesiva de osteoclastos y osteoblastos en zonas delimitadas denominadas 
Unidades Multicelulares Básicas $\left(\mathrm{BMU}_{\mathrm{s}}\right)$ (Frost 1985) o Unidades de Remodelación Ósea (BRU) (Parfitt, 1979) (Figura 3).

El comienzo de la remodelación (activación) está determinado por la acción de los osteocitos que detectan microfracturas óseas y/o por estímulos hormonales u otros factores sobre las células que recubren la superficie ósea (lining cells). Estas células secretan proteínas precursoras de los osteoclastos los cuales se diferencian y comienzan a resorber hueso delimitando una cavidad que tendrá forma de túnel en el hueso compacto y de laguna en el trabecular.
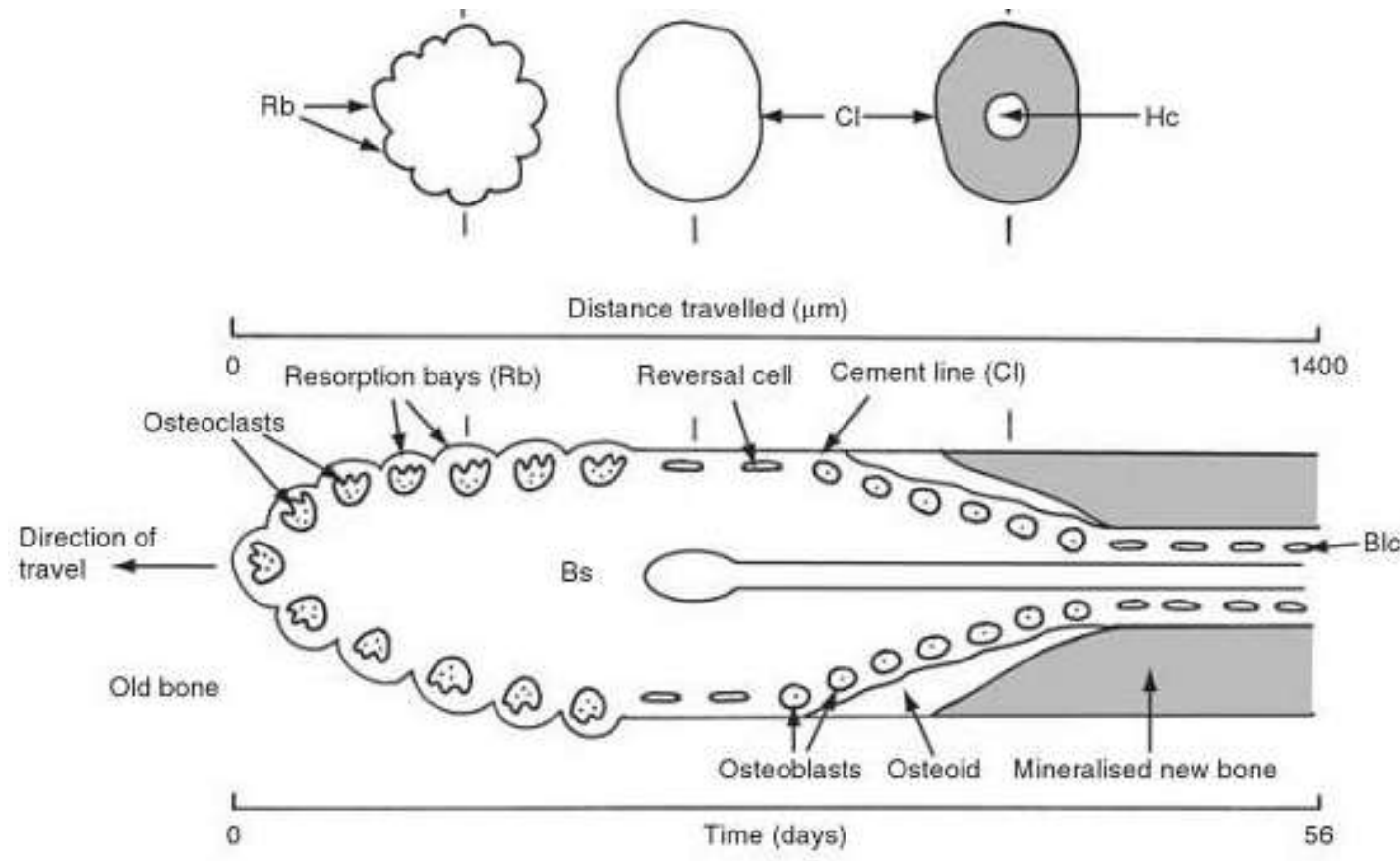

Figura 3. Vista longitudinal de la Unidad Multicelular Básica (BMU).

(Brickley M, Ives R. 2008) 
Una vez finalizada la etapa de resorción los osteoclastos mueren por apoptosis. En la etapa de reposo o inversión la cavidad labrada por los osteoclastos es tapizada por células mononucleares (Riancho y Gutiérrez 2003). Posteriormente, un conjunto de osteoblastos que se diferencia a partir de sus precursores, se disponen en una monocapa y comienzan a sintetizar osteoide, que al cabo de 11 días iniciará su mineralización (Mandalunis 2006). A medida que las laminillas concéntricas se depositan y mineralizan, el tamaño del espacio de remodelación se contrae. Esta etapa de formación continúa hasta rellenar la cavidad realizada por los osteoclastos (2-3 meses) y finaliza al completarse la remodelación ósea (Figura 4 y 5$)$.

Las $\mathrm{BMU}_{\mathrm{s}}$ se activan de manera asincrónica por lo que, mientras un ciclo de remodelado se halla en fase de resorción, otros se encuentran en fase de reposo o en fase de formación.

El nuevo segmento de tejido óseo que resulta de la acción de cada BMU se denomina Unidad Estructural Básica (BSU). En el hueso cortical estas unidades histomorfológicas están representadas por las osteonas secundarias o sistemas de Havers y en el hueso trabecular por osteonas trabeculares o paquetes óseos (Bruce et al. 1998). Las osteonas secundarias (producto del remodelado) se diferencian de las osteonas primarias (producto del modelado) por la presencia de la línea de cemento que representa el límite entre la resorción y la redepositación. 


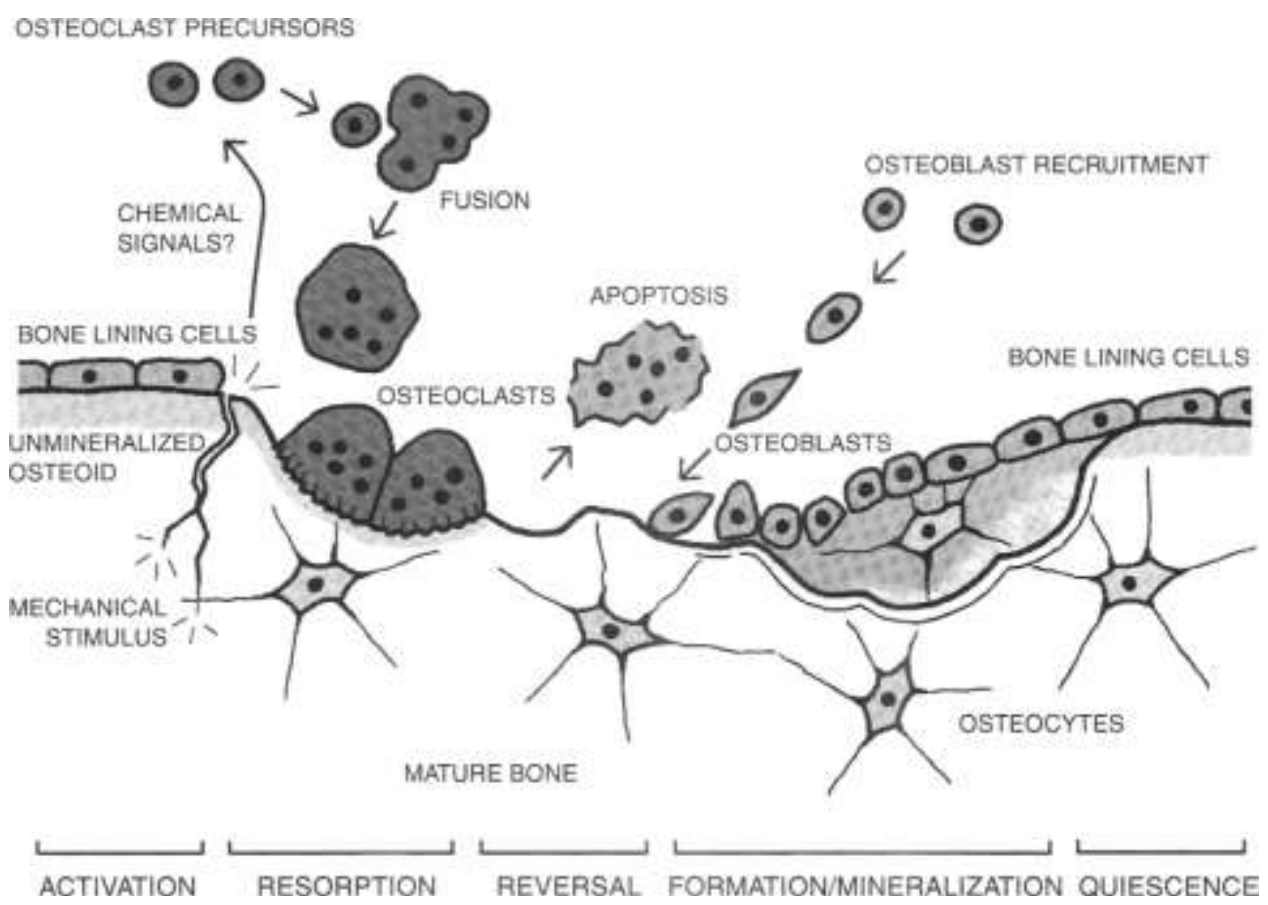

Figura 4. Esquema que representa la remodelación ósea en una Unidad Multicelular Básica (BMU). El proceso comienza con la activación y finaliza con la mineralización y quiescencia (izq. a der.) (Ortner 2003)

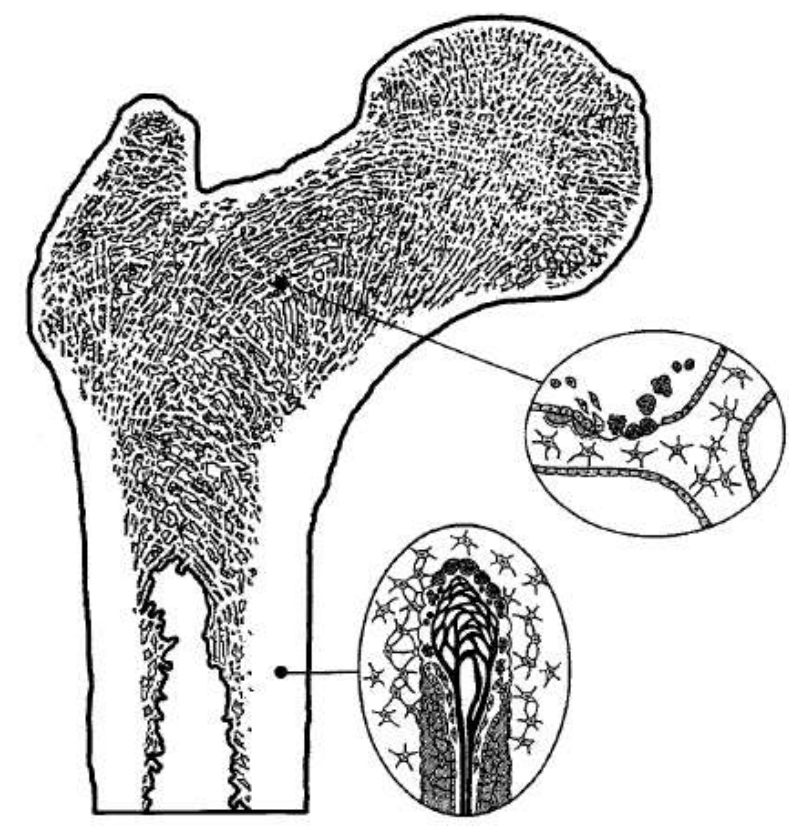

Figura 5. El dibujo representa la remodelación del hueso cortical y trabecular en fémur. (Ortner 2003) 
Durante los procesos de remodelación intracortical se desarrollan varios tipos de osteonas secundarias (Robling y Stout 2008; Stout y Crowder 2012):

Osteonas tipo I: son las más comunes, conocidas como osteonas secundarias. Se visualizan frecuentemente en individuos adultos (Takahashi y Frost 1966) como resultado de la remodelación intracortical normal.

Osteonas tipo II: son pequeños sistemas haversianos completos, con línea de cemento y laminillas concéntricas inmersas dentro de una osteona preexistente (Ericksen 1991, Yoshino et al. 1994) producto de la remodelación intra-osteonal en respuesta a una demanda de la homeostasis mineral (Stout 1989).

Osteonas fragmentarias: representan remanentes de antiguas osteonas en diferentes estadíos de resorción y se caracterizan por carecer de conductos de Havers.

Osteonas doble zona: presentan un anillo hipercalcificado dentro de las láminas concéntricas (Robling y Stout 2008) se diferencian de las tipo II por la falta de una línea de cemento interna y representan la recuperación y reanudación del crecimiento después de un stress severo (Stout 1989).

Osteonas drifting: presentan una continua resorción en uno de sus lados y una incesante formación en el otro. Macroscópicamente y en un corte transversal se observan como una especie de torbellino o cola (Robling y Stout 2008). 
CAPÍTULO II 


\section{II.1- ESTIMACIÓN HISTOMORFOMÉTRICA DE LA EDAD}

La histomorfometría o histología cuantitativa (Robling y Stout 2008) es la cuantificación de la microestructura del tejido óseo, dónde las características histomorfológicas se describen en términos de números por unidad o tamaño de área (Stout y Crowder 2012). Así, a través del conteo y medición de las características histomorfológicas puede obtenerse información acerca del recambio óseo (remodelación), de la microarquitectura y de la actividad celular dinámica y estática (Stout y Crowder 2012).

En el campo antropológico y forense, el análisis histomorfométrico es de gran utilidad cuando los huesos (arqueológicos o modernos) se encuentran fragmentados o incompletos. En ambos casos, la histomorfometría ha sido y es comúnmente aplicada para estimar la edad a la muerte y para determinar diferencias interespecífica entre hueso humano y no humano (Mulhern y Ubelaker 2012).

La estimación histológica de la edad se basa en el análisis del grado de remodelación ósea. El remodelado es llevado a cabo por la acción sucesiva de osteoclastos, que crean espacios de resorción, y de osteoblastos, que rellenan dichos espacios formando unidades discretas, definibles y cuantificables microscópicamente, tales como la osteona secundaria o Unidad Estructural Básica (BSU).

Dado que la remodelación es un proceso que transcurre durante toda la vida, desde el nacimiento hasta la muerte, permite observar la asociación entre el número de osteonas y la edad cronológica constituyendo la base primaria de los métodos histológicos de estimación de edad (Stout op cit.). Con el incremento de la edad, los componentes originales del hueso compacto (e.g. hueso laminar circunferencial, osteonas primarias) son gradualmente reemplazados por nuevas estructuras. Posteriormente, en una edad avanzada, el proceso de remodelado continúa, no sólo a expensas del hueso laminar y de las osteonas primarias, sino 
también de las osteonas secundarias preexistentes, formando de esta manera fragmentos osteonales (Ubelaker 2005).

En los individuos mayores, la cantidad relativa de osteonas eliminadas aumenta hasta llegar a una asíntota. La asíntota de la Densidad Poblacional Osteonal (OPD) varía en los diferentes huesos dependiendo de ciertos factores como la tasa de activación de la remodelación, el diámetro cortical y el tamaño osteonal (Stout y Crowder 2012). Por ejemplo, en el fémur la asíntota de la OPD es alrededor de 50/mm² (Kerley 1965, Frost 1987) y se produce a una edad relativamente mayor debido al considerable tamaño de sus áreas corticales. Constituyéndose, de esta manera, en una pieza clave para estimar la edad en individuos de edad avanzada (Robling y Stout 2008).

Así, osteonas y fragmentos osteonales constituyen las variables que mejor predicen la edad y por lo tanto, son esgrimidas en la mayoría de los métodos de estimación de la edad (Stout y Crowder 2012).

\section{II.2- UN REPASO HISTÓRICO}

El primer estudio sobre cambios en la microestructura ósea y su aplicación al cálculo de la edad en esqueletos adultos fue propuesto por Kerley (1965) quien desarrolló un método basado en el análisis microscópico de la cortical de los huesos largos. Examinó 126 secciones completas de la diáfisis de fémur, tibia y peroné. La muestra estuvo integrada por americanos blancos y americanos descendientes de africanos de ambos sexos (88 masculinos y 29 femeninos) de edades entre 0 y 95 años. En cada una de las secciones desgastadas delimitó cuatro campos circulares por debajo del periostio: anterior, posterior, medial y lateral, definiendo y cuantificando cuatro variables microestructurales:

1) Osteonas completas o sistema de Havers (X1): canal vascular rodeado concéntricamente por hueso lamelar. En la periferia de la osteona se encuentra la línea reversa que marca el área de actividad osteoclástica y de formación de nuevo hueso. Las osteonas incluidas en el campo deben estar representadas al menos por el $80 \%$ del conducto de Havers. 
2) Osteonas fragmentarias $\left(X_{2}\right)$ : fragmentos de antiguas osteonas producto de la remodelación, sin conducto de Havers. Se encuentran entre las osteonas secundarias.

3) Porcentaje de hueso lamelar circunferencial $\left(X_{3}\right)$ : se compone de bandas o laminillas paralelas que se localizan en la parte exterior de la corteza. EI hueso laminar circunferencial es un rasgo destacado durante la infancia.

4) Sistemas no haversianos u osteonas primarias $\left(X_{4}\right)$ : incluye a todos los canales vasculares primarios o sistemas pseudo-haversianos. Son canales vasculares que rodean a pequeños vasos sanguíneos incluidos en el hueso durante el crecimiento óseo. Se diferencian de las osteonas secundarias por la ausencia de laminillas.

La observación microscópica fue realizada con un aumento 100x y el diámetro del campo fue de $1.25 \mathrm{~mm}$ (Kerley 1965).

Los resultados de Kerley demostraron, en fémur, un incremento progresivo del número de osteonas secundarias y fragmentarias entre el nacimiento y los 95 años de edad. Por el contrario, el porcentaje de hueso lamelar circunferencial se mantiene alto durante la infancia y decrece con el advenimiento de la edad. Asimismo, el número de canales no haversianos disminuye en la adolescencia y desaparecen alrededor de los 55 años. Estos resultados se repiten en tibia y fíbula.

Años más tarde, Kerley y Ubelaker (1978) reexaminaron los datos originales y mejoraron las ecuaciones de regresión originalmente propuestas. Advirtieron que las estimaciones calculadas a partir de osteonas fragmentarias eran más precisas en peroné e incrementaron el tamaño del campo a $1.62 \mathrm{~mm}$.

En 1969 Ahlqvist y Damsten, trabajando con individuos provenientes de autopsias, sin especificación étnica, notaron ciertas dificultades para diferenciar osteonas completas de fragmentarias y para estimar el porcentaje de hueso lamelar en un campo visual circunferencial. Debido a esto propusieron modificaciones del método original: ubicaron cuatro campos rectangulares en la mitad de los cuadrantes planteados por Kerley, evitando así la línea áspera y sólo 
cuantificaron el porcentaje total de hueso remodelado (osteonas completas y fragmentarias). Para la observación microscópica utilizaron un ocular reticulado de $10 \mathrm{~mm}^{2}$.

El método fue testeado en una muestra de 20 secciones de fémur y el porcentaje obtenido en cada uno de los cuatro campos fue promediado para obtener un único resultado final. De todos modos, la proporción de osteonas secundarias y osteonas fragmentarias arrojó un error estándar en la estimación de \pm 6.71 años, comparado con el obtenido por Kerley para peroné de \pm 5.27 años. Pese a las recomendaciones, sus resultados fueron menos precisos que los obtenidos por Kerley.

Singh y Gunberg (1970), trabajando en individuos provenientes de autopsias, ofrecieron una nueva alternativa para estimar la edad a partir de la estructura histológica de fémur, tibia y mandíbula. La muestra analizada fue de 59 individuos (52 masculinos y 7 femeninos) entre 39 y 87 años de edad. Examinaron secciones descalcificadas y sin descalcificar del borde posterior de la mandíbula y de la diáfisis de los huesos largos. Seleccionaron dos campos circulares, de $2 \mathrm{~mm}$ de diámetro observados a 100X, elegidos al azar en la tercera parte del periostio. Cuantificaron tres variables microestructurales:

1) Número de osteonas secundarias (X1): definidas sobre la presencia del conducto de Havers completo y de la línea de cemento. Aquellas cortadas oblicuamente o que sólo presentan un fragmento no fueron tenidas en cuenta.

2) Número promedio de lamelas por osteonas (X2): obtenido del total de lamelas de todas las osteonas observadas en dos campos microscópicos.

3) Promedio del diámetro mínimo de los conductos de Havers (X3): el diámetro fue medido sólo en los conductos visualmente completos en el campo. El promedio resulta de la sumatoria de los diámetros por el total de conductos medidos. Aquellos conductos oblicuos que presentaron un diámetro tres veces mayor que su ancho, no fueron tenidos en cuenta. 
Los autores no incluyeron en sus observaciones a los canales no haversianos ni a las osteonas fragmentarias.

Los resultados demuestran para huesos largos que el número total de osteonas y el diámetro del canal de Havers se correlacionan significativamente con la edad a diferencia del número de lamelas por osteona. En mandíbula, la correlación fue ligeramente mayor a la obtenida para fémur y tibia.

El modelo propuesto por Singh y Gunberg se basa exclusivamente en lo observado para la muestra masculina dada la escasa representación de individuos femeninos. De todos modos, al igual que Kerley, no hallaron diferencias significativas entre sexos, probablemente debido a que ambas investigaciones son similares en el tamaño muestral de mujeres.

En este caso, el error estándar de las estimaciones fue menor que el obtenido por Kerley y por Ahlqvist y Damsten, pudiendo estimar la edad con una precisión de 2,58 años en el $67 \%$ y de 5,16 años en el $95 \%$ de los individuos en el rango de edad entre 40 y 80 años (Keough 2007).

En 1979, Thompson desarrolla un método que trata de superar los inconvenientes planteados en los estudios previos. Reduce al mínimo la destrucción de la pieza ósea, obteniendo para ello cilindros de hueso cortical (núcleos) de 0,4 cm de diámetro de la porción anterior de la diáfisis de fémur, tibia, húmero y cúbito. La muestra integrada por individuos blancos de Nueva Inglaterra, incluyó 116 cadáveres (64 masculinos y 52 femeninos) de edad conocida, entre 30 y 97 años. Cuantificó 19 variables histológicas y no histológicas como el espesor cortical y la densidad ósea. Las secciones fueron examinadas con aumento $100 x$ y los datos sometidos a análisis de regresión lineal a fin de seleccionar la variable, o combinación de variables, con menor error estándar y mayor coeficiente de determinación.

De este estudio surgieron varias ecuaciones de regresión demostrativas de que el área osteonal fue la variable más exacta en húmero (ES= 6.2 años). Además de demostrar que, después de los 50 años, comienza un proceso de constante degradación del espesor cortical y una disminución de la densidad mineral ósea 
diferencial entre ambos sexos (sexo femenino: $8 \%$ de espesor cortical y $10 \%$ de densidad ósea por década; sexo masculino: $4 \%$ de espesor cortical y $6 \%$ de densidad ósea por década) (Keough 2007).

Posteriormente, Thompson (1981) testeo su método en una muestra de 54 individuos ente 17 y 78 años. El análisis demostró la precisión de la técnica y la exactitud de los resultados obtenidos, en este caso, a partir del fémur.

En 1991, Ericksen publica un nuevo método para estimar la edad a la muerte. Analiza secciones delgadas, de $1.0 \mathrm{~cm}$ de ancho, de la porción anterior de la diáfisis femoral opuesta a la línea áspera. En cada sección selecciona cinco puntos equidistantes, que se fotografían, obteniéndose en cada uno de ellos un campo cuadrangular de $0.886 \mathrm{~mm}^{2}$ y un área total de $4.43 \mathrm{~mm}^{2}$. La muestra estuvo integrada por 328 individuos (154 femeninos y 174 masculinos) entre 14 y 97 años, de origen heterogéneo (EE.UU, Chile y República Dominicana) con la finalidad de ampliar la composición étnica de la misma y por ende la aplicación de los resultados. Cuantifica cinco variables microestructurales y tres promedios:

1) Osteonas secundarias $/ \mathrm{mm}^{2}\left(X_{1}\right)$

2) Osteonas tipo $\mathrm{II} / \mathrm{mm}^{2}\left(X_{2}\right)$

3) Osteonas fragmentarias $/ \mathrm{mm}^{2}\left(X_{3}\right)$

4) Espacios de resorción $/ \mathrm{mm}^{2}\left(X_{4}\right)$

5) Canales no haversianos $/ \mathrm{mm}^{2}\left(X_{5}\right)$

6) Promedio del porcentaje de hueso circunferencial lamelar $\left(X_{6}\right)$

7) Promedio del porcentaje de hueso osteonal $\left(X_{7}\right)$

8) Promedio del porcentaje de osteonas fragmentarias $\left(X_{8}\right)$

El conteo total de cada una de las primeras cinco variables en los cinco campos fue dividido por 4.43 a los fines de determinar el conteo por $\mathrm{mm}^{2}$. Las variables fueron sometidas a análisis de regresión lineal simple y múltiple para determinar su relación con la edad y establecer una ecuación de regresión 
utilizable para estimarla. Además, realiza un análisis exploratorio de los factores responsables de las diferencias sexuales observadas durante el análisis estadístico.

Todas las variables, excepto los espacios de resorción, mostraron correlación altamente significativa con la edad. Del análisis de regresión múltiple surgieron varias ecuaciones para femeninos, masculinos y sexos agrupados. La mayoría presentó un error estándar \pm 10 años, con un coeficiente de determinación de 0.48 a 0.72. En particular, las ecuaciones específicas para masculinos (ES=10.05) y femeninos $(E S=10.00)$ proveyeron mejores resultados que las ecuaciones para sexos agrupados $(E S=10.08)$. Las diferencias entre sexos se observaron principalmente en dos microestructuras, osteonas completas y osteonas fragmentarias $^{7}$, lo cual, consecuentemente, demuestra la necesidad de generar fórmulas propias para cada población.

Posteriormente y como respuesta a la necesidad de desarrollar un método ante la falta de huesos largos, Stout y Paine (1992) propusieron y revisaron fórmulas para costilla y clavícula. Desarrollaron estas ecuaciones predictivas a partir de la cuantificación de las siguientes variables: área cortical, densidad de osteonas completas, densidad de osteonas fragmentarias y densidad total de osteonas visibles. Analizaron una muestra de 40 individuos de edad conocida (13 a 62 años). Seguidamente testearon las formulas en una muestra independiente (12 costillas y 7 clavículas), no hallando diferencias significativas entre las medias de las edades conocidas y las estimadas. La ecuación, basada en la combinación de ambas piezas demostró mayor precisión y fiabilidad, lo cual llevó a los autores a recomendar su aplicación cuando ambas piezas se encuentren disponibles.

En 1996, Stout y colaboradores, aplicaron la formula obtenida a partir de la clavícula de Stout y Paine en una muestra independiente de un cementerio del

\footnotetext{
${ }^{7}$ Para el análisis de diferencias sexuales el investigador agrupó la muestra por períodos de edad de diez años. Las diferencias fueron encontradas principalmente en las variables vinculadas con la remodelación ósea. En ambos sexos las osteonas II se incrementan con la edad, los espacios de resorción no varían por $\mathrm{mm}^{2}$, los canales no haversianos decrecen con la edad y el porcentaje de área ocupada por hueso no remodelado decrece, especialmente después de los 40 años.
} 
Siglo XIX en Suiza. Debido a las diferencias observadas entre la edad estimada y la edad real (5.5 años) se propuso una nueva fórmula basada en la combinación de ambas muestras $^{8}$. Los autores recomiendan su utilización para estimar la edad en personas mayores.

Años después, Watanabe y colaboradores (1998) establecieron fórmulas predictivas de estimación de edad basadas en una muestra japonesa. Analizaron 98 fémures, 72 masculinos (de 43 días a 92 años) y 26 femeninos (de 2 a 88 años). Las secciones fueron coloreadas con la técnica de Villanueva ${ }^{9}$. Cada sección fue registrada a través de microradiografías, cuantificándose las siguientes variables: área, perímetro, diámetro máximo y mínimo de osteonas y canales haversianos, número de osteonas Tipo II y de osteonas fragmentarias. Estos autores introducen una nueva variable denominada área del triángulo, delimitada por tres líneas adyacentes entre tres canales de Havers.

Los parámetros relacionados con las osteonas mostraron un alto coeficiente de correlación con la edad a diferencia de los hallados para los canales haversianos. Todos fueron sometidos a un análisis de regresión múltiple y stepwise. El error estándar de las estimaciones, 3.16 a 11.50 años es, para los autores, evidencia de mayor confiabilidad en el método que los propuestos en otros trabajos.

Entrados en el siglo XXI y dada la evidencia de la variación poblacional en la dinámica de la remodelación ósea, lo cual puede dar lugar a estimaciones poco precisas cuando una ecuación predictiva para estimar la edad basada en una población es aplicada a las demás, se han propuesto nuevos métodos histológicos de estimación específicos para cada población.

Así, en Holanda Maat y colaboradores (2006) desarrollaron ecuaciones predictivas basadas en una muestra contemporánea holandesa. Examinaron segmentos de la diáfisis femoral de 162 individuos (86 masculinos y 76 femeninos)

\footnotetext{
${ }^{8}$ Individuos provenientes de autopsias (Stout y Paine, 1992) y los del cementerio suizo (Siglo XIX) (Stout et al., 1996).

${ }_{9}^{9}$ Para más detalle ver Villanueva AR (1974).
} 
con edades comprendidas entre los 15 y 96 años. La observación microscópica fue realizada con un aumento $100 x$ sobre microradiografías. Cuantificaron una sola variable (cantidad de hueso laminar no remodelado) y formularon ecuaciones predictivas. El error estándar (ES) de las estimaciones osciló entre 9.16 y 10.6 años.

En Malasia, Nor y colaboradores (2006) elaboraron ecuaciones predictivas para húmero, cúbito, radio, fémur y tibia. La muestra seleccionada estuvo integrada por 64 individuos (50 masculinos y 14 femeninos) entre 21 y 78 años. Cuantificaron diez variables, cinco demostraron una correlación significativa con la edad. Los parámetros seleccionados fueron: conteo de osteonas (completas y fragmentarias), diámetro osteonal, área osteonal, diámetro medular y perímetro osteonal. La ecuación propuesta para fémur arrojo un erro estándar (ES) de 14.04 años.

En Sudáfrica, Keough y colaboradores (2009) desarrollaron estándares para estimar la edad, a nivel de la microestructura, en una población sudafricana. Para ello analizaron una muestra de 146 individuos de edad y sexo conocido (105 masculinos y 41 femeninos) con un rango de edad entre 19 y 82 años. Cuantificaron diez variables histomorfométricas de las cuales cuatro mostraron una correlación con la edad, el $N^{\circ}$ total de osteonas $(r=0.53)$, el porcentaje de hueso no remodelado $(r=-0.53), N^{\circ}$ total de canales no haversianos $(r=-0.55)$ y el porcentaje promedio de hueso fragmentado $(r=0.55)$. Estas variables fueron utilizadas para calcular formulas de regresión lineal simple y múltiple. El error estándar de la estimación oscilo entre los 13.31 y 14.04 años.

En Korea, Han y colaboradores (2009) formularon una ecuación a partir de la corteza anterior de fémur en una muestra contemporánea. Analizaron 72 piezas, 44 masculinos y 28 femeninos, cuya media de edad fue de 66,6 y 70,3 años respectivamente. Las secciones fueron teñidas con la técnica de Villanueva y cuantificaron cuatro variables: densidad poblacional osteonal, tamaño promedio osteonal, diámetro promedio del canal de Havers y ancho cortical. Las 
observaciones fueron realizadas con un microscopio polarizado, de $100 x$ y las variables analizadas con un procesador de imágenes.

Los resultados demostraron que el promedio del tamaño osteonal presentó una alta correlación con la edad $\left(R^{2}=0.668\right)$, seguido por la densidad poblacional osteonal $\left(R^{2}=0.656\right)$. El ancho cortical y el tamaño de los conductos presentaron correlaciones débiles $\left(R^{2}=0.165\right.$ y 0.087 respectivamente). La ecuación propuesta por los autores arrojo un valor de $r^{2}=0.789$ con un ES= 6.65 años.

En Argentina se han realizado aportes y adecuaciones de técnicas microsestructurales sobre tejidos duros (huesos- dientes) aplicados a estudios bioantropológicos (Restelli et al. 1997, Vasallo et al. 2000, Vasallo y Restelli 2000, Vasallo et al. 2001).

Vasallo y colaboradores (2000) sobre una muestra de 20 individuos, entre 15 y 98 años, del Cementerio Municipal de la Plata, elaboraron una ecuación predictiva basada en una sola variable, el porcentaje de osteonas fragmentarias $\left(\mathrm{r}^{2}\right.$ = 0.8611). La misma puede aplicarse a tibia y fémur indistintamente.

Por último, cabe mencionar, aunque no esté relacionado directamente con la presente investigación, que paralelamente se han descripto numerosos métodos para la estimación de edad a la muerte a partir de la aplicación de otras técnicas histomorfométricas, las cuales varían de una muestra a otra, según las piezas óseas seleccionadas e.g tibia (Hauser et al. 1980); húmero (Iwamoto et al. 1978; Yoshino et al. 1994; Nor et al. 2006), costilla (Cho et al. 2002), el tipo de tejido óseo utilizado (cortical o trabecular) y las estructuras microscópicas observadas (Stout 1998); suministrando diferentes ecuaciones predictivas. 


\section{CAPÍTULO III}

MATERIAL Y MÉTODOS 


\section{III.1- LA COLECCIÓN LAMBRE}

Los antecedentes de la integración de la actual colección "Prof. Dr. Rómulo Lambre" se remontan al año 2002, instancia en la cual el Concejo Deliberante (Ord. № 9471, octubre de 2002) autoriza al Cementerio Municipal de La Plata a celebrar un convenio con la Universidad Nacional de La Plata para la cesión de restos esqueletales "...debidamente identificados y sepultados en el osario común...", en particular a la "...Facultad de Ciencias Médicas-Departamento de Ciencias Morfológicas- para la creación de una osteoteca..." a los fines educativos y científicos. Como Anexo a dicha ordenanza se ejecuta el convenio entre la Municipalidad de La Plata en persona del Intendente Municipal y la Universidad de La Plata, en persona de su Presidente (diciembre de 2002). En el 2003, se formula un Acta modificatoria firmada por ambos representantes institucionales con deslinde de responsabilidades en lo que respecta a la custodia de dicho patrimonio.

La normativa que pauta (Ordenanza Municipal 7638/90) la guarda de los individuos inhumados en el Cementerio Municipal con información documental identificatoria, contempla rigurosamente su custodia sujeta a la participación de las familias en las decisiones respecto a los restos mortales. Es así que establece un período entre 4 y 6 años de entierro y, de no mediar una respuesta a la notificación fehaciente, los restos son exhumados y destinados a osario común o cremación.

En el 2005 y con la intención de generar una colección osteológica de referencia a partir de restos esqueletarios debidamente documentados cedidos, se firma un Acuerdo de Cooperación (ver en anexo) entre la Facultad de Ciencias Médicas y la Facultad de Ciencias Naturales y Museo (UNLP) que involucra al Laboratorio de Investigaciones Morfológicas Aplicadas y a las Cátedras de Citología, Histología y Embriología "A" (FCM) y Métodos y Técnicas de la Investigación Antropobiológica (FCNyM) a los fines de hacer efectiva la conformación de la osteoteca. 
En el 2007 se instaura formalmente en ámbito de la Facultad de Ciencias Médicas denominándola "Colección Prof. Dr. Rómulo Lambre" y se designa a la Cátedra de Citología, Histología y Embriología “A” el espacio físico para su guarda.

Desde entonces, el cementerio periódicamente realiza entregas de conjuntos de restos óseos incrementado así el tamaño de la colección. Por lo tanto la estrategia para la incorporación de estos materiales consiste en la curación permanente, que abarca desde el acondicionamiento hasta el relevamiento documental.

\section{III.1.1-Acondicionamiento}

El acondicionamiento de los materiales es el primer paso en la construcción de una colección osteológica. En este caso, los restos cedidos por el cementerio se encontraban esqueletizados, lo cual obligó a su separación de sedimentos y envolturas. Posteriormente fueron lavados con agua a escasa presión y cepillo de cerdas blandas. Los sedimentos fueron inspeccionados utilizando una malla de sostén de trama fina a los efectos de retener dientes y piezas óseas de menor tamaño. El material se dejó secar, y posteriormente se procedió al rotulado de cada elemento esqueletal, para lo cual se asignó a cada individuo un código indicativo de procedencia y un número de orden correlativo interno propuesto por el equipo de investigación (e.g. CMLP.O14). Cada esqueleto se colocó en una caja o recipiente de plástico dependiendo de su tamaño. Tanto las cajas como los recipientes están debidamente rotulados para su identificación. Finalizado el acondicionamiento, los restos quedaron depositados en la Cátedra de Citología, Histología y Embriología "A" (FCM, UNLP).

Al mismo tiempo que se acondicionó el material, se registró en un protocolo ad hoc el estado de conservación general, la presencia de material cultural (ropa, placas, rosarios) y entomofauna asociada (dípteros y coleópteros). Seguidamente se realizó el inventario por individuo en el que se registran las piezas esqueletarias presentes en cada uno de los casos. 


\section{III.1.2- Relevamiento documental}

El relevamiento de la información documental involucró una serie de pasos previos que permitieron asociarla con los restos acondicionados. En este sentido, el personal del cementerio coloca un número identificatorio en cada una de las bolsas que contiene los restos esqueletales de un individuo, estos números remiten a las Acta de defunción de las cuales se obtienen los datos de edad, sexo, nacionalidad, fecha y causal de muerte correspondientes a cada individuo. A partir de esta información se construyó una base de datos que nos permite realizar una descripción del perfil demográfico de los restos esqueletales disponibles en la Colección.

\section{III.1.3- Composición de la Colección}

La Colección cuenta al día de hoy con 420 individuos fallecidos entre 1936 y 2001, esta información es relevante en tanto que representa un momento histórico particular, constituyéndose en una colección contemporánea con características diferenciales respecto de colecciones arqueológicas. En este momento los individuos acondicionados y disponibles para su estudio comprenden el $60 \%$ de hombres y el 40 \% de mujeres. La composición etaria, según documentación fehaciente abarca desde perinatos hasta individuos seniles.

La distribución de frecuencias por intervalos de edad nos muestra que los rangos de 0-1 (25\%), recién nacidos (16 \%) y 70-79 (16 \%) años son los que presentan mayor incidencia relativa (Gráfico 1). 


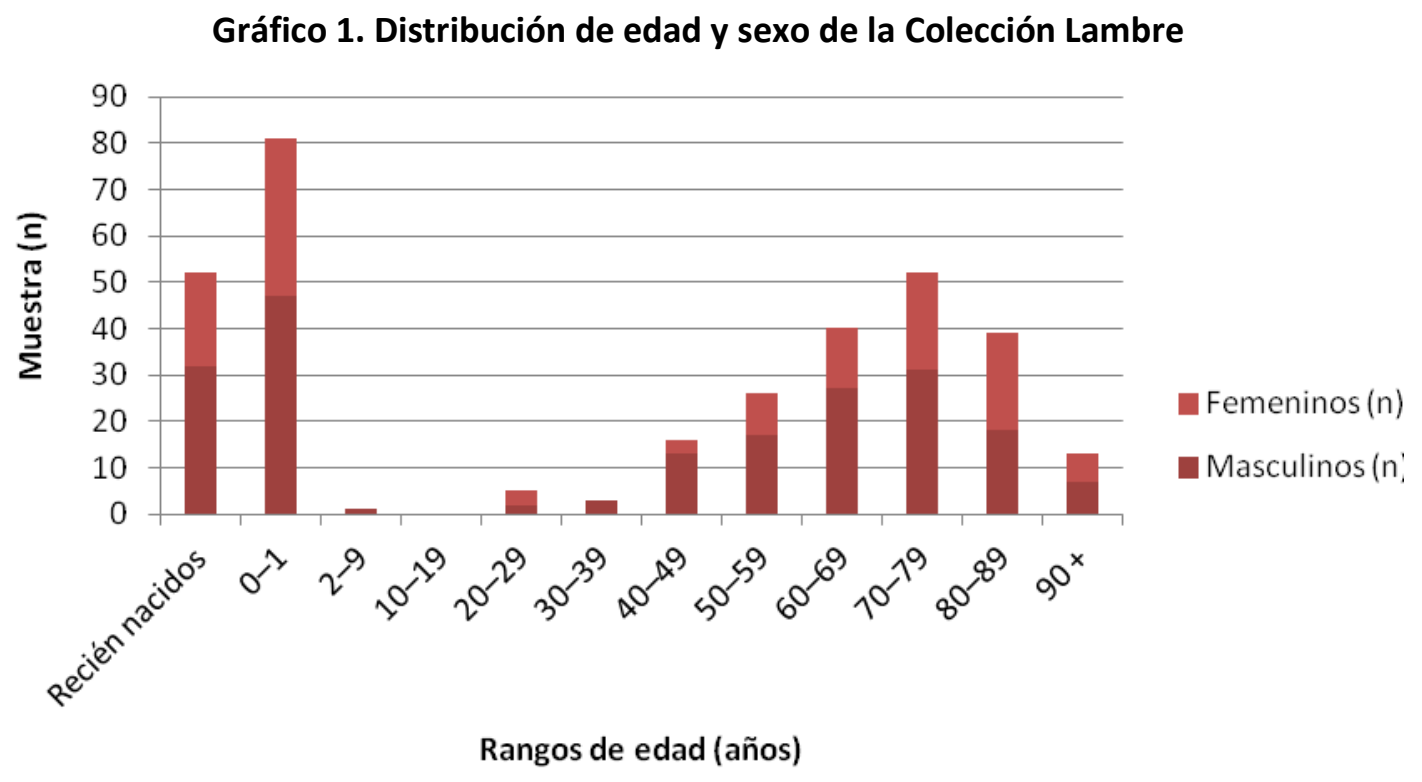

En las Actas de defunción también se consigna nacionalidad y causa de muerte. La totalidad de los individuos subadultos hasta los 18 años tienen nacionalidad argentina, mientras que entre los adultos (mayores de 18 años) aunque la nacionalidad más representada sigue siendo la "argentina" (58.5\%), se encuentran también individuos de nacionalidad "italiana" (4.6 \%), "española" (2.6 \%), "uruguaya” (1 \%) "paraguaya” (0.5\%), "chilena” (0.5\%), "portuguesa” (0.5 \%) y "boliviana" (0.5\%). Para el 31,3\% restante no se registra ésta información en las actas de defunción individuales (Gráfico 2).

\section{Gráfico 2. Nacionalidad de los individuos adultos}

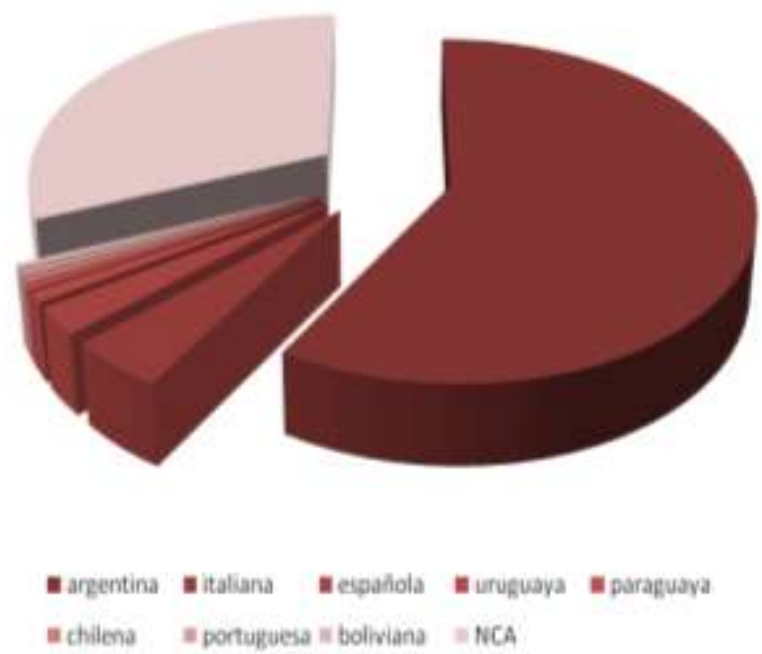


Las causas de muerte resultan relevantes en tanto que constituyen una de las características particulares de esta colección a la vez que contribuyen al diagnóstico osteopatológico de los individuos que la componen (Plischuk, 2012). Los datos relevados indican que la "asfixia fetal intrauterina no traumática" (14.3 \%) y el "paro cardio-respiratorio no traumático" (43.3 \%) son las que presentan mayor incidencia. 
La selección del material requirió de un primer análisis holístico sobre la colección en general debido a las dificultades que pudieran presentarse durante la preparación, desgaste y cuantificación de las secciones óseas (muestra). Se establecieron los siguientes criterios generales:

- Evaluación de pertenencia individual. Presencia/ausencia de elementos óseos (en este caso fémur) para cada esqueleto.

- Estado de preservación del fémur en particular, que contempló el análisis de procesos tafonómicos ${ }^{10} \mathrm{y}$ diagenéticos ${ }^{11}$.

- Presencia/Ausencia de patologías

En este marco el primer punto constituyó el ordenador de la colección arrojando como resultado la potencialidad para el análisis de 150 fémures en su mayoría izquierdos. Los criterios restantes actuaron como indicadores de exclusión según el grado de manifestación en cada caso. En la tabla 1 se expresa la conformación de la muestra. Solo el 50 \% ha resultado apto para el análisis microscópico.

Cabe aclarar que, en el transcurso de la investigación se eliminaron además algunas secciones, que aunque fueron desgastadas, no pudieron ser cuantificadas debido a una disrupción de la microestructura ósea producida por factores diagenéticos como bacterias y hongos.

10 La tafonomía es el estudio de los procesos que operan desde la muerte de un organismo hasta el momento en el que es recuperado para su estudio (White y Folkens 2005).

${ }^{11}$ La diagénesis es la transformación de los restos por procesos físicos y químicos dentro del sedimento. 
Tabla 1. Conformación de la muestra

\begin{tabular}{l|lr}
\hline Muestra & N & \\
\hline Criterios de Inclusión: & & \\
Aptos para análisis & 71 & $47.3 \%$ \\
Criterios de exclusión: & 42 & $28 \%$ \\
Patológicos (fracturas osteoartriticas, & 23 & $15.3 \%$ \\
artritis coxofemoral, periostitis) & & \\
Tafonómicos (Estadios 2-3 de Meteorización Behrensmeyer, 1978) & & \\
Criterios de eliminación: & & $9.3 \%$ \\
Procesos diagenéticos & 14 & \\
\hline Total & $\mathbf{1 5 0}$ & $\mathbf{1 0 0} \%$ \\
\hline
\end{tabular}

En síntesis, la muestra quedó conformada por 71 individuos, 21 femeninos y 50 masculinos, de la colección Lambre. El rango de edad, para ambos sexos, oscila entre los 22 y 91 años con una media de 58.66 (Tabla 2 y Gráfico 3).

Tabla 2. Distribución de edad y sexo

\begin{tabular}{lccccc}
\hline \hline Sexo & N & Media & DS. & Mínimo & Máximo \\
\hline F & 21 & 61,10 & 15,228 & 26 & 88 \\
M & 50 & 57,64 & 15,970 & 22 & 91 \\
Total & 71 & 58,66 & 15,726 & 22 & 91 \\
\hline \hline
\end{tabular}


Gráfico 3. Distribución de edad y sexo de la muestra

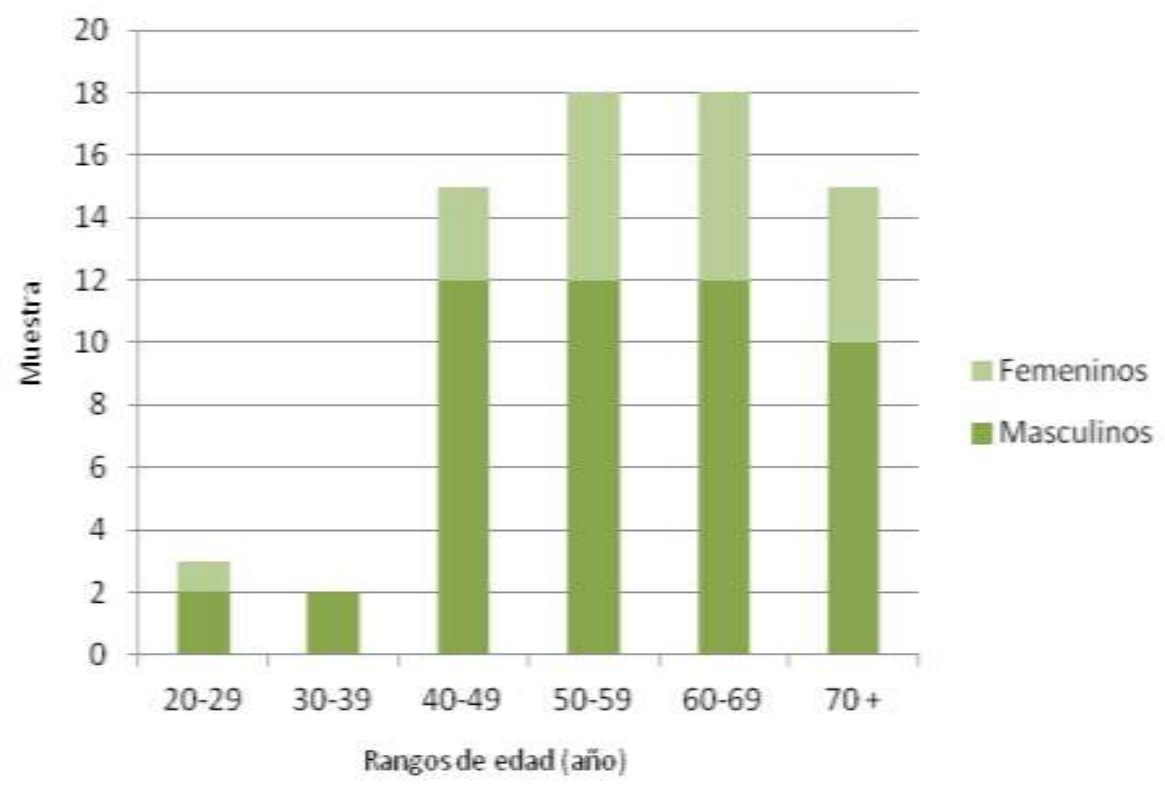

\section{III.2.1- Preparación de la muestra}

Las secciones histológicas se obtuvieron a partir de la remoción de tejido cortical de la mitad anterior de la diáfisis femoral tal y como sugieren estudios previos analizados (Singh y Gunberg op cit.; Thompson op cit.; Ahlqvist y Damsten op cit; Ericksen op cit, Maat op cit; Keough 2007). Asimismo, se ha demostrado que la mitad anterior de la diáfisis femoral es el área más resistente al deterioro tafonómico después de un periodo prolongado de entierro (Kerley 1965; Maat et al. 2006), es fácilmente identificable y además, la superficie cortical al no tener inserciones musculares presenta cierto grado de estabilidad biomecánica (Ericksen 1991, Keough et al. 2009).

Las muestras para observación histológica fueron realizadas, sin descalcificación previa, por personal técnico de la Cátedra de Citología, Histología y Embriología A de la Facultad de Ciencias Médicas. UNLP. 


\section{III.2.2- Procesamiento de la muestra}

En este acápite se describen separadamente dos técnicas que fueron aplicadas secuencialmente en dos etapas de la investigación. Los alcances y limitaciones de cada una de ellas serán discutidos en el capítulo correspondiente

\section{Técnica por desgaste}

Las muestras fueron procesadas por técnica de desgaste modificada en adecuación a los estudios histomorfométricos (Vasallo y Restelli 2000) y siguiendo las recomendaciones de Maat et al. 2001. Las mismas apuntan a la reducción del espesor del tejido duro (hueso) a fin de poder observarlo microscópicamente. Los pasos a seguir incluyen:

1. Obtención de láminas delgadas (1-2mm de espesor) del hueso diafisiario, los cortes fueron realizados con sierra manual.

2. Aplicación de la técnica de desgaste, en una primera instancia, con piedra de afilar previamente humedecida y posteriormente con una lija al agua (espesor no 220). Se humedece el centro de la lija con agua corriente y se agrega detergente en aquellas piezas que presentaron grasitud. El desgaste se realiza en ambos lados de la pieza hasta obtener un espesor suficiente para la transmisión de la luz.

3. Control del espesor de la lámina a través de la observación periódica al microscopio a fin, por un lado, de alcanzar la medida óptima para la observación de las variables a cuantificar y, por el otro, constatar la presencia de grietas que evidencian la fragilidad de la muestra. A aquellas piezas que presentaron cierta fragilidad se les aplicó un tratamiento con solución revitalizadora (24-48 hs). Compuesta por las siguientes soluciones: Sol. Alcohólica de Fenol al 5\% (20 cc.), Formol Neutro 10 \% (20 cc.), CINa al 5 \% (20 cc.), Alcohólica de Glicerina 5 \% (20 cc.) (Restelli et al. 1997).

4. Lavado con agua destilada y secado de la lámina. 
5. Montaje sobre portaobjeto limpio y desengrasado. Se deposita una gota de esmalte, y sobre él, se coloca la lámina y el cubreobjetos. Se deja secar en estufa 48 hs a 370 C aproximadamente.

\section{Técnica de inclusión en resina}

En una segunda etapa y según lo aconsejado por la bibliografía específica se probó la técnica de inclusión en resina en reemplazo de la de desgaste, a los fines de optimizar la obtención de los preparados histológicos. Tal decisión metodológica se basó, luego de la experiencia adquirida, en la necesidad de mantener la integridad de la muestra durante los procesos de corte y desgaste para poder documentar con mayor precisión la microanatomía del tejido óseo. La técnica utilizada, luego de un ajuste de prueba, fue la de inclusión en plásticos duros como la resina epoxi (Paine 2007).

Actualmente, el desarrollo de medios duros de inclusión (monómeros plásticos), de micrótomos y sistemas de cortes especiales, ha permito cortar hueso sin descalcificar y, con ello, facilitar la realización de investigaciones imposibles de llevarse a cabo con las técnicas tradicionales (Cano-Sánchez et al. 2005). Las primeras pruebas comenzaron con la inclusión del hueso en derivados celulósicos a fin de obtener bloques de plástico de dureza semejante al hueso. Complementariamente se incorporaron micrótomos con cuchilla de diamante adecuados tanto a la dureza como al tamaño de la muestra.

Dentro de una amplia variedad de derivados plásticos para inclusión, tanto los acrílicos como el Metacrilato de metilo y las resinas epoxi son los más utilizados para estas aplicaciones.

Las resinas epoxi se emplean principalmente en microscopía electrónica, por su elevado grado de estabilidad al ser sometidas al vacío y bombardeo de electrones. Su utilización en microscopía óptica es menos frecuente ya que no permite una adecuada penetración de los colorantes específicos (Prieto Carrero 1993). 
Las ventajas de estos medios de inclusión son: completa penetración, endurecimiento homogéneo de los bloques y estabilidad de los preparados durante períodos largos de almacenamiento. Todo ello facilita su corte y colocación en portaobjetos. En particular, la preparación de los cortes delgados según la Técnica Histológica para la Inclusión en Resina se realizó en el Laboratorio Geológico del Lic. Ricardo Ponti.

La técnica contempla los siguientes pasos:

1. Infiltración consiste en sumergir la muestra en un molde con resina epoxi (Dicast LY 554 con endurecedor HY 554) hasta cubrir totalmente la pieza. El tiempo de desmolde es de 24 a 36 hs.

2. Pulido sobre una de las caras del taco obtenido por infiltración. Para el desgaste se utilizan abrasivos en polvo (carburo de silicio, corindón, alúmina) de diferentes granulometrías. Una vez obtenida una superficie plana y pulida la muestra se seca en un horno a 35 grados aproximadamente durante 3 horas.

3. Pegado posterior del taco a través de una de sus caras a un portaobjetos. El pegado se realiza con resina, por lo tanto el tiempo de secado es de 24 a 36 hs a temperatura ambiente ó bien en horno a 35 grados.

4. Obtención de las secciones mediante sistemas de corte, desbastado y pulido. Una vez obtenida la muestra pegada al porta objetos se realiza un corte de desbaste paralelo al portaobjetos, se utiliza un disco diamantado para obtener una lamina de aproximadamente $1 \mathrm{~mm}$, luego se procede con el pulido de la lámina hasta obtener el espesor deseado: 30 - 40 micras.

5. Montaje que implica cubrir la lámina con resina epoxi o un adhesivo plástico fotosensible para evitar la formación de burbujas. 


\section{III.3- Evaluación histomorfométrica de la muestra}

Para la observación microscópica se empleó un Fotomicroscopio Trinocular Nikon (Mod. Eclipse E200) con objetivo 10X y ocular 10X, equipado con cámara digital Nikon (Mod. Coolpix S10). Se seleccionaron y fotografiaron, al menos, cuatro campos microscópicos por sección, en la zona subperiosteal.

El área de cada campo fue obtenida a través de la combinación del microscopio y la magnificación de la cámara (1.219 mm x $0.904 \mathrm{~mm}$ ), dando como resultado un campo fotográfico rectangular de $1.10 \mathrm{~mm}^{2}$. La combinación de los cuatro campos arrojo el área total muestreada que en este caso fue de $4.40 \mathrm{~mm}^{2}$.

\section{III.3.1- Procesamiento de imágenes}

Una vez obtenidas las microfotografías se procedió al procesamiento y análisis de las imágenes. La imagen es una representación visual de un objeto o grupo de objetos. El procesamiento de Imágenes modifica la información dentro de la misma para hacer de ésta un elemento de análisis, traduciéndola a un formato numérico de tipo binario, proceso conocido como digitalización de la imagen.

El primer paso consiste en elegir la base de imagen con la que se va a trabajar, ya sea fotografías monocromas (Nivel de Gris) o color (RGB). En nuestro caso hemos convertido las imágenes en monocromas (Escala de Gris 12). Posteriormente fueron mejoradas para realzar su apariencia y aumentar la posibilidad de poder extraer datos a la hora de la cuantificación. Para ello se modificó el índice de intensidad (brillo, contraste, gamma), y/o se aplicaron filtros especiales.

Un paso fundamental consiste en calibrar la imagen antes de medir. Las operaciones de medida se realizaron en términos de posiciones de los pixeles de las imágenes, de manera que estos deben escalarse para que se ajusten a cualquier sistema de coordenadas. Tal acción permite obtener medidas reales y útiles para su aplicación. En nuestro caso la escala de medida elegida fue micras $(\mu)$. 
La utilización de microfotografías tiene la ventaja de crear un documento verificable, permanente, libre del peligro implícito a los cambios de los oculares y a los movimientos de la sección delgada, que hacen confundir el campo visual original.

\section{III.3.2- Cuantificación de las variables}

La histomorfometría estática permite la cuantificación de estructuras histomorfológicas (i.e componentes celulares y tisulares) en un momento dado a partir de medidas de longitud $(\mathrm{mm})$, áreas $\left(\mathrm{mm}^{2}\right)$ o conteo de células $(\# / \mathrm{mm}$ o $\# / \mathrm{mm}^{2}$ ) (Stout y Crowder 2012).

La observación e identificación de las variables se realizó a través de un Analizador de Imágenes, Software Image Pro Plus 4.5 (Media Cybernetics). Este programa permitió efectuar las mediciones y conteo sobre cada microfotografía, cuatro por sección, en forma semiautomática.

El conteo total de los cuatro campos para cada microestructura fue dividido por 4.40 (área total) para determinar el conteo por $\mathrm{mm}^{2}$.

La observación e identificación de las variables microestructurales de la cortical del fémur, correlacionadas con la edad de muerte, se realizaron según criterios previamente publicados por varios autores (Kerley y Ubelaker 1978, Singh y Gunberg op cit., Ericksen 1991, Vasallo et al. 2000, Han et al. 2009, Keough 2009). Se seleccionaron cinco variables descriptas en la bibliografía especializada (Tabla 3).

La nomenclatura y abreviaturas se corresponden con las recomendaciones de la American Society for Bone and Mineral Research (1987) (Parfitt 2002). 


\begin{tabular}{lc}
\hline Variables & Abreviaturas \\
- Densidad Poblacional Osteonal & OPD \\
- $\mathrm{N}^{\circ}$ total de osteonas & N. On. \\
- No total de osteonas fragmentarias & N. On. Fg. \\
- Promedio del diámetro del canal de Havers $(\mu \mathrm{m})$ & Hav. Can. \\
- Porcentaje de osteonas fragmentarias & \% On. Fg. \\
\hline
\end{tabular}

$\mathbf{N}^{\circ}$ total de osteonas (N. On.): Osteonas secundarias con el $90 \%$ del perímetro del canal haversiano intacto o no remodelado (Robling y Stout 2008).

Una osteona o sistema de Havers, se reconoce en una sección transversal por un canal vascular rodeado por laminillas concéntricas, que contienen osteocitos en sus lagunas. Cada osteona es rodeada por una línea de cemento que marca el área de actividad osteoclástica y osteoblástica (Kerley 1965, Kerley y Ubelaker 1978).

Las osteonas completas se definen sobre la base de la presencia del C. de Havers completo. Histológicamente, cada osteona está claramente definida, demarcada de sus vecinas y de los sistemas intersticiales por la línea de cemento (Singh y Gunberg 1970).

№ total de osteonas fragmentarias (N.On.Fg.): Osteonas secundarias producto de la remodelación, en la cual el $10 \%$ o más del perímetro del Conducto de Havers, ha sido remodelado. También se incluyen remanentes de osteonas secundarias preexistentes que no contienen Havers (Robling y Stout 2008).

Densidad Poblacional osteonal en $\mathrm{mm}^{2}$ (OPD): es la suma de N. On y N. On. Fg dividida por el área total muestreada (Sa. Ar) (Stout y Crowder 2012). 
Promedio del diámetro del canal de Havers $(\mu \mathrm{m})$ (Hav. Can.): Se midió el diámetro menor de cada conducto. La medida fue obtenida solo cuando el c. haversiano estuvo completamente visible en el campo. Los conductos que midieron tres veces más que su ancho, no fueron considerados (Singh y Gunberg 1970). El promedio se obtuvo a partir de la sumatoria de todos los diámetros divididos por la cantidad de osteonas medidas.

Porcentaje de Osteonas fragmentarias (\% On. Fg.): se obtiene el porcentaje de osteonas fragmentarias respecto a la suma entre las osteonas completas (N. On) y las osteonas fragmentarias (N. On. Fg) (Vasallo et al. 2000).

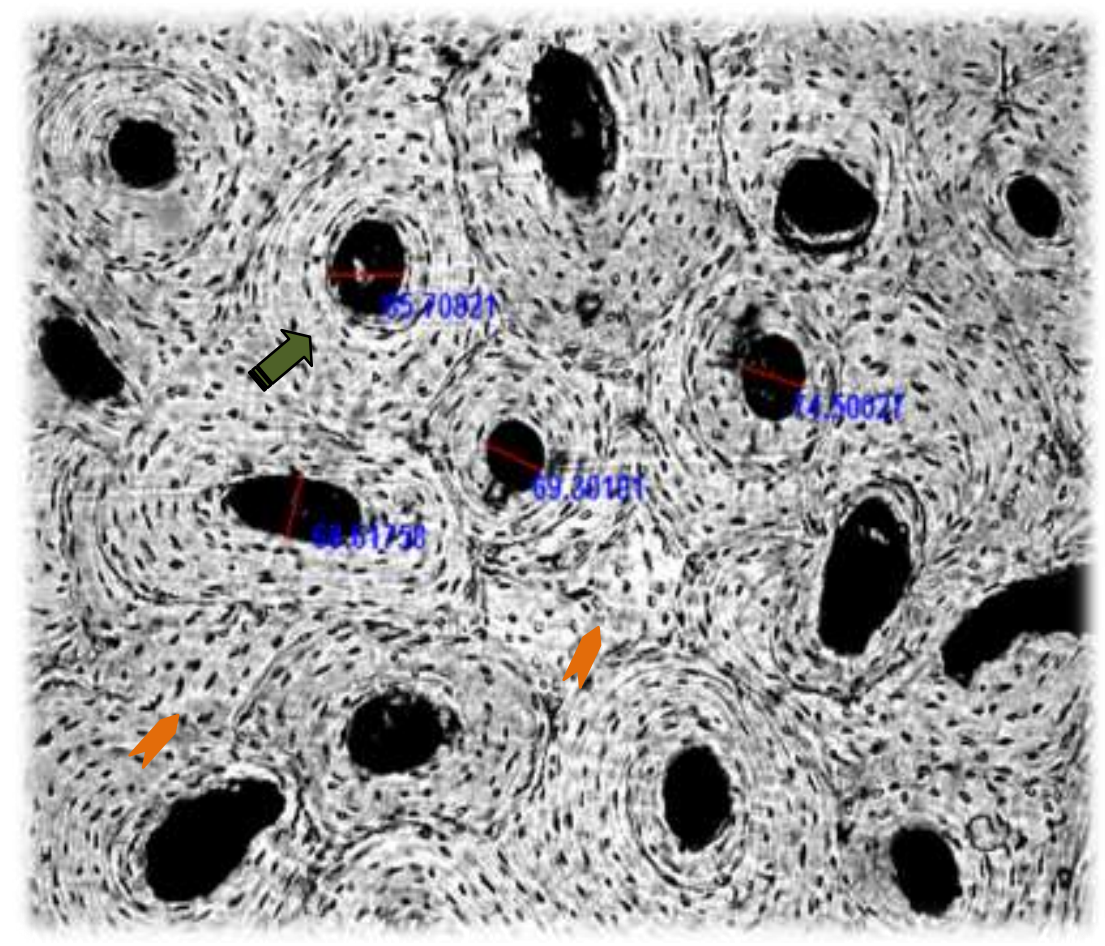

Foto 1. Microfotografía (preparado incluido en resina). Referencias: Flecha verde: osteonas completas (N. On.). Flecha naranja: osteonas fragmentarias (N. On. Fg.). Línea roja: diámetro conducto de Havers (Hav. Can). 


\section{III.4- Procesamiento estadístico}

El análisis de los datos se realizó con el programa SPSS 17.0.

Estadística Descriptiva: para la descripción y análisis de la muestra se calcularon los estadísticos de tendencia central (media) y de dispersión (desviación típica), tanto para sexos agrupados como estratificados. Seguidamente contrastamos los siguientes supuestos:

- Normalidad: se aplicó el test de Kolmogorov- Smirnov que permite contrastar la hipótesis de que las muestras obtenidas proceden de poblaciones normales.

- Homocedasticidad u Homogeneidad de varianzas: para ello utilizamos la Prueba de Levene, a través de la cual contrastamos la hipótesis de que los grupos definidos por la variable factor (v. histomorfométrica) proceden de poblaciones con la misma varianza.

Estadística Inferencial: las estimaciones y predicciones se efectuaron mediante diversos test estadísticos:

- Prueba de T para muestras independientes, permite contrastar hipótesis referida a la diferencia entre dos medias independientes. En nuestro caso comparamos la media de cada una de las variable histomorfométrica entre los sexos.

- Análisis de Regresión lineal múltiple, permite establecer la relación que se produce entre una variable dependiente $(\mathrm{Y})$ y un conjunto de variables independientes $\left(X_{1}, X_{2}, \ldots \ldots . . . X_{k}\right)$. Se aplicó esta técnica estadística para la construcción del modelo o ecuación predictiva que nos permita estimar la edad a partir de las variables microestructurales. Para ello se seleccionó el método "stepwise" o "paso a paso", a través del cual se intenta buscar de entre todas las posibles variables explicativas o predictoras (VI) aquellas que expliquen mejor a la variable dependiente (edad) sin que ninguna de ella 
sea combinación lineal de las restantes.

Los pasos para la construcción del modelo fueron los siguientes:

1) Determinación de la bondad de ajuste de los datos al modelo de regresión lineal múltiple. Para ello se calcularon los siguientes estadísticos:

- Coeficiente de Correlación Múltiple (R), mide la intensidad de la relación entre un conjunto de variables independientes y una variable dependiente. Para ello se calculó una matriz de correlaciones parciales en la que se pudo observar:

1. La interrelación entre las variables independientes con el fin de ver si se establece multicolinealidad entre las mismas.

2. La relación entre cada una de las variables independientes respecto a la dependiente.

Para cuantificar la relación entre las variables se utilizó el coeficiente de correlación de Pearson (r). El mismo oscila entre -1 (relación lineal perfecta negativa) y +1 (relación lineal positiva perfecta), un valor próximo a 0 (cero) indica relación nula, es decir que entre las dos variables no existe asociación lineal, por lo tanto, carece de sentido determinar el modelo y/o ecuación de regresión.

La correlación existente entre cada par de variables fue graficada a través de diagramas de dispersión.

- Coeficiente de correlación Múltiple al Cuadrado o Coeficiente de Determinación $\left(R^{2}\right)$, mide la proporción de la variabilidad de la variable dependiente explicada por la variable independiente que en ese momento ha sido admitida al modelo.

- Error típico de la predicción (ETB), nos indica la parte de la variable dependiente que dejamos por explicar. A medida que se incrementa el coeficiente de determinación el error desciende. 
-Análisis de la varianza, permite valorar hasta qué punto es adecuado el modelo de regresión lineal para estimar los valores de la variable dependiente.

2) Estimación de los parámetros o coeficientes de regresión de la ecuación predictiva o ecuación de regresión múltiple.

Una vez analizada la intensidad de la relación entre las variables, se procedió a estimar los parámetros de la ecuación de predicción. 


\section{III.5- ASPECTOS ÉTICOS Y LEGALES}

En este acápite haremos hincapié en aquellas normativas que de alguna manera intentan ordenar sistemáticamente los aspectos comportamentales que los grupos humanos asumen ante la muerte, incorporando necesariamente su concepción del mundo de los muertos, tratamientos mortuorios y las consecuentes acciones que trascienden al espacio inhumatorio. Asimismo, la investigación científica sobre restos óseos humanos, la transmisión académica del conocimiento generado y su transferencia ha creado, en este campo, posturas teóricas controvertidas, que exige poner al alcance de todos los sectores involucrados los recaudos, cuidados y especial tratamiento que debe darse al objeto de estudio.

La ética ha sido fuertemente desarrollada como parte del ejercicio de la profesión médica en todas las épocas, pero adquiere importancia fundamental a partir de la Segunda Guerra Mundial, contexto en que se estableció el Código de Nuremberg (1947). Este sentó las bases de los códigos de ética venideros, a nivel internacional y enfatizó en el consentimiento informado entre otros criterios moralmente aceptables como requisito dentro de la investigación científica.

El advenimiento de la experimentación biomédica, sus progresos científicos y tecnológicos ha obligado a varios países a la conformación de Comités de Ética y la reflexión ética como parte de la enseñanza de la disciplina y su práctica profesional, y se ha extendido a otras aéreas del conocimiento, en especial a aquella cuyo objeto de estudio ha sido el hombre en todo tiempo y espacio, como es el caso de la antropología social y biológica. (Villa Monroy 2010).

En 1964 la Asociación Mundial de Médicos explicita la Declaración de Helsinki, distinguiendo entre investigación terapéutica y no terapéutica, el cual es actualizado periódicamente y utilizado como modelo por comités de ética de diversas disciplinas (Turner 2005).

En el marco de las últimas dos décadas en donde proliferaron esta clase de normativas, la bioética aplicada a la investigación en restos esqueletales se vio 
reflejada en una serie de debates en donde participaron distintos actores involucrados en el tema aunque, cabe destacar, no siempre con una valoración similar para cada uno de ellos (Antón 2005). Un disparador a nivel mundial en este sentido fue la sanción e instauración en 1990 del NAGPRA (Native American Graves Protection and Repatriation Act), en donde se discutió y reglamentó el modo en que los arqueólogos y bioantropólogos manejan, curan y preservan los restos humanos (Fagan 2007). Esta ley sirve como muestra representativa de un debate crucial en la antropología, (principalmente en la bioantropología), campo disciplinar en el cual se persigue el análisis de restos humanos pero consientes de la importancia y el valor de los sistemas de creencias de pueblos nativos o no dominantes. Uno de de los aspectos positivos que surgieron como fruto de tal reglamentación fue el aumento en el número de estudios de colecciones osteológicas museísticas, a la vez que se produjo una mayor interacción entre investigadores y grupos nativos (Larsen y Walker 2005). Sin embargo la implementación del NAGPRA fue problemática en aquellos temas referidos a la devolución de restos óseos humanos pertenecientes a instituciones de investigación, radicando el principal problema en el establecimiento de criterios de filiación precisos y reconocidos por todas las partes intervinientes.

En nuestro país estos temas fueron tratados con mayor frecuencia en la última década, no siempre con la adecuada valoración de aquellas opiniones provenientes de la comunidad académica. Incluso cuando el conocimiento generado a partir del análisis de restos óseos sea de utilidad para aquellos sectores ubicados en apariencia en esferas opuestas dentro de esta problemática (Chiquichano et al. 2008, Muñoz y Gómez Otero 2008, Salceda et al. 2009b). La escasa normativa regulatoria elaborada a lo largo de un siglo (Ley 9080, Ley 23.302 y Ley 25.517) es ambigua y no cuenta con la profundidad suficiente que permita una política de trabajo y de relación entre los actores sociales involucrados.

En este marco nuestro grupo de trabajo sometió los estándares referidos al manejo de restos óseos humanos en la Colección Lambre a la evaluación del Comité de Bioética de la Facultad de Ciencias Médicas de la UNLP (Exp. 800- 
13812/12). A su vez este trabajo se encuentra enmarcado en la legislación vigente (Ordenanza Municipal 7638/90), a la vez que es guiado por la ya mencionada Declaración de Helsinki, por las directrices explicitadas en el artículo 4 de la "Declaración de la Asociación de Antropología Biológica Argentina" en "Relación con la Ética del Estudio de Restos Humanos" (2007) y por el "Código Deontológico para el estudio, conservación y gestión de restos humanos de poblaciones del pasado" (2011) (ver declaraciones correspondientes en el anexo).

En lo que respecta al código, este parte de la premisa fundamental de que el "antropólogo biólogo, como miembro de la sociedad civil y de una comunidad científica y como formador de futuros profesionales, posee tanto derechos como un conjunto de obligaciones y deberes para con la comunidad, la profesión y su objeto de estudio principalmente".

Sostenemos que estas colecciones son parte fundamental de la historia de una sociedad "...tanto por el poder identitario que poseen para la sociedad como por el conocimiento irreemplazable que brindan en el ámbito científico..." (Aranda y Del Papa 2009). Es por esto que las políticas de conservación deberán ser programadas en sentido amplio, teniendo en cuenta tanto los aspectos prácticos de la curación (Lemp Urzúa et al. 2008) como la atención de los dilemas éticos referidos anteriormente.

Por todo lo expuesto pensamos que es vital promover un Código de Ética normatizado para la Antropología Biológica en nuestro país, el cual debería atender premisas básicas como las propuestas por Alfonso y Powell (2005), las cuales se detallan a continuación: 


\section{Declaración de principios}

En su quehacer investigativo los bioantropólogos deben:

1. Esforzarse por mantener la objetividad e integridad en la realización de investigaciones y análisis.

2. Adherirse a las más precisas técnicas en investigación, docencia y publicación.

3. Informar sobre sus hallazgos, sin omisión de ningún dato significativo, revelando detalles de sus teorías, métodos y diseños de investigación que podrían influir en las interpretaciones de sus resultados.

4. Hacer todo esfuerzo razonable para finalizar a tiempo sus proyectos, especialmente cuando el apoyo financiero para los mismos ha sido aceptado.

5. Establecer acuerdos explícitos con respecto a la división del trabajo, remuneración, acceso a los datos, derechos de autor, responsabilidades de antropólogos, investigadores de otras disciplinas y estudiantes involucrados.

6. Dar a conocer sus resultados de investigación a la comunidad académica y a la sociedad en general en forma oportuna.

7. Ser conscientes de situaciones que puedan conducir a un mal uso de sus descubrimientos.

8. Conocer leyes y reglamentos locales, provinciales, nacionales e internacionales que guarden relación con la disciplina.

\section{Obligaciones éticas para con los restos, la ciencia y la comunidad}

1. Los restos humanos deben ser tratados con cuidado y dignidad, ya sea con fines de entierro, manipulación, almacenamiento y/o análisis.

2. Los restos humanos deben ser analizados con fines educativos o científicos. 
3. Los restos humanos no deben ser considerados propiedad privada.

4. Las leyes y regulaciones relativas al patrimonio cultural o a restos humanos deben ser respetados.

5. Los estudios y metodologías deben guardar el debido respeto a las personas que representan y a sus grupos filiatorios. De ser posible se deberá contar con la autorización de estos últimos.

6. No se deberán utilizar restos humanos con fines publicitarios.

7. La comercialización de restos humanos contribuye a su destrucción, por lo que se deberá evitar su tráfico, venta, o apropiación ilegal. Se deberá informar cualquier circunstancia relacionada a la las autoridades competentes.

8. Se abstendrá de trabajar o incluso consultar material que haya sido adquirido ilegalmente, dado que tal acción redundará en un aumento de ilícitos relacionados.

9. Todos los resultados deben ser publicados, idealmente en primer lugar, a la evaluación por pares a fin de evitar abusos, negligencia, y/o fraude. Posteriormente deberá ponerse a disposición del público, a través de exhibiciones, publicaciones no especializadas, o por otros medios de comunicación. En los casos en que los restos estén afiliados a un determinado grupo, este deberá ser informado de los resultados antes que el resto de la comunidad.

10. Los ensayos destructivos de restos humanos deben ser considerados en función de la naturaleza y cantidad de información que pueden proporcionar.

11. Todas las metodologías deben tener en cuenta la conservación de los restos. Las muestras no deben ser completamente destruidas. Por el contrario, los 
investigadores deben asegurar su conservación a fin de garantizar que la repetición de dicho estudio sea posible.

12. Los tratamientos invasivos y las acciones realizadas para un estudio en particular no deben obstaculizar futuros análisis por medio de diferentes técnicas.

13. Dada la potencial pérdida parcial o total del registro durante la excavación se recomienda elaborar copias del material de archivo generado y su depósito en la institución correspondiente. Esta información incluye cualquier tipo de registro escrito, mapas, resultados de análisis, imágenes, dibujos, películas y grabaciones.

14. La información sobre procedencia y materiales que acompañaron los restos se considera parte de la investigación, los cuales, así como los restos humanos, no conforman una posesión personal. Estos materiales y la documentación asociada deben acompañar al material esqueletal y se depositarán en la institución correspondiente.

15. Los datos, análisis, y archivos personales, especialmente en las investigaciones inéditas deberán registrarse periódicamente en archivos adecuados para no perderse en caso de fallecimiento del investigador a cargo.

16. Deberán ser tomadas las precauciones pertinentes referidas a seguridad y salud a fin de prevenir la contaminación de investigadores, estudiantes, y demás partes interesadas.

\section{Proceso de publicación}

1. Se deberá reconocer a toda persona que haya contribuido a la investigación y publicación. La autoría reflejará con exactitud las contribuciones de los principales participantes en la investigación y el proceso de escritura. 
2. Los datos y material tomado de otro investigador, publicados o trabajos inéditos deberán ser explícitamente identificados haciendo referencia al autor. Las citas de las ideas desarrolladas en la obra escrita de otros no deben ser omitidas.

3. Se deberá reconocer y hacer públicas a comunidades, instituciones, y / o personas que apoyaron o financiaron la investigación.

4. Las imágenes de restos humanos no deberán ser publicadas sin antes consultar a las partes interesadas. Los derechos de autor deberán ser respetados.

\section{Docencia y supervisación}

El bioantropólogo que detente un rol de docencia debe estar familiarizado con el contenido del código y sus propias políticas institucionales y llevar a cabo sus responsabilidades bajo esas directrices.

1. Deberán proporcionar a los estudiantes una versión honesta del ámbito de aplicación y la perspectiva de sus cursos, expectativas claras sobre el desempeño de los estudiantes, y evaluaciones oportunas y de sencillo acceso de su trabajo.

2. Se deberá asegurar un trato equitativo y justo de todos los estudiantes.

3. No deberá presentar trabajos de estudiantes como suyos.

4. Se deberán reconocer contribuciones de estudiantes y actuar en su nombre con respeto de autorías y otros reconocimientos.

5. Asimismo, no debe obligar a favores personales, sexuales o económicos, junto con cualquier tipo de ventaja profesional, a cualquier estudiante $u$ otra persona, incluyendo sus compañeros y asistentes de investigación. 
6. Se deberá evitar que cualquier diferencia o animosidad personal con otros colegas impidan el acceso a los mismos por parte de los estudiantes.

7. Los estudiantes a su vez, deberán reconocer el tiempo y esfuerzo que implica la tutoría.

8. Los estudiantes deberán esforzarse por lograr un alto nivel de profesionalismo y honestidad académica y asumir la debida responsabilidad por su propia educación.

Finalmente, el código de ética podría incluir una sección especial para los curadores para asegurarse de la preservación y seguridad de las colecciones. 


\section{CAPÍTULO IV}

RESULTADOS 
La muestra original analizada estuvo conformada por 150 fémures, resultando sólo 71 aptos para análisis microscópico. Aquellos que presentaron algún tipo de patología fueron excluidos y, en el transcurso de la investigación, se eliminaron algunas secciones, las cuales fueron desgastadas pero no pudieron ser cuantificadas debido a una disrupción de la microestructura ósea producida por factores diagenéticos.

En la tabla 4 se detalla la distribución de la muestra $(n=71)$ por rangos de edad (cinco intervalos) para femeninos y masculinos, y sexos agrupados.

Tabla 4. Distribución de la muestra por rangos de edad

\begin{tabular}{ccccc}
\hline \hline & & \multicolumn{3}{c}{ Sexo } \\
\cline { 3 - 5 } Edad & & $\mathrm{F}$ & $\mathrm{M}$ & Total \\
\hline & $20-29$ & 1 & 2 & 3 \\
& $30-39$ & 0 & 2 & 2 \\
& $40-49$ & 3 & 12 & 15 \\
& $50-59$ & 6 & 12 & 18 \\
& $60+$ & 11 & 22 & 33 \\
& Total & 21 & 50 & 71 \\
\hline \hline
\end{tabular}

Se analizaron 284 fotografías (cuatro por cada preparado) sobre las cuales se cuantificaron cinco variables microestructurales. Tanto los datos documentados (edad y sexo de cada individuo) como los relevados cuantitativamente fueron volcados en una Matriz Básica de Datos (tabla I, anexo resultados) que inicialmente fue procesada a través del cálculo de los estadísticos descriptores (medidas de tendencia central y dispersión) operatoria que se resume en la tabla 5.

Nótese que la distribución de la muestra en cuanto a sexo y edad no es equilibrada. Por un lado, en general se observa una menor proporción de individuos femeninos y, por otro, es notoria la falta de individuos de edades medias provocando una polarización de los rangos etarios representados. 


\begin{tabular}{|c|c|c|c|c|c|c|c|c|c|}
\hline & \multirow[b]{3}{*}{ Edad } & \multicolumn{8}{|c|}{ Sexo } \\
\hline & & \multicolumn{4}{|c|}{$\mathrm{F}$} & \multicolumn{4}{|c|}{$M$} \\
\hline & & $\mathrm{n}$ & Media & Error & $\begin{array}{c}\text { Desviación } \\
\text { típica }\end{array}$ & $n$ & Media & Error & $\begin{array}{c}\text { Desviación } \\
\text { típica }\end{array}$ \\
\hline \multirow[t]{5}{*}{ Can. Hav. } & $20-29$ & 1 & 46,3900 &.- &.- & 2 & 39,6750 & 1,28500 & 1,81726 \\
\hline & $30-39$ & - & - & - & - & 2 & 47,5450 & 2,43500 & 3,44361 \\
\hline & $40-49$ & 3 & 47,9600 & 2,60661 & 4,51479 & 12 & 46,8700 & 1,03811 & 3,59612 \\
\hline & $50-59$ & 6 & 44,3400 & 1,02570 & 2,51243 & 12 & 47,6858 & 1,51419 & 5,24530 \\
\hline & $60+$ & 11 & 47,4409 & 1,60851 & 5,33483 & 22 & 47,4792 & 1,08671 & 5,09714 \\
\hline \multirow[t]{5}{*}{ N. On. } & $20-29$ & 1 & 12,00 &.- &.- & 2 & 9,00 & ,000 & ,000 \\
\hline & $30-39$ & - & - & - & - & 2 & 10,50 & ,500 & 707 \\
\hline & $40-49$ & 3 & 14,33 & 1,856 & 3,215 & 12 & 11,25 & 698 & 2,417 \\
\hline & $50-59$ & 6 & 11,83 & 1,014 & 2,483 & 12 & 12,50 & 764 & 2,646 \\
\hline & $60+$ & 11 & 12,09 & 495 & 1,640 & 22 & 13,86 & ,952 & 4,465 \\
\hline \multirow[t]{5}{*}{ N. On. Fg. } & $20-29$ & 1 & 6,00 &.- &.- & 2 & 3,00 & ,000 & ,000 \\
\hline & $30-39$ & - & - & - & - & 2 & 5,00 & ,000 & ,000 \\
\hline & $40-49$ & 3 & 8,00 & 1,732 & 3,000 & 12 & 7,33 & 678 & 2,348 \\
\hline & $50-59$ & 6 & 11,50 & 1,586 & 3,886 & 12 & 12,00 & 640 & 2,216 \\
\hline & $60+$ & 11 & 16,00 & 1,375 & 4,561 & 22 & 14,91 & 1,122 & 5,264 \\
\hline \multirow[t]{5}{*}{ \% On. Fg. } & $20-29$ & 1 & 33,3333 &.- &.- & 2 & 25,0000 & ,00000 & 00000 \\
\hline & $30-39$ & - & - & - & - & 2 & 32,2917 & 1,04167 & 1,47314 \\
\hline & $40-49$ & 3 & 35,2363 & 3,77677 & 6,54156 & 12 & 39,1271 & 2,69965 & 9,35186 \\
\hline & $50-59$ & 6 & 48,4372 & 4,61817 & 11,31216 & 12 & 49,0621 & 2,30336 & 7,97908 \\
\hline & $60+$ & 11 & 56,2350 & 2,18715 & 7,25396 & 22 & 51,2481 & 1,93825 & 9,09121 \\
\hline \multirow[t]{5}{*}{ OPD } & $20-29$ & 1 & 16,4760 & . & . & 2 & 10,9840 & 00000 & 00000 \\
\hline & $30-39$ & - & - & - & - & 2 & 14,1876 & 45767 & 64724 \\
\hline & $40-49$ & 3 & 20,4424 & 3,09653 & 5,36335 & 12 & 17,0099 & 93901 & 3,25282 \\
\hline & $50-59$ & 6 & 21,3577 & 1,71514 & 4,20123 & 12 & 22,4256 & ,80067 & 2,77359 \\
\hline & $60+$ & 11 & 25,7125 & 1,30301 & 4,32158 & 22 & 26,3366 & 1,54477 & 7,24560 \\
\hline
\end{tabular}

Can.Hav (Diámetro promedio de los canales de Havers). N.On (Número de osteonas completas por campo). N.On.Fg (Número de osteonas fragmentarias por campo). \% On.Fg (Porcentaje de osteonas fragmentarias por campo). OPD (Densidad Poblacional Osteonal). 
El análisis estadístico inferencial por nosotros propuesto, en adecuación a los datos y a lo aconsejado en la bibliografía específica, exige la contrastación de dos supuestos básicos: normalidad y homogeneidad de varianza. Resultando:

- La prueba de normalidad de Kolmogorov Smirnov (Tabla 6) no significativa (p $>0,05)$ para ambos sexos. Por lo tanto, se puede asumir que las variables cuantitativas se ajustan a una distribución normal en ambos grupos.

Tabla 6. Prueba de Kolmogorov-Smirnov para una muestra

\begin{tabular}{|c|c|c|c|c|c|c|c|}
\hline Sexo & & & Can.Hav. & N.On. & N.On.Fg. & \% On.Fg. & OPD \\
\hline \multirow[t]{5}{*}{$\mathbf{F}$} & $\mathrm{n}$ & & 21 & 21 & 21 & 21 & 21 \\
\hline & \multirow[t]{2}{*}{ Parámetros normales ${ }^{a, b}$} & Media & 46,5790 & 12,33 & 13,10 & 49,9167 & 23,2756 \\
\hline & & Desviación típica & 4,47739 & 2,153 & 5,186 & 11,45736 & 4,95102 \\
\hline & \multicolumn{2}{|l|}{ Z de Kolmogorov-Smirnov } & ,801 & 1,046 & 699 & ,658 & 730 \\
\hline & \multicolumn{2}{|l|}{$P$ - valor } & ,543† & $224 \dagger$ & ,712† & ,780† & ,661+ \\
\hline \multirow[t]{5}{*}{ M } & $\mathrm{n}$ & & 50 & 50 & 50 & 50 & 50 \\
\hline & \multirow[t]{2}{*}{ Parámetros normales ${ }^{a, b}$} & Media & 47,0731 & 12,58 & 11,52 & 46,0063 & 22,0595 \\
\hline & & Desviación típica & 4,78986 & 3,648 & 5,331 & 11,01326 & 6,97402 \\
\hline & \multicolumn{2}{|l|}{ Z de Kolmogorov-Smirnov } & ,606 & 1,295 & ,746 & ,511 & ,886 \\
\hline & \multicolumn{2}{|l|}{ P - valor } & ,856† & ,070† & ,634† & ,956† & ,413† \\
\hline
\end{tabular}

- Can.Hav (Diámetro promedio de los canales de Havers). N.On (Número de osteonas completas por campo). N.On.Fg (Número de osteonas fragmentarias por campo). \% On.Fg (Porcentaje de osteonas fragmentarias por campo). OPD (Densidad Poblacional Osteonal). a. La distribución de contraste es la Normal. b. Se han calculado a partir de los datos.

- $(+)$ no significativo $(P>0,05)$.

- En cuanto a la prueba de Levene sobre homogeneidad de varianzas (tabla 7), demuestra que la probabilidad asociada al estadístico $F$ es no significativa ( $P$ $>0,05)$ para cada una de las variables seleccionadas: Can-Hav. $(p>0,695)$; N.On. ( $p>0,051)$; N.On.Fg. ( $p>0,592)$; \% On.Fg. ( $p>0,791)$; OPD $(p>0,113)$. Por lo tanto, se asume que las varianzas de las variables histomorfométricas en ambos sexos son homogéneas. 
Tabla 7. Prueba de Homogeneidad de varianza

\begin{tabular}{|c|c|c|c|}
\hline & & \multicolumn{2}{|c|}{$\begin{array}{l}\text { Prueba de Levene para la } \\
\text { igualdad de varianzas }\end{array}$} \\
\hline & & $\mathrm{F}$ & P-valor. \\
\hline Can.Hav. & $\begin{array}{l}\text { Se han asumido varianzas } \\
\text { iguales }\end{array}$ & 155 & ,695† \\
\hline N.On. & $\begin{array}{l}\text { Se han asumido varianzas } \\
\text { iguales }\end{array}$ & 4,057 & ,051† \\
\hline N.On.Fg. & $\begin{array}{l}\text { Se han asumido varianzas } \\
\text { iguales }\end{array}$ & 290 & ,592† \\
\hline$\%$ On.Fg. & $\begin{array}{l}\text { Se han asumido varianzas } \\
\text { iguales }\end{array}$ & ,071 & ,791† \\
\hline OPD & $\begin{array}{l}\text { Se han asumido varianzas } \\
\text { iguales }\end{array}$ & 2,571 & ,113† \\
\hline \multicolumn{4}{|c|}{$\begin{array}{l}\text { - Can.Hav (Diámetro promedio de los canales de Havers). N.On (Número de } \\
\text { osteonas completas por campo). N.On.Fg (Número de osteonas } \\
\text { fragmentarias por campo). \% On.Fg (Porcentaje de osteonas fragmentarias } \\
\text { por campo). OPD (Densidad Poblacional Osteonal). a. La distribución de } \\
\text { contraste es la Normal. b. Se han calculado a partir de los datos. } \\
\text { - }(\dagger) \text { no significativo }(P>0,05) \text {. }\end{array}$} \\
\hline
\end{tabular}

\section{- Prueba de $t$ de Student para muestras independientes}

Con el objetivo de conocer la variación dimórfica en la expresión de las variables histomorfométricas se procedió a calcular, en primer lugar, los estadísticos descriptores de cada una de ellas en ambos sexos, los cuales se presentan en la tabla 8.

En segundo lugar, se aplicó la prueba de t para muestras independientes cuyos resultados se presentan en la tabla 9. 
Tabla 8. Estadísticos de grupo del procedimiento de la Prueba de $\mathbf{t}$

\begin{tabular}{lccccc}
\hline \hline & Sexo & $\mathrm{N}$ & Media & $\begin{array}{c}\text { Desviación } \\
\text { típica }\end{array}$ & $\begin{array}{c}\text { Error típico } \\
\text { de la media }\end{array}$ \\
\hline Can. Hav. & $\mathrm{M}$ & 50 & 47,0731 & 4,78986 &, 67739 \\
& $\mathrm{~F}$ & 21 & 46,5790 & 4,47739 &, 97705 \\
\hline N.On. & $\mathrm{M}$ & 50 & 12,58 & 3,648 &, 516 \\
& $\mathrm{~F}$ & 21 & 12,33 & 2,153 &, 470 \\
\hline N.On.Fg. & $\mathrm{M}$ & 50 & 11,52 & 5,331 &, 754 \\
& $\mathrm{~F}$ & 21 & 13,10 & 5,186 & 1,132 \\
\hline \% On.Fg. & $\mathrm{M}$ & 50 & 46,0063 & 11,01326 & 1,55751 \\
& $\mathrm{~F}$ & 21 & 49,9167 & 11,45736 & 2,50020 \\
\hline OPD & $\mathrm{M}$ & 50 & 22,0595 & 6,97402 &, 98628 \\
& $\mathrm{~F}$ & 21 & 23,2756 & 4,95102 & 1,08040 \\
\hline \hline
\end{tabular}

Tabla 9. Prueba de t para muestras independientes

\begin{tabular}{lllll}
\hline \hline & & & & \\
& & $\mathrm{Gl}$ & $\mathrm{P}$ - valor \\
\hline Can.Hav. & $\begin{array}{l}\text { Se han asumido varianzas } \\
\text { iguales }\end{array}$ &, 404 & 69 &, $687^{\dagger}$ \\
\hline N.On. & $\begin{array}{l}\text { Se han asumido varianzas } \\
\text { iguales }\end{array}$ &, 289 & 69 &, $774{ }^{\dagger}$ \\
\hline N.On.Fg. & $\begin{array}{l}\text { Se han asumido varianzas } \\
\text { iguales }\end{array}$ & $-1,145$ & 69 &, $256{ }^{\dagger}$ \\
\hline \% On.Fg. & $\begin{array}{l}\text { Se han asumido varianzas } \\
\text { iguales }\end{array}$ & $-1,349$ & 69 &, $182+$ \\
\hline OPD & $\begin{array}{l}\text { Se han asumido varianzas } \\
\text { iguales }\end{array}$ &,- 725 & 69 &, $471^{\dagger}$ \\
\hline \hline
\end{tabular}

Can.Hav (Diámetro promedio de los canales de Havers). N.On (Número de osteonas completas por campo). N.On.Fg (Número de osteonas fragmentarias por campo). \% On.Fg (Porcentaje de osteonas fragmentarias por campo). OPD (Densidad Poblacional Osteonal).

$(+)$ no significativo $(P>0,05)$. 
El nivel crítico asociado a cada una de las variables $(p>0,05)$ demostró que las diferencias entre las medias de ambos sexos no son significativas, razón por la cual decidimos considerar la muestra total para análisis posteriores.

\section{- Análisis de Regresión Lineal Múltiple}

En este acápite se detallan estadísticos, pruebas y análisis aplicados para determinar la relación y el grado de asociación entre la edad (Variable Dependiente: VD) y las variables histomorfométricas (Variables Independientes: VI) así como los parámetros de la ecuación predictiva.

Primeramente se calcularon las correlaciones parciales, cuya matriz se presenta en la tabla 10, y se confeccionaron gráficos de dispersión (Gráfico 4), que dan cuenta de la bondad de ajuste de los datos al modelo de regresión lineal.

La mayoría de las variables demostraron una asociación significativa con la edad en un $1 \%$ de nivel de significación para sexos agrupados (tabla 10). El N. On. Fg presentó una alta correlación positiva con la edad $(R=0,779)$ seguida por la OPD $(R=0,741)$, el \% On.Fg $(R=0,646)$ y el N.On $(R=0,330)$ que a diferencia de las anteriores presentó una correlación positiva baja. Contrariamente, el diámetro promedio de los conductos de Havers no presentó relación lineal con la edad $(R=$ 0,158; P > 0,187), y por lo tanto dicha variable fue excluida del modelo dada su ineficacia como predictora de la edad.

Si se analiza la relación entre las variables independientes, se observa que el N.On.Fg presenta una asociación estrecha con el \% On.Fg $(0,843)$ y la OPD $(0,897)$; el \% On.Fg con la OPD $(0,559)$ y la OPD con el N.On $(0,696)$. Estos resultados son indicativos de multicolinealidad entre esas variables. 
Tabla 10. Matriz de Correlaciones Parciales

\begin{tabular}{|c|c|c|c|c|c|c|c|}
\hline & & Edad & N.On.Fg. & $\%$ On.Fg. & OPD & N.On. & Can.Hav. \\
\hline \multirow[t]{2}{*}{ Edad } & Correlación de Pearson & 1 &, $779^{* *}$ & $646^{* *}$ &, $741^{* *}$ &, $330^{* *}$ & 158 \\
\hline & Sig. (bilateral) & & ,000 & ,000 & ,000 & 005 & 187 \\
\hline \multirow[t]{2}{*}{ N.On.Fg. } & Correlación de Pearson &, $779^{* *}$ & 1 &, $843^{* *}$ &, $897^{* *}$ &, $307^{* *}$ & ,005 \\
\hline & Sig. (bilateral) &, 000 & &, 000 & ,000 & ,009 & ,965 \\
\hline \multirow[t]{2}{*}{ \% On.Fg. } & Correlación de Pearson &, $646^{* *}$ &, $843^{* *}$ & 1 &, $559^{* *}$ &,- 165 & 038 \\
\hline & Sig. (bilateral) & ,000 & ,000 & & ,000 & ,170 & ,755 \\
\hline \multirow[t]{2}{*}{ OPD } & Correlación de Pearson &, $741^{* *}$ &, $897^{* *}$ &, $559^{* *}$ & 1 & $696^{* *}$ & ,064 \\
\hline & Sig. (bilateral) & ,000 & ,000 & ,000 & & ,000 & ,598 \\
\hline \multirow[t]{2}{*}{ N.On. } & Correlación de Pearson &, $330^{* *}$ &, $307^{* *}$ &,- 165 &, $696^{* *}$ & 1 & 128 \\
\hline & Sig. (bilateral) & ,005 & ,009 & 170 & ,000 & & ,286 \\
\hline \multirow[t]{2}{*}{ Can. Hav. } & Correlación de Pearson & 158 & ,005 & ,038 & ,064 & 128 & 1 \\
\hline & Sig. (bilateral) & 187 & 965 & ,755 & ,598 & ,286 & \\
\hline
\end{tabular}

**La correlación es significativa al nivel 0,01 (bilateral).

Can. Hav (Diámetro promedio de los canales de Havers). N.On (Número de osteonas completas por campo). N.On.Fg (Número de osteonas fragmentarias por campo). \% On.Fg (Porcentaje de osteonas fragmentarias por campo). OPD (Densidad Poblacional Osteonal). 
Gráfico 4. Diagramas de dispersión entre la edad y las variables histomorfométricas
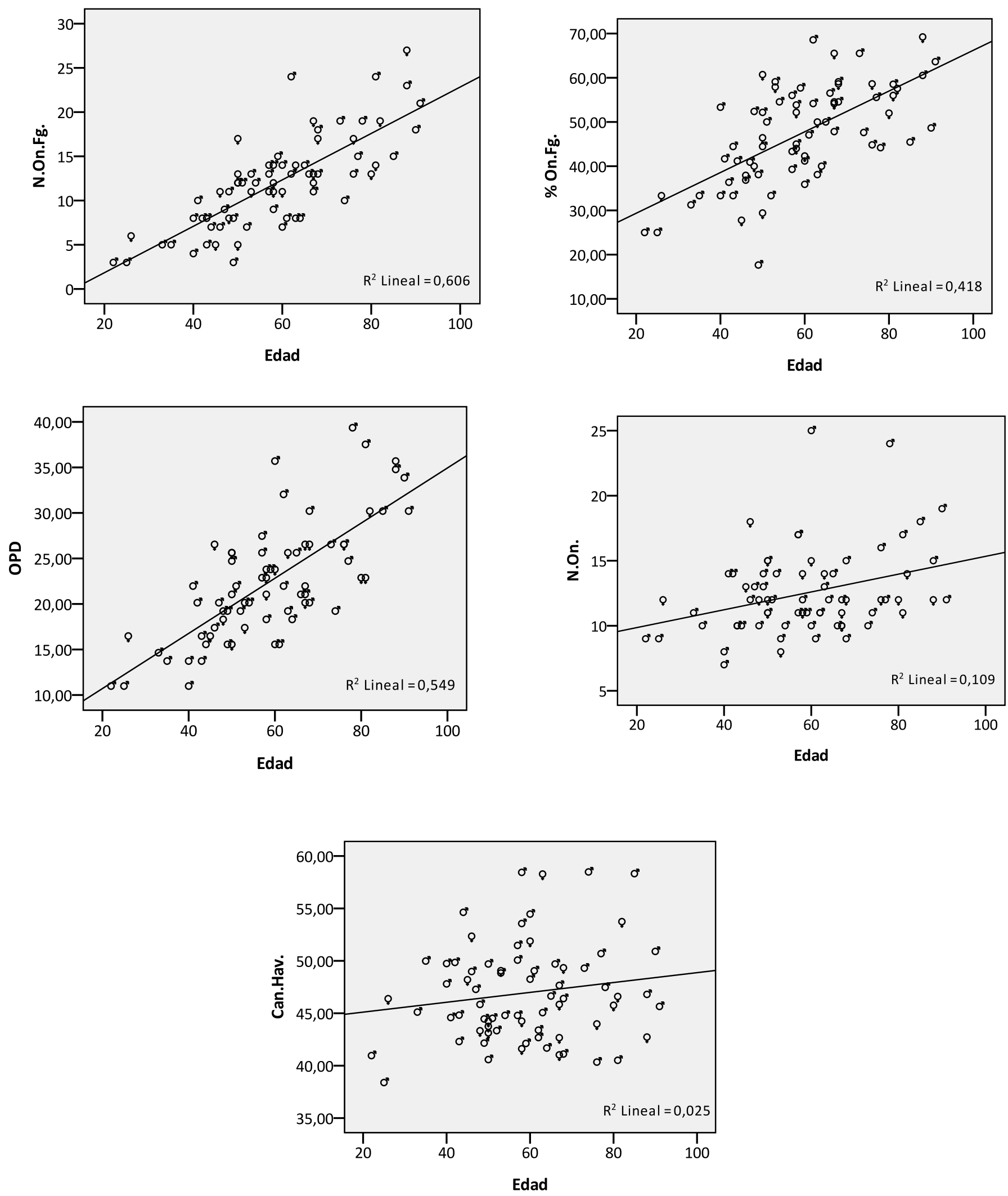
Las tablas 11 y 12 resumen los estadísticos utilizados en las pruebas de bondad de ajuste de los datos al modelo de regresión lineal múltiple.

En particular, la variable seleccionada por el método stepwise fue el N.On.Fg. que presenta: la más alta correlación parcial con la edad $(R=0,779)$, un $R^{2}=0,606$ y un error de 9,93. Es decir, que la edad de un individuo es explicada en un 60,6 \% por el número de osteonas fragmentarias (N.On.Fg) con un error en la estimación de 9,93 años (Tabla 11).

La significación del modelo de regresión fue corroborada a través del análisis de la varianza $(F)$, resultando altamente significativo $(p<0,000)$. Tal situación no sólo permite inferir la existencia de una relación lineal significativa, sino, además, que el modelo obtenido ofrece un buen ajuste a nuestros datos, permitiéndonos efectuar pronósticos para otros casos (tabla 12).

Tabla 11. Resumen del modelo de regresión líneas múltiple ${ }^{b}$

\begin{tabular}{|c|c|c|c|c|c|}
\hline \multirow[b]{2}{*}{ Modelo } & \multirow[b]{2}{*}{$\mathrm{R}$} & \multirow[b]{2}{*}{$\mathrm{R}^{2}$} & \multicolumn{3}{|c|}{ Error típico de } \\
\hline & & & $\mathrm{R}^{2}$ corregida & la estimación & Durbin-Watson \\
\hline 1 &, $779^{a}$ & 606 & 601 & 9,939 & 1,448 \\
\hline
\end{tabular}

Tabla 12. Análisis de la varianza ANOVA ${ }^{b}$

\begin{tabular}{|c|c|c|c|c|c|c|}
\hline \multicolumn{2}{|c|}{ Modelo } & \multirow{2}{*}{$\begin{array}{c}\text { Suma de } \\
\text { cuadrados }\end{array}$} & \multirow{2}{*}{$\frac{g l}{1}$} & \multirow{2}{*}{$\begin{array}{c}\text { Media } \\
\text { cuadrática }\end{array}$} & \multirow{2}{*}{$\frac{F}{106,247}$} & \multirow{2}{*}{$\frac{\text { P- valor }}{, 000^{a^{*}}}$} \\
\hline 1 & Regresión & & & & & \\
\hline & Residual & 6816,203 & 69 & 98,786 & & \\
\hline & Total & 17311,887 & 70 & & & \\
\hline
\end{tabular}

a. Variables predictoras: (Constante), N.On.Fg.

b. Variable dependiente: Edad

* significativo $(P<0,05)$ 
En la tabla 13 se muestran los coeficientes de la ecuación de regresión. La columna etiquetada coeficientes no estandarizados contiene aquellos correspondientes a la regresión parcial que definen la ecuación predictiva. La constante representa el origen de la recta $\left(B_{0}\right)$ y el N.On.Fg la pendiente $\left(B_{k}\right)$.

Finalmente, a través del estadístico t y su nivel crítico $(0,000)$, se corroboró que la variable seleccionada contribuye significativamente a mejorar la calidad del modelo propuesto.

Tabla 13. Coeficientes de regresión parcial ${ }^{\mathrm{a}}$

\begin{tabular}{|c|c|c|c|c|c|c|}
\hline \multirow{2}{*}{\multicolumn{2}{|c|}{ Modelo }} & \multicolumn{2}{|c|}{ Coeficientes no estandarizados } & \multirow{2}{*}{$\begin{array}{c}\begin{array}{c}\text { Coeficientes } \\
\text { tipificados }\end{array} \\
\text { Beta }\end{array}$} & \multirow[b]{2}{*}{$\mathrm{t}$} & \multirow[b]{2}{*}{ P-valor } \\
\hline & & B & Error típico. & & & \\
\hline \multirow[t]{2}{*}{1} & (Constante) & 30,975 & 2,934 & & 10,558 &, $000 *$ \\
\hline & N.On.Fg. & 2,310 & ,224 & ,779 & 10,308 &, $000^{*}$ \\
\hline
\end{tabular}

Variable dependiente: Edad

* significativo $(P<0,05)$

Con los resultados obtenidos se construyó el algoritmo predictivo, siendo el siguiente el modelo mejor ajustado:

$E D A D=30,975+2,310$ N.On.Fg. 
Identificada la variable (N.On.Fg) que mejor predice la edad en la muestra analizada, y para sexos agrupados, se evaluó su comportamiento en los diferentes grupos de edad. Para ello se realizaron, primero un análisis de varianza (ANOVA) de un factor y una prueba a posteriori (post hoc) para determinar cuál o cuáles de los diferentes rangos de edad son los que difieren entre sí.

La tabla 14 contiene los estadísticos descriptivos asociados a la variable seleccionada para cada rango de edad. El análisis de ANOVA (F) resultó significativo $(0,000)$ demostrando que las medias de la variable en los distintos grupos de edad difieren significativamente (tabla 15).

Tabla 14. Estadística Descriptiva N.On.Fg por rangos de edad

\begin{tabular}{|c|c|c|c|c|c|c|c|c|}
\hline & \multirow[b]{2}{*}{$\mathrm{N}$} & \multirow[b]{2}{*}{ Media } & \multirow{2}{*}{$\begin{array}{l}\text { Desviación } \\
\text { típica }\end{array}$} & \multirow[b]{2}{*}{ Error típico } & \multicolumn{2}{|c|}{$\begin{array}{c}\text { Intervalo de confianza para la } \\
\text { media al } 95 \%\end{array}$} & \multirow[b]{2}{*}{ Mínimo } & \multirow[b]{2}{*}{ Máximo } \\
\hline & & & & & Límite inferior & Límite superior & & \\
\hline $20-29$ & 2 & 3,00 & ,000 & ,000 & 3,00 & 3,00 & 3 & 3 \\
\hline $30-39$ & 2 & 5,00 & ,000 & ,000 & 5,00 & 5,00 & 5 & 5 \\
\hline $40-49$ & 15 & 7,47 & 2,386 & ,616 & 6,15 & 8,79 & 3 & 11 \\
\hline $50-59$ & 18 & 11,83 & 2,771 & ,653 & 10,46 & 13,21 & 5 & 17 \\
\hline $60+$ & 33 & 15,27 & 4,995 & ,870 & 13,50 & 17,04 & 7 & 27 \\
\hline Total & 70 & 12,07 & 5,290 & 632 & 10,81 & 13,33 & 3 & 27 \\
\hline
\end{tabular}

Tabla 15. ANOVA de un factor

\begin{tabular}{lccccc}
\hline \hline & $\begin{array}{c}\text { Suma de } \\
\text { cuadrados }\end{array}$ & gl & cuadrática & F & P-valor \\
\hline Inter-grupos & 921,864 & 4 & 230,466 & 14,850 &, $000^{*}$ \\
Intra-grupos & 1008,779 & 65 & 15,520 & & \\
Total & 1930,643 & 69 & & & \\
\hline \hline
\end{tabular}

* Significativo $(\mathrm{P}<0,05)$ 
Gráfico 5- Gráfico de medias por rangos de edad para la variable N.On.Fg

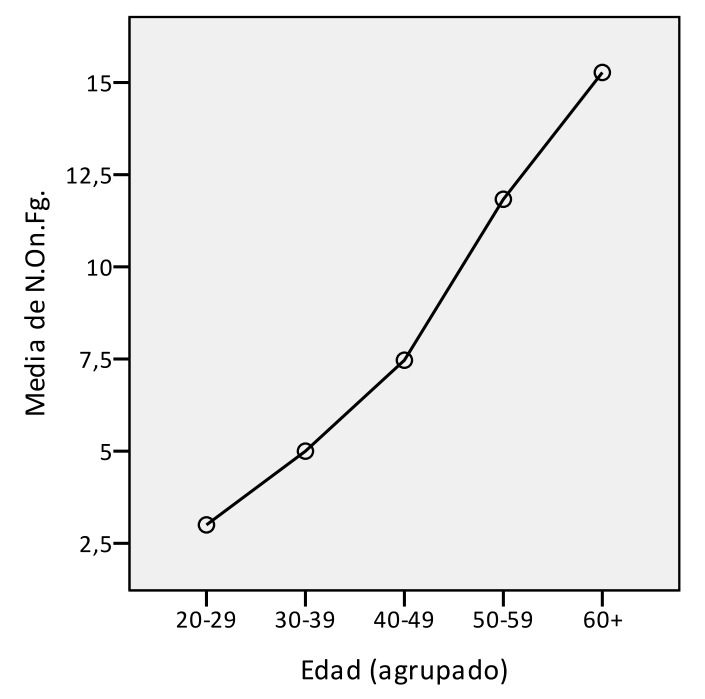

En la tabla II (anexo resultados) de Comparaciones Múltiples de Tukey se detallan las combinaciones entre los grupos de edad (dos a dos), las diferencias entre las medias, el error típico de esas diferencias y el nivel crítico asociado. Los grupos cuyas medias difieren significativamente $(p<0,05)$ están marcados con un asterisco.

En la tabla 16, como parte de la prueba post hoc, se presentan los subconjuntos homogéneos formando, en este caso, tres subgrupos en función del grado de similitud entre sus medias. Se observa un incremento abrupto en el número de osteonas fragmentarias a partir de los 50 años, que continúa progresivamente hasta los $60+$ años, formando claramente un grupo aparte. También el gráfico de medias refuerza dicha tendencia lineal (Gráfico 5). Estos resultados, y el solapamiento de los intervalos de edad para cada subgrupo, fundamentan la decisión de reagrupar la muestra considerando, para la cualidad edad, dos grupos: uno de ellos integrado por los individuos con edades documentadas menores o iguales a 49 años y el otro compuesto por aquellos de 50 años a más. 
Tabla 16. Subconjuntos Homogéneos (N.On.Fg) HSD de Tukey

\begin{tabular}{lcccc}
\hline \hline & & \multicolumn{3}{c}{ Subconjunto para alfa = 0.05 } \\
\cline { 3 - 5 } Edad (agrupado) & $\mathrm{N}$ & 1 & 2 & 3 \\
\hline $20-29$ & 2 & 3,00 & & \\
$30-39$ & 2 & 5,00 & 5,00 & \\
$40-49$ & 15 & 7,47 & 7,47 & 11,83 \\
$50-59$ & 18 & & 11,83 & 15,27 \\
$60+$ & 33 & & &, 701 \\
Sig. & &, 459 &, 091 & \\
\hline \hline
\end{tabular}

\section{Grupo Menores o iguales de 49 años}

En esta segunda etapa y tomando como base la observación de los resultados obtenidos en la primera fase del trabajo, se decidió no incluir en el análisis los rangos de edad 20-29 y 30-39 años dado que el número de individuos que los integran $(n=5)$ no es representativo.

El análisis posterior del N.On.Fg no presentó una relación lineal con la edad $(R=0,238 ; P>0,456) ;$ de esta manera, y a diferencia de los resultados obtenidos para la muestra agrupada, los fragmentos osteonales serían ineficaces para explicar la edad en individuos menores de 49 años.

Seguidamente, se decidió realizar un análisis de regresión múltiple a los efectos de evaluar el grado de relación entre la edad y el resto de las variables histomorfométricas. El mismo permitió determinar entre la edad y el N.On por un lado y la OPD por otro una correlación altamente significativa con un $R=0,845$ ( $P<$ $0,01)$ y $R=0,810(P<0,01)$ respectivamente. Por el contrario, el porcentaje de On.Fg presentó una correlación negativa y no significativa $(R=-0,252 ; P=0,429)$.

La tabla III (ver anexo de resultados) ofrece un resumen del modelo final obtenido por el método stepwise. En este caso, el modelo de regresión fue construido en dos pasos: en el primero (Modelo 1) se seleccionó la variable predictiva N.On con un $\mathrm{R}=0,845, \mathrm{R}^{2}=0,715$ y un error de 1,8 años $\mathrm{y}$, en el segundo paso (Modelo 2) la variable predictiva seleccionada fue $O P D$ con un $R=0,915, R^{2}=$ 
0,837 y un error de 1,43 años. Nótese que al introducir una segunda variable se ha incrementado en un $12 \%$ la variabilidad total explicada. De esta manera y para el grupo en cuestión, la edad de un individuo es explicada en un $83,7 \%$ por las dos variables seleccionadas en el modelo final.

La significación del modelo de regresión fue corroborada a través del análisis de la varianza $(F)$, resultando altamente significativo $(p<0,000)$ (ver tabla IV, anexo resultados). Tal situación no sólo permite inferir la existencia de una relación lineal significativa entre las variables, sino, además, muestra que el modelo obtenido ofrece un buen ajuste a nuestros datos, permitiéndonos efectuar pronósticos para otros casos.

En la tabla $V$ se muestran los coeficientes de la ecuación de regresión (ver tabla $x$, anexo resultados). Con los resultados obtenidos se construyó el algoritmo predictivo, siendo el siguiente el modelo mejor ajustado:

$$
E D A D=27,229+N . \text { On }(0,818)+O P D(0,549)
$$

Finalmente, a través del estadístico t y su nivel crítico $(0,000)$, se corroboró que la variable seleccionada contribuye significativamente a mejorar la calidad del modelo propuesto. 


\section{Grupo mayores de 50 años}

Contrariamente a los resultados obtenidos en el grupo anterior, el N.On.Fg presentó una alta correlación positiva con la edad $(R=0,696)$, con un $R^{2}=0,484$ y un error de 8,55 años (tabla $\mathrm{VI}$, anexo de resultados). Es decir, que para los adultos mayores de 50 años el número de fragmentos osteonales explicarían el 48,4 \% de la variabilidad observada en la edad, con un error en la estimación de 8,55 años.

En este caso, la significación del modelo de regresión fue corroborada a través del análisis de la varianza (F), resultando altamente significativo ( $p<0,000)$. Tal situación no sólo permite inferir la existencia de una relación lineal significativa entre las variables, sino, además, que el modelo obtenido ofrece un buen ajuste a nuestros datos, permitiéndonos efectuar pronósticos para otros casos (tabla VII, anexo de resultados).

En la tabla VIII (anexo de resultados) se muestran los coeficientes de la ecuación de regresión. Con los resultados obtenidos se construyó la siguiente ecuación predictiva, siendo el siguiente el modelo mejor ajustado:

\section{$E D A D=40,781+(N$. On.Fg) 1,838}

Finalmente, a través del estadístico t y su nivel crítico $(0,000)$, se corroboró que la variable seleccionada contribuye significativamente a mejorar la calidad del modelo propuesto (ver tabla VIII del anexo). 
Por último, la siguiente tabla presenta las tres ecuaciones predictivas obtenidas en la presente investigación:

Tabla 17. Ecuaciones de predicción obtenidas a partir del análisis de regresión

\begin{tabular}{lcc} 
Ecuación & $\mathrm{R}^{2}$ & $\begin{array}{c}\text { Error de la estimación } \\
\text { (años) }\end{array}$ \\
\hline $\mathrm{Edad}^{1}=30,975+$ N.On.Fg $(2,310)$ & 0,606 & 9,93 \\
\hline $\mathrm{Edad}^{2}=27,229+$ N.On $(0,818)+$ OPD $(0,549)$ & 0,837 & 1,43 \\
\hline $\operatorname{Edad}^{3}=40,781+$ N.On.Fg $(1,838)$ & 0,484 & 8,55
\end{tabular}

$\overline{{ }^{1} \text { Ecuación para muestra agrupada (20-91 años), }{ }^{2} \text { Ecuación para grupo menores de } 49 \text { años (39-49), }{ }^{3} \text { Ecuación para grupo }}$ mayores de 50 años. N.On (Número de osteonas completas por campo). N.On.Fg (Número de osteonas fragmentarias por campo). OPD (Densidad Poblacional Osteonal). 
Uno de los objetivos planteados en la presente investigación consistió en indagar sobre la fiabilidad de los métodos histológicos de estimación de edad en una muestra regional documentada. Para evaluar la validez de los mismos utilizamos el sistema de medición propuesto por Lovejoy y colaboradores (1985), a través de la medición del sesgo ${ }^{12}$ y la precisión ${ }^{13}$.

En una primera etapa de la investigación, se testearon tres ecuaciones predictivas propuestas por Singh y Gunberg (1970) para número de osteonas completas por campo (N.On) y diámetro promedio de los conductos de Havers por campo (can. Hav), Kerley y Ubelaker (1978) para osteonas fragmentarias $/ \mathrm{mm}^{2}$ (N.On.Fg) y Vasallo y colaboradores (2000) para el porcentaje de osteonas fragmentarias (\% On.Fg). En el cuadro $x$ se detalla las ecuaciones antes mencionadas.

La observación y cuantificación de las variables se realizó según los criterios previamente publicados por los autores. Asimismo, los resultados fueron analizados sin tener en cuenta la acción del dimorfismo sexual sobre cada una de las características histomorfológicas. En la tabla IX (anexo resultados) se detalla las edades estimadas a partir de los diferentes métodos.

Tablas 18. Métodos validados

\begin{tabular}{lcc}
\hline \multicolumn{1}{c}{ Método } & Ecuación Predictiva & Error \\
\hline Singh y Gunberg (1970) & $\mathrm{Y}=29.59+0.79 \mathrm{x}_{1}-0.28 \mathrm{x}_{3}$ & 3.25 \\
\hline Kerley y Ubelaker (1978) & $\mathrm{Y}=5.241+0.509 \mathrm{x}_{2}+\left(0.017 \mathrm{x}_{2}\right)^{2}-\left(0.00015 \mathrm{x}_{2}\right)^{3}$ & 6.98 \\
\hline Vasallo y col. (2000b) & $\mathrm{Y}=7.94435+1.11699(\%$ On.Fg) & - \\
\hline \hline
\end{tabular}

$\mathrm{x}_{1}$ : Osteonas tipo II por campo, $\mathrm{x}_{2}$ : Número de osteonas fragmentarias $/ \mathrm{mm}^{2}, \mathrm{x}_{3}$ : Diámetro promedio de los conductos de Havers, (\% On.Fg): Porcentaje de osteonas fragmentarias.

\footnotetext{
12 sesgo se utiliza para analizar el significado del error de la estimación, si tiende a subestimar o sobre-estimar la edad real. Significa la suma de la diferencia entre la edad estimada y la edad real o $\Sigma$ (edad estimada - edad real).

13 precisión mide la diferencia entre la edad real y la edad estimada. La precisión de la medición es la suma de la diferencia entre la edad estimada y edad real en valor absoluto o edad estimada $\Sigma$ ledad estimada - edad real|.
} 
- Edad documentada vs edad estimada por el método de Singh y Gunberg (1970)

Gráfico 6. Edad docuementada vs edad estimada Singh y Gunberg

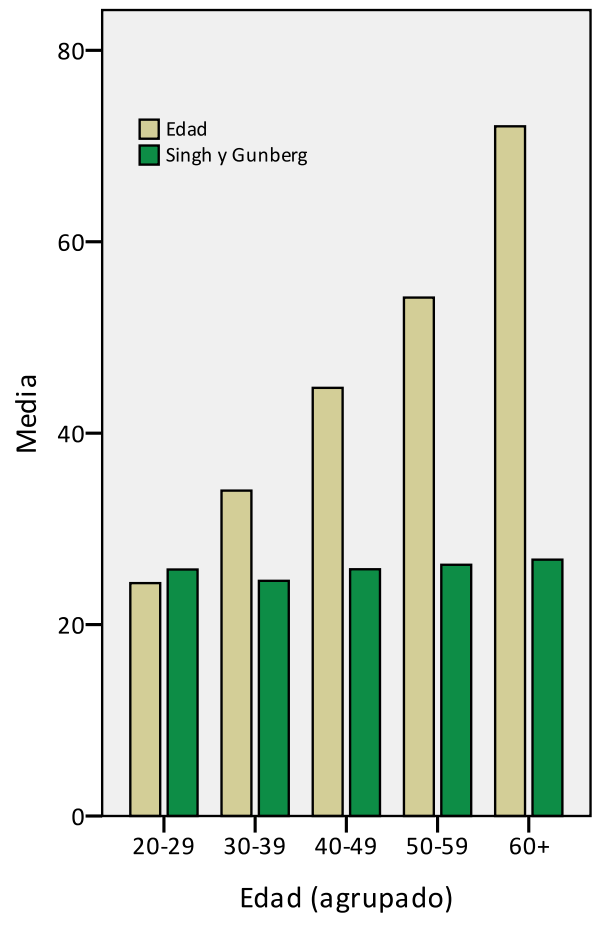

Del análisis surge que, contrariamente a los resultados obtenidos por Singh y Gunberg, el número de osteonas completas y el diámetro promedio de los conductos de Havers carecen de precisión para estimar la edad en individuos mayores de 40 años

(Gráfico 6). Nótese en el gráfico 7 que la edad estimada es notablemente menor provocando un sesgo negativo, es decir una subestimación de la edad en más de dos décadas. Sin embargo, los

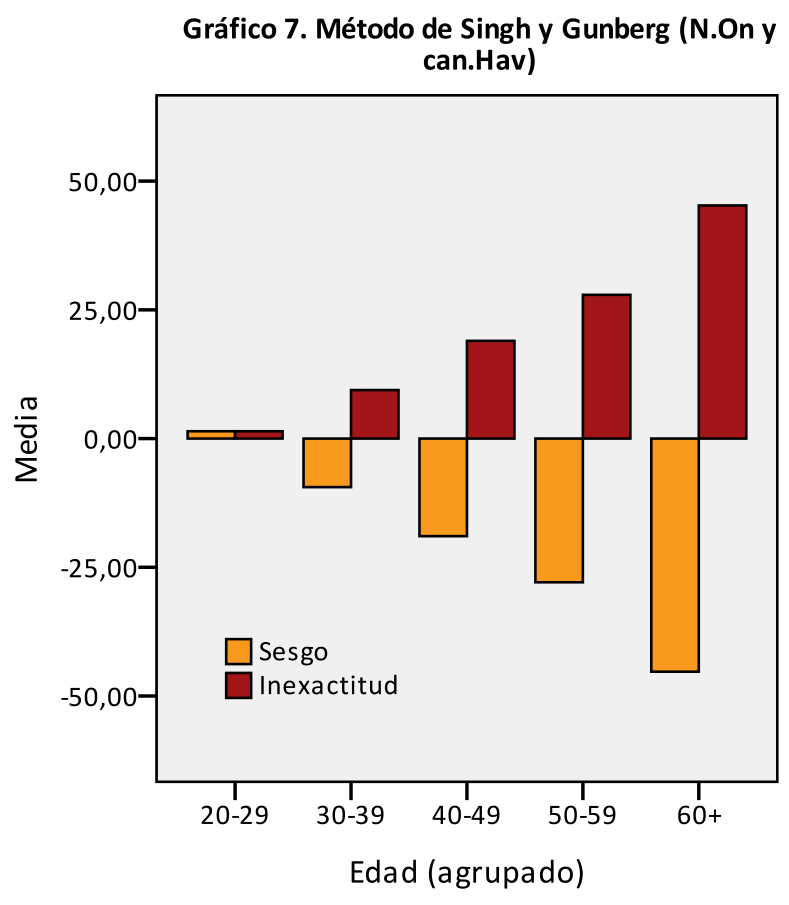

individuos menores de 40 años presentaron estimaciones más ajustadas con un error entre 1 y 10 años.

\section{- Edad documentada vs edad estimada por el método de Kerley (1978)}

Algo similar ocurre con el método de Kerley para osteonas fragmentarias, las estimaciones se alejan notablemente de los datos documentados (gráfico 8). Asimismo, se puede observar como el sesgo y la inexactitud se incrementan conforme aumentan los rangos de edad (Gráfico 9). Por lo tanto, el método propuesto por Kerley no es fiable, en términos de exactitud y precisión, para ser aplicado a la muestra en cuestión. 

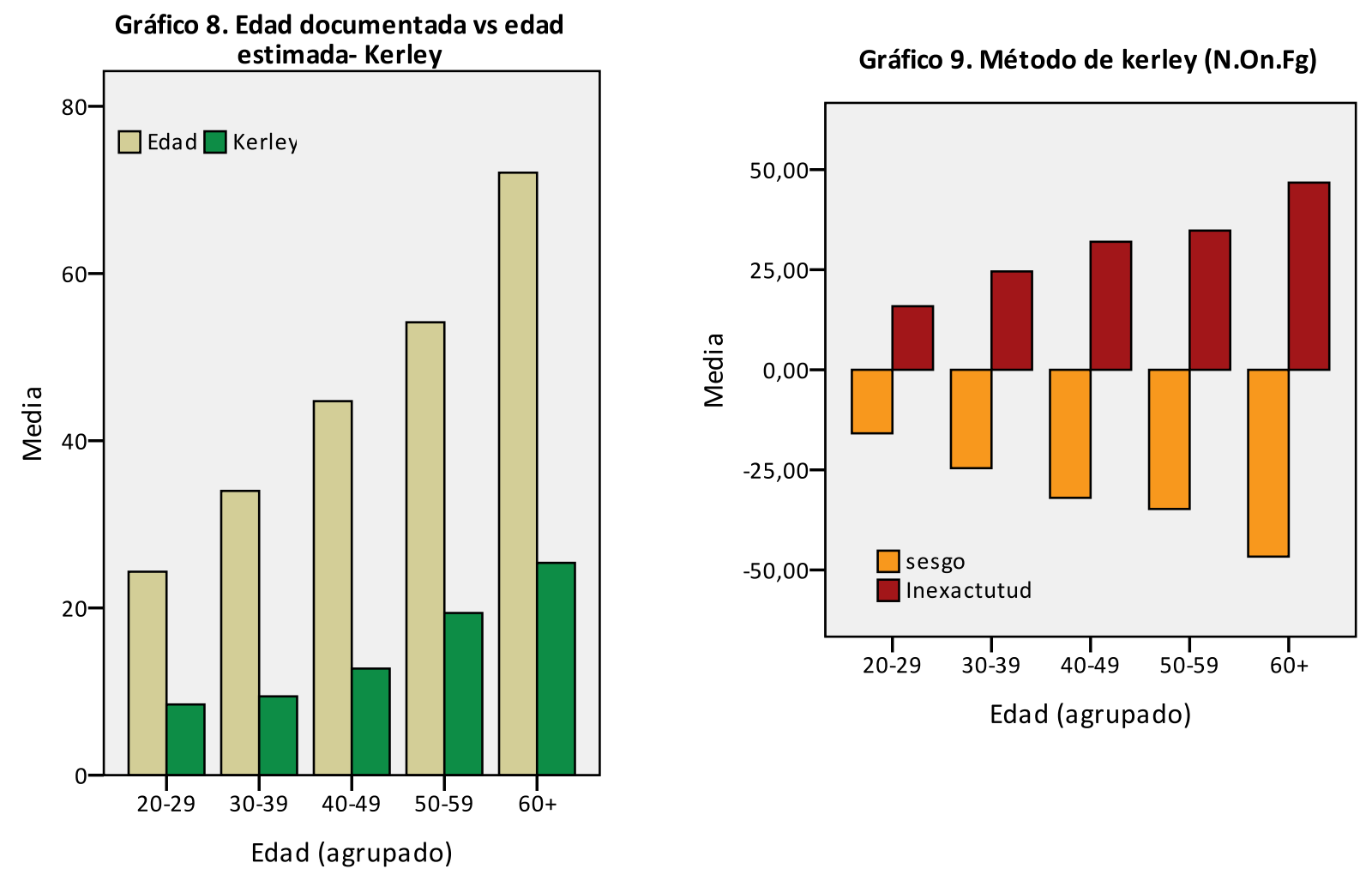

- Edad documentada vs edad estimada por el método de Vasallo y Colaboradores (2000)

El modelo propuesto por Vasallo y colaboradores merece un tratamiento especial dado que, al igual que la presente investigación, fue formulado sobre una muestra, de 20 individuos, perteneciente al Cementerio Municipal de La Plata. El rango etario de los individuos estudiados fue de 15 a 98 años con una media de 58.45 años.

En general, el modelo propuesto para el porcentaje de osteonas fragmentarias presenta estimaciones más ajustadas que los métodos anteriormente validados (Gráfico 10). Ahora bien, tal y como se observa en el gráfico 11, la fiabilidad del método no es la misma en los rangos de edad menores o iguales de 49 años respecto de los rangos mayores de 50 años. Los individuos entre 20 y 39 años presentaron mayor variación entre la edad estimada y la documentada con una sobrestimación (sesgo positivo) y una inexactitud entre 10 y 15 años. Por el contrario, a partir de los 40 años las estimaciones fueron más precisas, entre los 40 y 59 años se observa una disminución del sesgo a 6 y 8 años 
Gráfico 10. Edad documentada vs edad estimada por el Método de Vasallo y col.

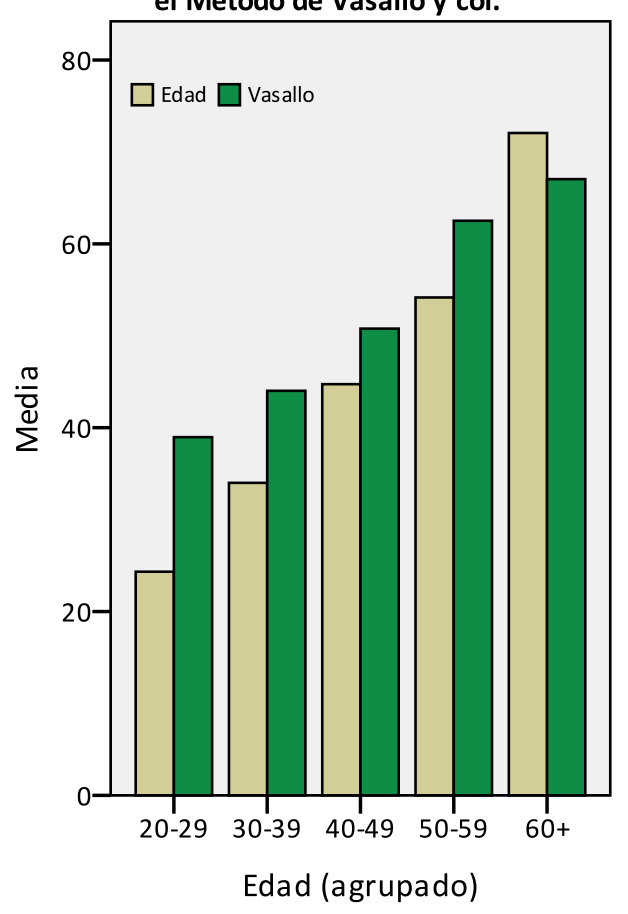

disminuyeron notablemente en ambos grupos. Sin embargo, el porcentaje de osteonas fragmentarias fue más eficaz en los individuos mayores de 50 años, perdiendo precisión en los individuos menores de 49 años.

Gráfico 12. Grupo menores de 49 años

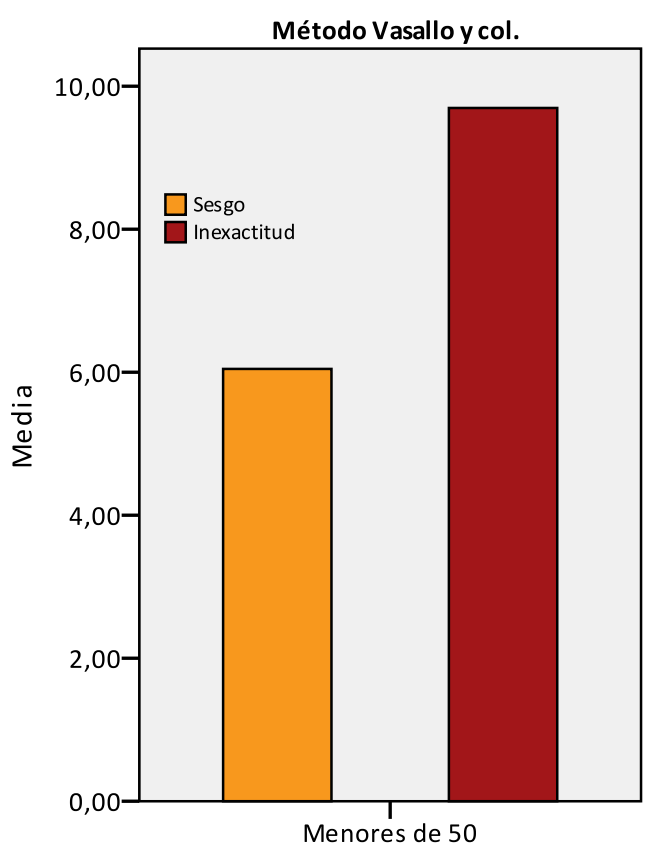

$y$, en los individuos mayores de 60 años las valoraciones han sido subestimadas (sesgo negativo) con un error de 5 años.

Dada la distribución de los resultados, se decidió realizar un nuevo testeo para lo cual se reagrupó la muestra en dos subgrupos, menores 0 iguales de 49 años (Gráfico 12) y mayores de 50 años (Gráfico 13). Como era de esperar, el sesgo y la inexactitud

Gráfico 11. Método Vasallo y col. (\%On.Fg)

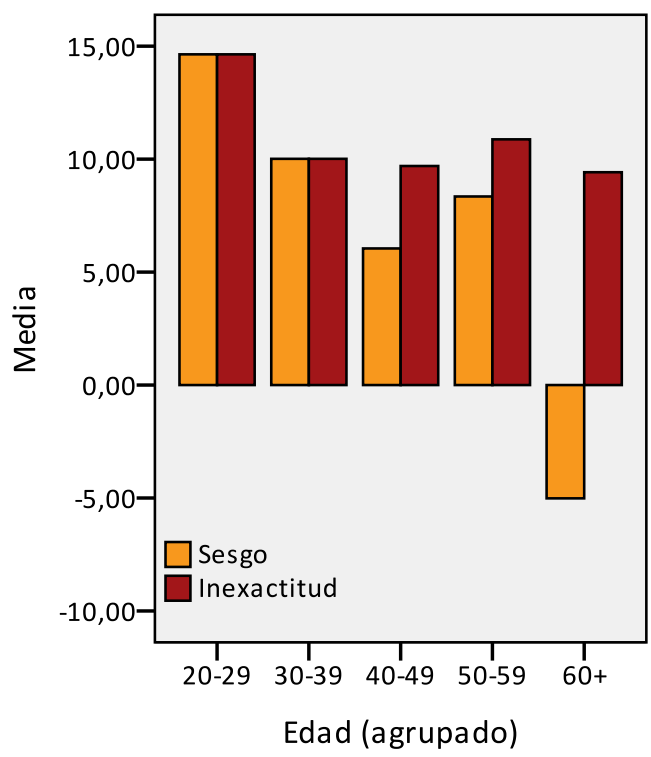

Gráfico 13. Grupo mayores de 50 años Método Vasallo y col.

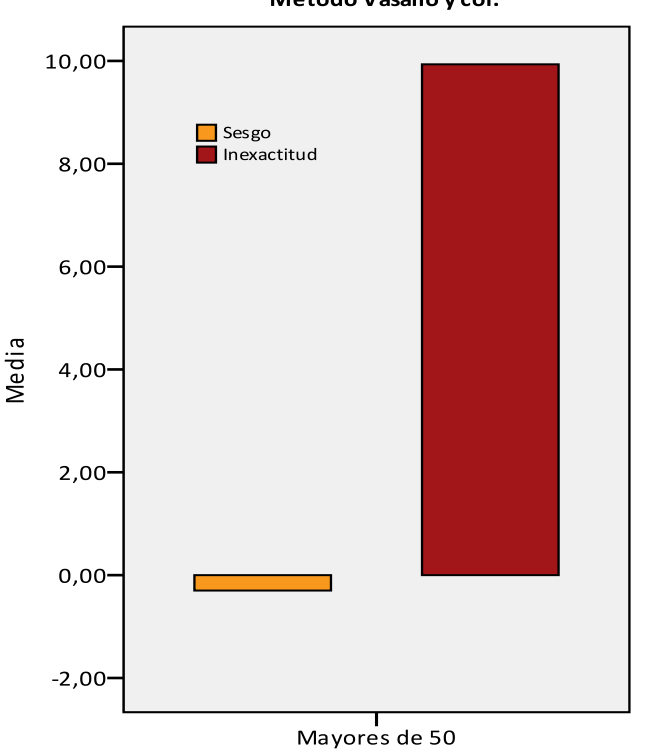


- Edad documentada vs edad estimada por el método propuesto en la siguiente investigación

En una segunda etapa se validaron las ecuaciones predictivas obtenidas en la presente investigación. Del análisis surge que el modelo basado en el N.On y la OPD (Gráfico 14) es fiable, en términos de exactitud y precisión, para individuos menores de 49 años con un error en la estimación de 2 años (sesgo positivo).

Del mismo modo, el modelo basado en N.On.Fg (Gráfico 15) fue altamente fiable en términos de precisión con un sesgo mínimo de 1 año para individuos mayores de 50 años aunque se observa una mayor variación respecto de la exactitud. Esta variabilidad observada podría ser inherente al grupo etario en particular antes que al modelo utilizado.

Gráfico 14. Edad documentada vs edad estimada

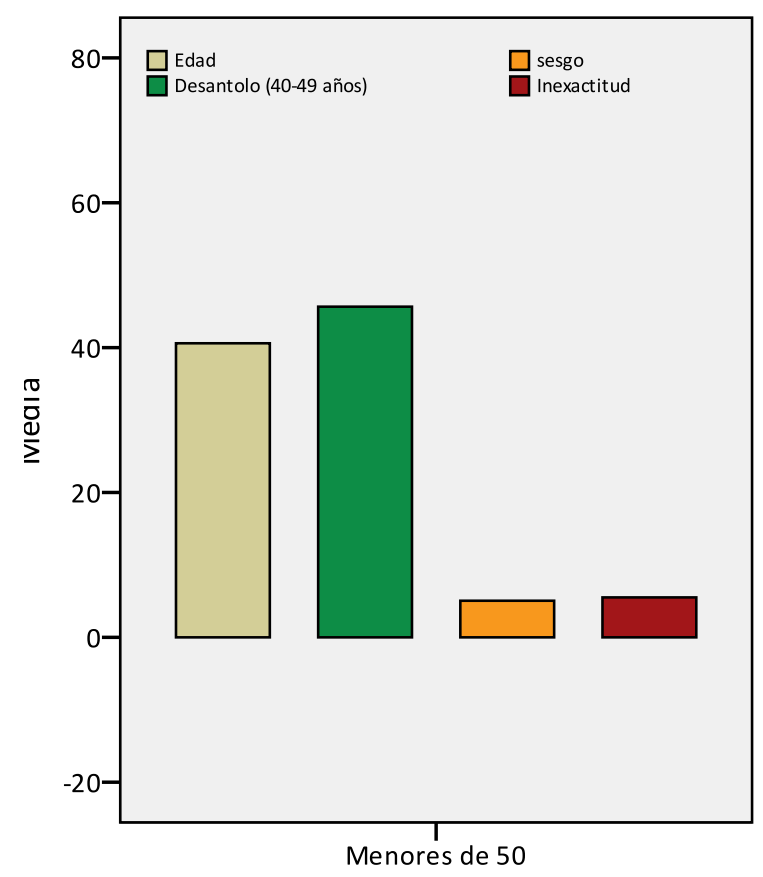

Gráfico 15. Edad documentada vs edad estimada

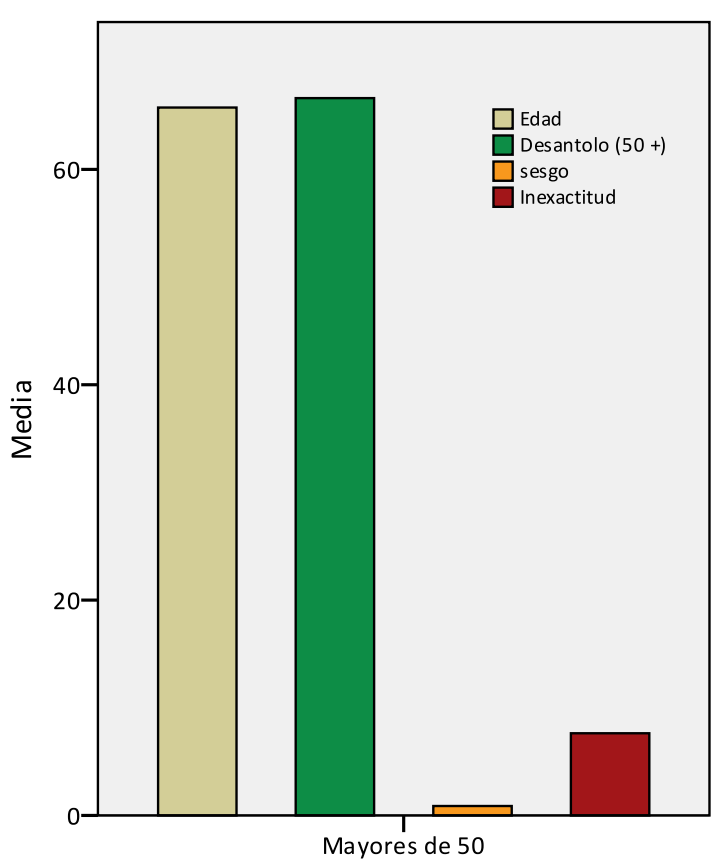


CAPÍTULO V

DISCUSIÓN 
En nuestro propósito de desarrollar ecuaciones predictivas a partir del análisis de validez y ajuste de diferentes métodos microscópicos para estimación de edad a la muerte en restos óseos humanos adultos, analizamos individuos documentados de la colección osteológica “Prof. Dr. Rómulo Lambre" (FCM-UNLP, Res. N 376).

Luego de una primera etapa de revisión bibliográfica, realizamos un análisis riguroso y comparativo de los métodos previamente publicados por varios autores (Kerley 1965, Kerley y Ubelaker 1978, Singh y Gunberg 1970, Ericksen 1991, Vasallo et al. 2000, Han et. al 2009, Keough 2009). Esto nos permitió identificar, seleccionar y cuantificar cinco variables microestructurales: el número de osteonas completas por campo (N.On), el número de osteonas fragmentarias por campo (N.On.Fg), el diámetro promedio de los conductos de Havers (can. Hav), el porcentaje de osteonas fragmentarias (\% On.Fg) y la densidad poblacional osteonal (OPD).

Los avances logrados durante el desarrollo de la presente investigación posibilitaron, no sólo adecuar procedimientos técnicos y metodológicos a las características particulares de la muestra en estudio (colección de esqueletos adultos, de ambos sexos, documentados en cuanto a procedencia y causal de muerte), sino también, indagar en el transcurso de la investigación, sobre dificultades y alternativas posibles para obtener muestras histológicas adecuadas y óptimas para su relevamiento microscópico.

Es así que, en este acápite, discutiremos acerca de la composición de la muestra de referencia; del uso, limitaciones e implicancias metodológicas del análisis histomorfométrico aplicado a restos óseos humanos actuales y arqueológicos; y por último, sobre la validez de los modelos propuestos en la presente investigación comparados con los obtenidos a partir de otras series esqueletales. 


\section{V.1- COLECCIÓN LAMBRE}

La composición demográfica de la colección, y por ende de la muestra analizada, presenta características particulares en cuanto a su distribución por sexo y edad. Por un lado, existe una proporción mayor de individuos del sexo masculino y por otro, se observa una polarización de los rangos etarios representados. Debemos señalar, que estudios realizados por nuestro equipo muestran una similitud entre el perfil demográfico de la colección Lambre con el de mortalidad de la Argentina (ver Plischuk et al. 2007) en donde la subrepresentación de los individuos con edades entre 2 y 40 años se asocia a la etapa con menor riesgo de muerte de la población local.

Por lo tanto, al momento de realizar estudios poblacionales utilizando colecciones osteológicas contemporáneas, pueden presentarse obstáculos tales como la escasa representación de individuos jóvenes y una mayor representación de individuos masculinos. Tal es el caso, entre otros, de la "Colección Terry", hoy conocida como una de las colecciones osteológicas más importantes. La misma tuvo en sus inicios similares inconvenientes y los esfuerzos que realizara la Dra. Mildred Trotter en la década de 1950 contribuyeron a su equilibrio (Hunt y Albanese 2005). En nuestro caso, hemos encaminado los esfuerzos en el mismo sentido a partir de la periódica incorporación de material osteológico a la colección contribuyendo de este modo al balance de la muestra.

No obstante ello, el tamaño de la muestra y su composición en cuanto a la distribución de edad y sexo, ha sido y es motivo de preocupación para investigadores, sobre todo cuando son tomadas como base para proponer nuevos métodos de estimación de edad y sexo (Bouvier y Ubelaker 1977, Lazenby 1984, Walker et al. 1994, Schmitt 2002, Robling y Stout 2008).

Particularmente, los métodos histológicos de estimación de edad han sido establecidos, por lo general, a partir de muestras numéricamente limitadas (Schmitt 2002) afectando directamente el sesgo y la precisión del modelo predictivo. El análisis de una muestra sesgada positivamente generará modelos que 
estimen con mayor precisión las categorías de edad más jóvenes, mientras que aquellas sesgadas negativamente lo harán para los grupos de mayor edad (Lazenby 1984).

En nuestro caso, los modelos predictivos derivados de la muestra analizada $(n=71)$ presentaron un error estándar en la estimación promedio de 4.99 años, es decir que fueron fiables en términos de precisión con un sesgo mínimo de 1 a 2 años (sesgo positivo), aunque se observó una mayor variación respecto de la exactitud en los individuos mayores de 50 años.

En este sentido, Hennig y Cooper (2011) examinaron la relación entre el tamaño de la muestra ( $n$ ) y el error estándar de la estimación (SEE) a través de una exhaustiva revisión bibliográfica de diferentes métodos histomorfométricos de estimación de edad y analizaron las predicciones basados en la teoría de muestreo. En general, el estudio reveló que el promedio del tamaño muestral fue de 59 individuos y que el 84 \% (53/63) de los métodos se basaron en muestras de menos de 100 individuos. De manera que los errores presentaron una gran variación entre 1.51 y 16.00 años.

En el caso particular del fémur, el promedio del tamaño muestral fue de 36 individuos y el $78 \%(21 / 27)$ de las ecuaciones predictivas fueron calculadas a partir de muestras de menos 100 individuos, con una variación entre 1.51 y 13.85 años.

Por lo expuesto se observa que, si bien las variables que pueden afectar la precisión de diferentes métodos histomorfométricos son numerosas, el tamaño muestral incide directamente en la validez de los modelos finalmente propuestos.

Otro aspecto importante y no menor en la búsqueda de estándares regionales, es la composición étnica de las colecciones contemporáneas y documentadas. En general las estadounidenses son, en su mayoría, heterogéneas y multiétnicas, contando en su composición con individuos de diferente ancestría.

Así, la muestra utilizada por Kerley (1965) y Kerley y Ubelaker (1978) estuvo integrada por americanos y afroamericanos provenientes de morgues judiciales. Por su parte, Ahlqvist y Damsten (1969) examinaron individuos procedentes de autopsias pero sin especificar procedencia étnica lo cual dificulta en parte las 
comparaciones. Un caso similar es el de Singh y Gunberg (1979) quienes refieren a la muestra estudiada como integrada por "cadáveres americanos". Tampoco la muestra de base utilizada por Thompson (1979) de blancos de Nueva Inglaterra, agrega precisiones a este respecto a pesar de ser este trabajo un referente en cuanto al número de individuos considerados $(n=116)$. Una mención especial debemos hacer de la muestra usada por Ericksen (1991), ya que el autor, no sólo incluye en la misma un número importante de individuos $(n=328)$ sino que especifica la nacionalidad de los mismos (EE.UU, Chile y República Dominicana) con la finalidad de ampliar la composición étnica y la aplicación de los resultados.

Pero es recién a partir de fines del siglo XX cuando comienzan realmente a generarse colecciones de carácter regional intentando hacerlas representativas de características poblacionales locales y generando una diáspora que abarca todos los continentes. Eliopoulos et al. (2007) en Grecia, Dayal et al. (2009) en Sudáfrica, Ongkana y Sudwan (2009) en Tailandia, Purkait (2003) en India central, Watanabe et al. (1998) en Japón, Paredes et al. (1997) en Chile, Rojas Alfonso y Quintero Pardo (2011) en Colombia, Bosio et al. (2009) y Salceda et al. (2009) en Argentina.

\section{V.2- ASPECTOS TÉCNICOS}

\section{V.2.1- Obtención y preparación de las secciones histológicas}

En el inicio de la investigación se revisaron y consideraron tanto las herramientas como las recomendaciones técnicas dadas por la bibliografía específica (Stout 1988, Robling y Stout 2008).

Puesto que el análisis histológico es un método invasivo, nos basamos en aquellas técnicas de muestreo que limitan la cantidad de hueso requerida para su evaluación y de esta manera, preservamos la integridad de la pieza para estudios ulteriores (Chan et al. 2007, Robling y Stout 2008). Entre ellas podemos mencionar la propuesta de Thompson (1979) quien utilizando solo un pequeño fragmento de hueso ( $0.4 \mathrm{~cm}$ de diámetro de la diáfisis media anterior) propone un método menos 
invasivo que otros que necesitan de secciones transversales completas (Kerley 1965, Alqvist y Damsten 1969, Fangwu 1983, Hauser et al. 1980, Cera y Drusini 1985). No obstante, esto es discutible para Stout (1989) quien considera que el tamaño de la sección propuesta por Thompson es demasiado pequeña al tratarse de una única muestra. En este marco la alternativa de Ericksen (1991) al aconsejar una porción un tanto mayor $(1 \mathrm{~cm})$ de la corteza anterior, minimiza las críticas al área obtenida por Thompson.

En nuestro caso la decisión metódica escogida implica cortar secciones de tejido cortical de la mitad anterior de la diáfisis femoral, en forma de "C", de 0.5 a 1 $\mathrm{cm}$ de ancho, de manera que resulten lo suficientemente delgadas para facilitar el desgaste, y lo bastante anchas para conservar la integridad estructural al momento del corte (Frost 1958).

Otra consideración está ligada a la distribución de las estructuras histológicas, la cual no es la misma en toda la circunferencia de un hueso largo típico (Robling y Stout 2008). En este sentido, es sabido que las diferentes localizaciones anatómicas del fémur (anterior, posterior, medial y lateral) proporcionan valoraciones disímiles para los mismos rasgos histomorfológicos (Jowsey 1960, Drusini 1987, Pfeiffer et al. 1995).

Como esta decisión tiene efectos significativos en la ulterior precisión en la estimación es imperativo respetar la ubicación exacta del muestreo topográfico que se describe en cada uno de los métodos (Robling y Stout 2008).

Además, y como la evaluación histomorfométrica del hueso cortical mineralizado requiere de secciones delgadas no descalcificadas, las cuales deben obtenerse a través de la técnica de desgaste (Vasallo y Restelli 2000, Maat et al. 2001), en una primera etapa aplicamos a nuestra muestra este procedimiento técnico 
Luego de su implementación, y en particular durante el proceso de preparación de las secciones surgieron dificultades, inherentes a la técnica, que de no haber sido tenidas en cuenta hubieran influido drásticamente en los resultados:

- Algunas láminas no soportaron el desgaste, resultando en pequeños fragmentos. Consecuentemente, se produjo pérdida de información sesgando la observación e imposibilitando la identificación y conteo de estructuras óseas.

- En otros casos, y pese al control microscópico constante, se desgastó de forma excesiva, no pudiéndose observar las estructuras con claridad (figura x)

- Otra consecuencia del desgaste fueron las fracturas y micro grietas observadas en la cortical (Figura $\mathrm{x}$ ).

Dado que la preparación adecuada de las secciones es esencial para el análisis histológico, en cada minuto que se dedicó a la mejora de la calidad de las secciones delgadas se ganó facilidad y precisión en el análisis (Robling y Stout 2008). Por ello y debido a las dificultades especificadas más arriba, así como a la friabilidad que presentaban ciertos elementos óseos, se propuso, para una segunda etapa, el testeo de nuevas técnicas de inclusión en medios plásticos duros.

De esta manera se reemplazó la técnica de desgaste aconsejada en la bibliografía específica por la de inclusión en resina a los fines de optimizar la obtención de los preparados histológicos. Reiteramos que tal decisión metodológica se basó, luego de la experiencia adquirida, en la necesidad de mantener la integridad de las secciones durante los procesos de corte y desgaste para poder documentar con mayor precisión la microanatomía del tejido óseo. La técnica utilizada, luego de un ajuste de prueba, fue la de inclusión en resina epoxi. (Paine 2007).

Es reconocido en la bibliografía específica, que el desarrollo de medios duros de inclusión (monómeros plásticos), de micrótomos y sistemas de cortes especiales, permiten cortar hueso sin descalcificar y, con ello, facilitar la realización de investigaciones imposibles de llevarse a cabo con las técnicas tradicionales 
(Cano-Sánchez et al. 2005). Las primeras pruebas comenzaron con la inclusión del hueso en derivados celulósicos a fin de obtener bloques de plástico de dureza semejante. Complementariamente se incorporaron micrótomos con cuchilla de diamante adecuados, tanto a la dureza como al tamaño de la muestra.

Dentro de una amplia variedad de derivados plásticos para inclusión, tanto los acrílicos como el Metacrilato de metilo y las resinas epoxi son los más aconsejados para estas aplicaciones (An y Martin 2003, Cho y Stout 2003). En particular, las resinas epoxi se emplean principalmente en microscopía electrónica, por su elevado grado de estabilidad al ser sometidas al vacío y bombardeo de electrones. Sin embargo, su uso en microscopía óptica es menos frecuente dado que para observaciones histológicas no permite una adecuada penetración de los colorantes específicos.

A pesar de las críticas a su uso en estudios histológicos, en nuestro caso las pruebas realizadas demostraron su efectiva aplicabilidad para análisis histomorfométricos, los cuales no necesitan tinción del tejido óseo. Además esta técnica clarifica la imagen de tal manera que el relevamiento de las variables se torna sencillo.

En síntesis, observamos que algunas de las ventajas brindadas por estos medios de inclusión fueron la completa penetración y el endurecimiento homogéneo de los bloques, procesos que permitieron mejorar la calidad de las imágenes y mantener la integridad y estabilidad de las secciones, garantizando su perdurabilidad y disponibilidad para ser utilizadas en otras investigaciones, sean estas de carácter metodológico o poblacionales. 


\section{V.2.2- Observación y cuantificación de las variables}

En los últimos años han acontecidos avances significativos en las técnicas histomorfométricas; sin duda los más notables han sido el uso de sistemas computarizados y el desarrollo de programas digitales para la evaluación de la microarquitectura del tejido óseo (An y Martin 2003).

La aplicación de estas técnicas en los métodos histomorfométricos de estimación de edad ha sido particularmente valiosa (Ericksen 1991, Compston 1998, Cho y Stout 2003, Robling y Stout 2008), puesto que ha sustituido el uso de técnicas manuales (i.e grillas y micrométricos) permitiendo, además, relevar variables métricas más complejas, tales como el diámetro de los conductos haversianos, difíciles de registrar a partir de técnicas no computarizadas.

En nuestra experiencia, las técnicas manuales resultaron lentas y tediosas en la observación, y requirieron de la constante manipulación de lentes y focos, ocasionando en algunos casos, movimientos de la platina. En cuanto a la cuantificación fueron imprecisas y presentaron una importante variación intra e ineterobservador.

Contrariamente, los métodos computarizados semiautomáticos demostraron ser más rápidos, permitiendo un muestreo sistemático y fiable de las microestructuras. A su vez, la incorporación de microfotografías (imagen digital) para el análisis mejoró notablemente el rendimiento, el tiempo empleado y la precisión en la cuantificación. Esta última acción corroboró ampliamente las ventajas metodológicas enumeradas por Ericksen (1991) que hacemos nuestras:

1) el campo se define arbitrariamente y la corredera se puede desplazar para centrarse en las estructuras periféricas sin peligro de perderlo. En los casos de interpretación dudosa, se puede cambiar a un mayor aumento;

2) permite examinar y evaluar un mismo campo en diferentes momentos y por distintas personas. De esta manera, se convierte en un documento verificable y permanente; 
3) el conteo y las mediciones pueden ser registrados en la fotografía, libre del peligro implícito a los cambios de los oculares y a los movimientos de la sección delgada, que hacen confundir el campo visual original.

En síntesis, la aplicación de técnicas automáticas fue beneficiosa y redujo el tiempo de evaluación, sin embargo alertamos sobre el hecho que las tecnologías actuales no deberían reducir por completo la observación directa a través del microscopio óptico (Stout y Crowder 2012).

\section{V.2.3- Preservación, procesos tafonómicos y diagenéticos}

A partir de este y otros estudios, específicamente vinculados a la investigación arqueológica (Pfeiffer 1992, Eriksen 1997, Pan y Verri 2002), se hace evidente que la preservación del material óseo no solo puede evaluarse macroscópicamente. Según Cho y Stout (2003) a menudo la preservación de la microestructura no puede ser pronosticada a priori por el aspecto macroscópico de los restos esqueléticos, sino después de que las secciones histológicas fueron obtenidas. Tal fue nuestra experiencia ya que el $9.3 \%$ de las secciones realizadas fueron desgastadas y posteriormente eliminadas debido a un deterioro de la microestructura ósea producida por factores diagenéticos como bacterias y hongos. Por lo tanto, y de acuerdo con lo establecido por Jans y Kars (2002):

...this allows more detailed analysis of bone, such as the identification of included/infiltrated materials, birefringence and the identification of types of $\mathrm{mfd}$. It is expected that this more detailed and differentiated information will help to link histological preservation to chemical and macroscopic preservation and the environmental parameters. (Jans y Kars 2002: 346) ${ }^{14}$

Asimismo, debe notarse que el propio espacio inhumatorio y posterior manipulación antrópica de los restos óseos influyen inexorablemente en la

14 un análisis más detallado de los huesos, tales como la identificación de los materiales incluidos en infiltrados, y la identificación de los tipos de hongos y bacterias ayudará a vincular la preservación histológica a la preservación química y la preservación macroscópica a los parámetros ambientales. 
estimación de la edad (Caffell et al. 2001). Particularmente la elección de la zona del hueso de la cual se extraerá la sección a analizar, es de vital importancia y para ello debe tenerse presente que ante una alteración superficial del periostio no deben seleccionarse campos a nivel del subperiostio.

Esta situación ha llevado a los investigadores a desarrollar métodos de estimación de edad basados en otras zonas de la corteza femoral. Por ejemplo, Hauser y colaboradores (1980) al igual que Pfeiffer y colaboradores (1995) presentaron ecuaciones predictivas derivadas de la región del endostio y del subperiostio de fémur y tibia; en tanto que Samson y Branigan (1987) proponen como más eficaz la zona anterolateral y anteromedial de la cortical femoral.

Para la bioantropología en particular, la aplicabilidad de técnicas histomorfométricas de estimación de edad en casos arqueológicos y forenses, donde no siempre está clara la integridad estructural de los elementos óseos ni la correspondencia individual de las piezas, los cambios relativamente pequeños en la preservación del material deben ser considerados especialmente a la hora de inferir rango etario. Entendemos como Pan y Verri (2002) que para aplicar dichas técnicas a este tipo de materiales se deben cumplir pasos previos indicativos de la factibilidad de su aplicación, a saber:

1. Determinar estado de preservación/meteorización que presentan los restos a analizar.

2. En caso que se utilice la técnica de desgaste, la observación microscópica periódica a fin de lograr un espesor optimo para la visualización de la microestructura y, de esta manera evitar la destrucción del material.

3. La aplicación de una metodología no invasiva (e.g. microscopía electrónica) para aquellos casos que presenten alta meteorización y que no requiera desgaste. 


\section{V.3- A PROPÓSITO DE LOS RESULTADOS}

Como expresamos anteriormente, la remodelación es un proceso que ocurre durante toda la vida del individuo. De esta manera sabemos que la asociación entre el número de osteonas y la edad cronológica constituye la base primaria de los métodos histológicos de estimación de la edad (Stout 1989).

A partir del análisis realizado podemos establecer que, en general, las variables histomorfológicas demuestran, en mayor o menor medida, una asociación significativa con la edad para la muestra en general, excepto el diámetro promedio de los canales de Havers. A su vez, esta relación es positiva en todos los casos, es decir, que se evidencia un aumento progresivo de las variables con el incremento de la edad. Como hemos dicho un caso especial lo constituye la variable can. Hav (diámetro promedio de los conductos haversianos). Contrariamente al resto, el diámetro promedio de los conductos de Havers no presentó relación lineal con la edad $(R=0,158 ; P>0,187)$ y, por lo tanto, dicha variable fue excluida del modelo dada su ineficacia como predictora de la edad. Estos resultados fueron similares a los hallados por Nor et al. (2006) $(R=0,06$; $P<$ 0,01) y Han et al. (2009) $R=0,296$.

En cambio, en nuestro caso en particular, el N.On.Fg (número de osteonas fragmentarias) presentó una fuerte asociación con la edad $(R=0,779)$ tal y como ha sido observado en estudios previos (Kerley 1965, Alqvist y Damsten 1969, Iwamoto y Konishi 1982, Eriksen 1991, Watanabe 1998, Nor et al. 2009, Keough et al. 2009).

Para Kerley (1965) el número de osteonas se incrementa con la edad desde el nacimiento hasta los 95 años, siendo las osteonas fragmentarias las que presentan mayor asociación $(R=0,86)$. Estos resultados concuerdan con las valoraciones obtenidas por Eriksen (1991) al igual que con las de Iwamoto y Konishi (1982) y Keough (2009) aunque con coeficientes de correlación menores $(0,71 ; 0,63$ y 0,40 respectivamente).

La OPD (densidad poblacional osteonal) como variable que expresa la suma de osteonas completas y fragmentarias por $\mathrm{mm}^{2}$, representa todos los restos visibles de antiguas y nuevas osteonas producto de la actividad de remodelación 
cortical (Stout 1989). Según Stout y Paine (1992) la OPD aumenta con la edad hasta alcanzar una asíntota, punto en el cual las osteonas nuevas eliminan toda evidencia de las anteriores. Cuándo la corteza femoral alcanza la asíntota, la OPD no pueden aumentar más, imponiendo de esta manera, limitaciones obvias a los métodos histológicos de estimación de edad.

Sin embargo, este punto varía en los diferente huesos dado que depende de ciertos factores, como la tasa de remodelación, el diámetro cortical y el tamaño osteonal (Crowder y Stout 2012). Según Kerley (1965) y Frost (1987) la asíntota de la cortical del fémur es de $50 / \mathrm{mm}^{2}$ (i.e 50 osteonas por $\mathrm{mm}^{2}$ ) a diferencia de la costilla que es de $30 / \mathrm{mm}^{2}$ como aseveran Stout y Paine (1994).

También en nuestro caso, la OPD presentó una asociación significativa con la edad $(R=0,741)$ para la muestra agrupada, es decir, que la densidad osteonal evidenció un incremento edad dependiente. Sin embargo la densidad osteonal promedio en los individuos mayores de 60 años fue menor $\left(26 / \mathrm{mm}^{2}\right)$ aunque similar a la hallada por Han y colaboradores (2009) en una muestra Koreana. Para estos autores la OPD demostró una fuerte asociación con la edad $(R=0,810)$ alcanzando un valor de 26 osteonas por $\mathrm{mm}^{2}$.

En este punto, nuestros resultados se ven reforzados por las conclusiones de Stout y Crowder (2012) para quienes el fémur es una pieza confiable para estimar edad en adultos mayores, debido a que la OPD alcanza su asíntota a una edad relativamente mayor a causa del espesor de sus áreas corticales.

Por otra parte, el \% On.Fg (porcentaje de osteonas fragmentarias) también presentó una asociación positiva con la edad $(R=0,646)$ al igual que en estudios previos (e.g Vasallo et al. 2000) en individuos procedentes del Cementerio Municipal de La Plata. No obstante, el coeficiente de correlación obtenido por nosotros fue menor, diferencia que radica evidentemente, como expresáramos en el apartado de resultados, en el tamaño y distribución de la muestra. 
El N.On (número de osteonas completas) conjuntamente con las fragmentarias han sido esgrimidas en la mayoría de las técnicas de estimación histológica de la edad, por estar unas y otras involucradas en el proceso de remodelación.

Todos los autores que han trabajado en el tema (Kerley 1965, Singh y Gunberg 1969, Alqvist y Damsten 1970, Ericksen 1991, Yoshino et al. 1994, Watanabe et al. 1998, Walker 1992, Nor et al. 2009, Han et al. 2009, Keough et al. 2009) concuerdan que estas estructuras aumentan en número a lo largo de la vida.

En nuestro caso, aunque el número de osteonas completas presentó una correlación positiva baja $(R=0,330)$ para la muestra agrupada, observamos que en masculinos la asociación con la edad es más estrecha que en femeninos. Esto podría deberse, probablemente, a la sub representación numérica y etaria de los individuos femeninos.

De todos modos, aunque el sexo es uno de los factores que influye en la remodelación ósea y por ende en los análisis histomorfométricos (Stout 1988; Robling y Stout 2008) en nuestro caso, las variables histomorfométricas no presentaron variación dimórfica significativa. Este resultado concuerda con el estudio de Kerley (1965) y con el de Alqvist y Damsten (1969) quien directamente no tuvo en cuenta dicho análisis. Por su parte, Singh y Gunberg (1970) desarrollaron su método a partir de una muestra sólo masculina, pero también comprobaron que las ecuaciones dan buen resultado cuando se las aplica a una pequeña muestra de mujeres.

Estudios más recientes, en una muestra Danesa (Maat et al. 2006) y Sudafricana (Keough 2009) tampoco evidenciaron diferencias en cuanto al sexo.

Yoshino et al. (1994), Iwamoto y Konishi (1982), Samson y Branigan (1987) en cambio, hallaron diferencias en cuanto al sexo y propusieron métodos de estimación de la edad sólo para individuos masculinos pero, contrariamente a Sing y Gunberg, los resultados fueron menos precisos cuando se los aplicó a una muestra femenina. 
Thompson (1970) fue el primer autor que presentó ecuaciones específicas para masculinos, femeninos y para ambos sexos combinados. Años más tarde Ericksen (1991) demostró que las ecuaciones específicas para cada uno de los sexos fueron más precisas que las formuladas para sexos agrupados.

En nuestro caso, si bien el análisis estadístico no mostró diferencias significativas entre sexos, cuando observamos las variables según los rangos de edad notamos que aún cuando en ambos sexos el número de osteonas secundarias aumenta con la edad, en los hombres el aumento es constante, en cambio, en las mujeres alcanza cierta estabilidad relativa a partir de los 50 años (Feik et al. 1996). También se observa un aumento progresivo con la edad de las osteonas fragmentarias en ambos sexos, pero la cantidad de osteonas $/ \mathrm{mm}^{2}$ es mayor en mujeres entre los 50 y 60 años.

Coincidimos con Han y colaboradores (2009) en que la distribución de los rangos de edad de la muestra puede haber sido responsable de muchas de las observaciones, dada la sub representación de individuos femeninos menores de 50 años. Esto ha limitado los efectos de variables fisiológicas tales como la menopausia. Por lo tanto creemos que la incorporación de individuos jóvenes es de suma importancia para confirmar la existencia de diferencias sexuales a nivel histomorfométrico.

Finalmente algunos estudios han analizado los efectos del dimorfismo y la edad en la geometría de la diáfisis femoral. Feik y colaboradores (1996) observó que durante la edad adulta hay claras diferencias de género en la remodelación del fémur. Los hombres mostraron un aumento del área subperióstica y de la zona medular. Por su parte, en mujeres pueden diferenciarse dos momentos, uno de estabilidad relativa hasta la menopausia y luego un segundo momento caracterizado por el marcado aumento en todas las variables de la región anterior. En la vejez las diferencias de género disminuyen, la aposición perióstica se reduce y aumenta la resorción endosteal. El autor observa que entre la tercera y octava década, la zona cortical disminuye aproximadamente $4 \%$ en los hombres y $15 \%$ en 
las mujeres. Concluye que la diferenciación dimórfica es observable en las edades intermedias (41-60 años) disminuyendo en la vejez (Feik et al. 2000).

Otros estudios también han demostrado que la tasa de remodelación en el hueso cortical no es la misma entre hombres y mujeres de la misma edad, sobre todo en la etapa postmenopáusica ya que el proceso de remodelación ósea se acelera en las mujeres inmediatamente después de la menopausia (Parffit 1979, Brickley e Ives 2008).

En síntesis, las críticas y discrepancias actuales con los resultados de aquellos estudios que tuvieron en cuenta el sexo, podrían deberse tanto a las diferentes áreas de la corteza femoral de donde se tomaron las secciones óseas, como a diferencias entre las poblaciones en estudio, a las variables medidas y / o a combinaciones de estos y otros factores

\section{V.4- A PROPÓSITO DE METOdOS ESTAdísticos Y MODELOS}

\section{RESULTANTES}

Como notáramos en la discusión de los resultados, las variables aconsejadas por los distintos autores que trabajaron en la temática, sufrieron un primer tamizado analizando la asociación de cada una de ellas con la edad cronológica documentada. Para ello estas cuatro variables escogidas como más diagnósticas, fueron necesariamente sometidas a un análisis posterior que las incluye en su conjunto y que determinó, para la muestra agrupada, cual/les de ellas tuvieron el mayor peso en la estimación.

Así, el análisis de regresión lineal múltiple en nuestro caso, demostró que el número de osteonas fragmentarias explica el $61 \%$ de la variación de la edad observada con un error de estimación de 10 años. En este sentido Kerley (1965), si bien no aplicó regresión múltiple, fue el primero en desarrollar una ecuación predictiva señalando que para obtener estimaciones más precisas es aconsejable utilizar tantas variables como sea posible. Sus resultados también demostraron que un alto porcentaje de la variación observada es explicada por el número total de 
osteonas fragmentarias, aunque con un error mayor en la estimación que el obtenido en nuestra investigación.

Por su parte, Singh y Gunberg elaboraron modelos exploratorios en base a tres variables (número total de osteonas, el promedio de laminillas por osteonas y el diámetro promedio de los canales de Havers) obteniendo altos coeficiente de determinación y con errores en la estimación relativamente bajos. En el marco de sus investigaciones la fórmula propuesta en base sólo al número de osteonas fragmentarias, demostró que tal variable explica el $88 \%$ de la variación observada de la edad con un error de 3.82 años.

En cambio otras ecuaciones propuestas que consideraron a las osteonas fragmentarias, resultantes de análisis univariado y en muestra agrupada (Eriksen 1991, Keough 2009) presentaron en general bajos valores de determinación, sin errores estándares especificados o demasiado altos. En particular Keough (2009), utilizó pruebas considerando todas las variables pero los resultados demostraron ser poco predictivos y con errores altos de estimación.

Es Walker, en 1994, quien, aún obteniendo un bajo coeficiente de determinación, y usando el número de osteonas fragmentarias como variable predictiva, toma por primera vez la decisión metodológica de subagrupar la muestra en dos cohortes etarias ( $<50$ años y $>50$ años).

Como puede notarse las propuestas de coeficientes, su real valor de estimación y posible intervalo de error en relación con la edad cronológica documentada, son numerosas y variadas compendiando valores predictivos diferenciales. La muestra documentada utilizada y la polarización de los rangos de edad parecieran ser las principales causas estructurales de las diferencias entre los valores predictivos de las propuestas.

El análisis crítico de esta situación que refleja el desarrollo de la propia línea de especialización, y aun habiendo obtenido resultados promisorios en nuestro primer análisis del que obtuviéramos un modelo aplicable a contextos 
arqueológicos y forenses, motivó que siguiéramos indagando en las potencialidades intrínsecas de nuestra propia muestra por sus particularidades, ya explicitadas a lo largo del desarrollo de esta investigación.

De este modo y tomando como base la composición etaria de la muestra en su contexto histórico local, la distribución de edades individuales alerta sobre un sesgo que incluye a individuos adultos medios y adultos mayores ${ }^{15}$ (Buikstra y Ubelaker 1994) siendo necesario tomar una decisión metodológica para contemplar las particularidades de ambas categorías.

Esta razón conceptual no sólo nos llevó a subagrupar la muestra, sino también a procesar las submuestras con idénticos métodos estadísticos.

Los modelos obtenidos definen que:

1. Para adultos medios las variables predictivas son el número de osteonas completas y la densidad poblacional osteonal. La estimación explica el $84 \%$ de la variación con un error de 1,5 años. De esta manera y para el grupo en cuestión la edad de un individuo es explicada en un 83,7 \% por las variables seleccionadas en el modelo. Por lo tanto el modelo resulta por demás adecuado para ser aplicado a individuo/s de poblaciones no documentadas.

2. Para adultos mayores la variable predictiva sigue siendo el número de osteonas fragmentarias, explicando el $49 \%$ de la variación y con un error de estimación de 8,55 años. De esta manera y para el grupo en cuestión la edad de un individuo es explicada sólo en un 49 \% con 8 años de error en la estimación. Por lo tanto la baja predicción y el alto error del mejor modelo escogido luego del procesamiento del total de las variables histomorfométricas en adultos mayores es probatorio de que existen factores actuantes en el envejecimiento que no pueden ser detectados a partir del análisis histológico óseo. Por lo tanto, y aun siendo la

15 Adulto joven (20-35 años), Adulto medio (35-50 años), Adulto mayor (50+ años) (Buikstra y Ubelaker, 2004). 
mejor aproximación, los resultados obtenidos de la aplicación del modelo en poblaciones no documentadas deben tomarse con cautela.

\section{V.5- A PROPÓSITO DE LA VALIDACIÓN DE OTROS MÉTODOS EN LA COLECCIÓN LAMBRE}

A más de 40 años de la publicación de "The microscopic determination of age in human cortical bone" el método de Kerley (1965) fue testeado, en muestras independientes, y modificado por varios investigadores tratando de subsanar y ajustar algunos inconvenientes detectados, sobre todo aquellos vinculados con la precisión y exactitud.

Así, Bouvier y Ubelaker (1977) compararon el método de Kerley (1965) para fémur con el de Ahlqvist y Damsten (1969), demostrando que la edad estimada a partir del método de Kerley es más exacta (i.e se aproximaba más a la edad real) (Ubelaker 1996). Los autores atribuyeron las diferencias observadas se deben al tamaño muestral y a cuestiones metodológicas (Lazenby 1984). Sin embargo, para Robling y Stout (2008) lo aseverado por Bouvier y Ubelaker es discutible toda vez que los autores solo utilizan la fórmula para osteonas completas y, además, las secciones óseas analizadas pertenecen a la muestra original.

También Stout y Gehlert (1980) compararon la eficacia de los métodos de Kerley y Ubelaker (1978) y de Ahlqvist y Damsten (1969) en una muestra independiente de 13 individuos. Observaron que la fórmula para osteonas completas propuesta por Kerley fue más precisa para individuos menores de 51 años y, en general, las edades medias obtenidas a partir de la ecuación de Kerley y Ubelaker las más fiables.

Asimismo, Bekaert (2004) también comparó la precisión de los métodos de Kerley y Ubelaker (1978) y de Ahlqvist y Damsten (1969) concluyendo que el primero fue más eficaz en la estimación y su aplicación más sencilla. 
Willows (1991) además de aplicar el método de Kerley y Ubelaker (1978), introdujo para la comparación en su muestra independiente, al método de Thompson (1979). También observó que las estimaciones obtenidas a través del método Kerley y Ubelaker nuevamente fueron las más precisas para la muestra agrupada.

A pesar de ser el método de Kerley el más recomendado en cuanto a precisión y exactitud, como lo demuestran estudios previos, incluyendo el de Vasallo et al. (2000) para una muestra procedente del cementerio local de La Plata, en nuestro caso y para la variable número de osteonas fragmentarias no fue fiable en su predicción.

Consideramos que nuestras diferencias en los resultados obtenidos, fundamentalmente respecto a los de Vasallo et al. (op. cit) se deben a cuestiones ya planteadas y discutidas en el acápite 4.2 del presente capítulo y referidas específicamente al tamaño muestral (20 vs 71 respectivamente).

Otra cuestión se deriva de la aplicación del método de Singh y Gunberg (1970) en particular la ecuación basada en el número de osteonas completas y el diámetro promedio de los conductos de Havers. En nuestra muestra tal modelo mostró precisión sólo para los individuos menores de 40 años, siendo ineficaz en otros rangos etarios. No obstante ello, debemos ser cautelosos en afirmaciones, en particular por la sub representación de individuos en ese grupo en particular. Estos resultados concuerdan con los obtenidos por Crowder (2005) el cual observó que el método de Singh y Gunberg fue altamente impreciso (Robling y Stout 2008).

La validación del método de Vasallo et al. (2009), como expresáramos anteriormente, merece un párrafo en particular por tratarse de una investigación basada en una muestra que representa a la misma población (Cementerio Municipal de La Plata). Por lo tanto y aunque nuestra muestra no reúne las condiciones aconsejadas de muestra independiente en sentido estricto (Schmitt 2002), numéricamente es significativamente mayor (20 vs 71) y amerita dicha 
validación. Al aplicar la ecuación propuesta por Vasallo y colaboradores a nuestra muestra, observamos que las estimaciones fueron más eficaces en la muestra subagrupada que en la agrupada, aumentando su precisión en la estimación de la edad cronológica de individuos mayores de 50 años. Por lo tanto consideramos pertinente su uso en ese rango etario. 


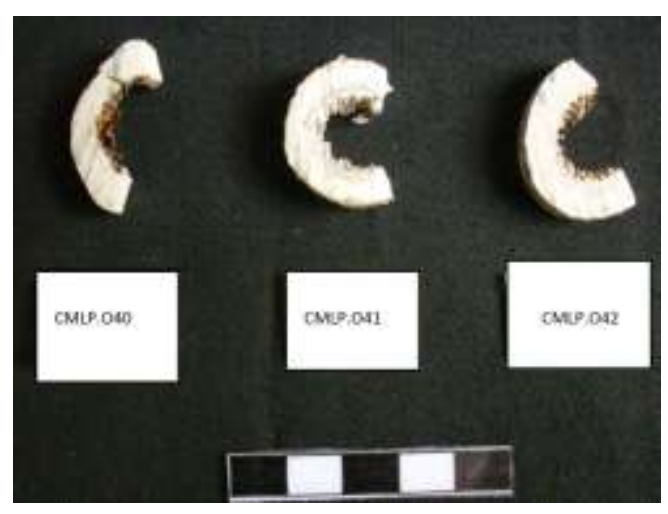

Foto 2. Cortes de fémur

(Mitad anterior de la diáfisis femoral)

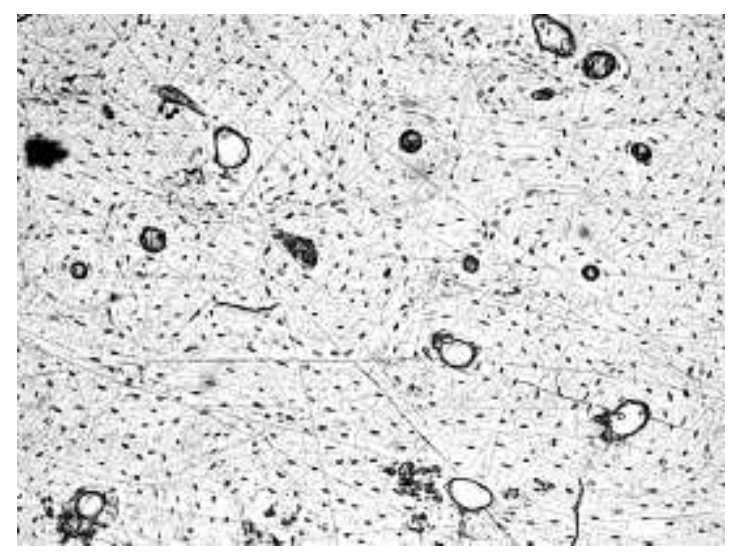

Foto 4. Preparado histológico por desgaste

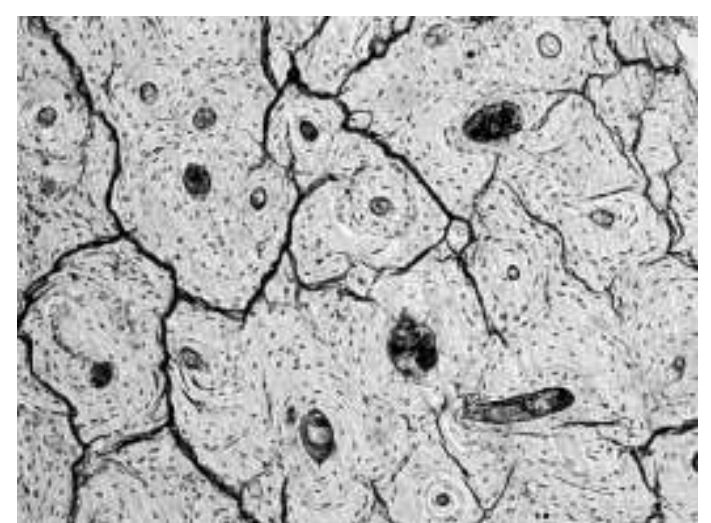

Foto 3. Microfracturas

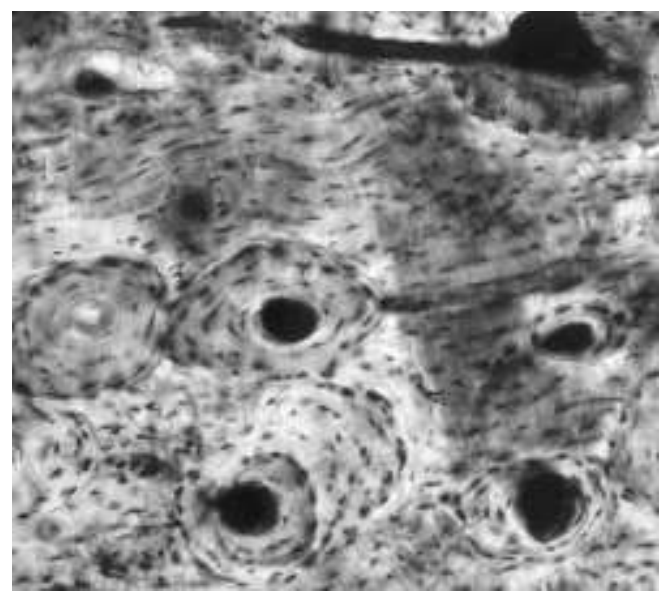

Foto 5. Preparado incluido en resina

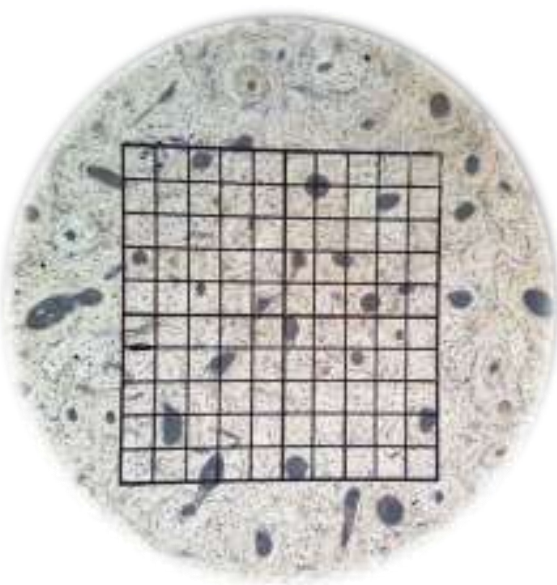

Foto 6. Grilla micrométrica

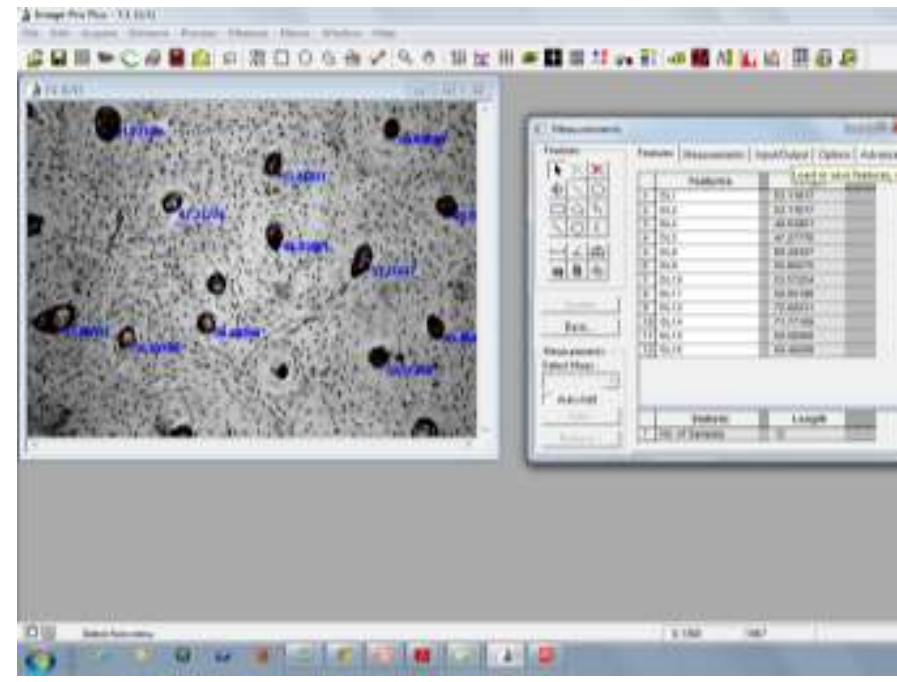

Foto 7. Programa computarizado 
CONSIDERACIONES

FINALES 
En el marco teórico que interpreta a la ontogenia humana como resultado de procesos actuantes durante la filogenia y considerándola sujeta a los mismos mecanismos y leyes que operan durante la evolución de los seres vivos en general, los individuos, y por ende las poblaciones, evidencian rasgos biológicos indicadores de ese proceso.

En particular el sistema esqueletario no está ajeno a esos mecanismos y, tanto a nivel macro como microscópico, es posible aislar en él rasgos que permiten individualizar los distintos períodos o etapas de la ontogenia (i.e crecimiento y desarrollo). Estos testeados y validados en su precisión como indicadores de edad son plausibles, a su vez, de ser aplicados a individuos $y / o$ poblaciones no documentadas.

En este marco consideramos que las modificaciones microestructurales ocurridas durante el proceso de remodelación ósea, permiten inferir la edad biológica en grupos humanos en condiciones de relativa homogeneidad biológica y ambiental.

Así nos propusimos analizar la validez y ajuste de diferentes métodos microscópicos para estimar edad a la muerte en restos óseos humanos adultos documentados a fin de ser aplicados en el campo arqueológico y forense.

En una muestra integrada por individuos adultos pertenecientes a la Colección Lambre y provenientes del Cementerio Municipal de la Plata con datos fehacientes de edad y sexo, se pusieron a prueba, en primer lugar aspectos técnicos para la obtención de los preparados histológicos. Optamos por la técnica de muestreo que minimiza la cantidad de hueso requerida preservando la integridad del fémur y por lo tanto consideramos aconsejable realizar los cortes en el tejido cortical de la porción anterior de la diáfisis femoral, siendo la inclusión en resina epoxi el procedimiento más efectivo a la hora de obtener secciones delgadas de buena calidad.

Asimismo la aplicación de métodos semiautomáticos y el uso de microfotografías mejoró notablemente el muestreo sistemático, y 
consecuentemente la cuantificación fiable de las cinco variables histomorfológicas seleccionadas de la bibliografía específica por su valor diagnóstico.

Los tres algoritmos predictivos propuestos por nosotros son aplicables diferencialmente según los rangos de edad, estando sujetos a una aproximación etaria preliminar en el individuo y/o grupo de individuos de una población no documentada.

Los análisis estadísticos inferenciales multivariados nos permiten aseverar que:

1) para adultos de 22 a 91 años la variable predictiva es el número de osteonas fragmentarias;

2) para adultos medios (menores de 49 años) las variables predictivas son el número de osteonas completas y la densidad poblacional osteonal;

3) para adultos mayores (más de 50 años) la variable predictiva es el número de osteonas fragmentarias.

Finalmente, reiteramos que la histomorfometría o histología cuantitativa (Robling y Stout 2008), ofrece estimaciones precisas y efectivas para adultos mayores de 50 años (Crowder 2005), en contraste con la mayoría de los métodos basados en la morfología macroscópica del esqueleto en donde el límite de las estimaciones es, precisamente, los 50 años de edad cronológica (Ubelaker 1996, Franklin 2010). La histomorfometría cobra mayor importancia en aquellos casos en los cuales los restos se encuentran fragmentados o incompletos, y resulta imposible la aplicación de métodos macroscópicos para la estimación de edad (Bednarek 2008, Franklin 2010).

Si bien la utilización de las técnicas histológicas de estimación de edad han presentado cierta incertidumbre respecto de su exactitud y fiabilidad, concordamos con Stout y Crowder (2012) que la identificación de cuestiones metodológicas específicas así como la mejora de los protocolos, harán de la histomorfometría una herramienta útil para el análisis bioantropológico y forense. 


\section{Perspectivas futuras}

- Ampliar la muestra adulta de la Colección Lambre, equilibrando sexos e incrementando el número de individuos en el rango etario adulto medio a fin de explorar dimorfismo sexual en la expresión de las variables histomorfológicas.

- Testear las tres ecuaciones propuestas en una muestra independiente documentada a fin de evaluar el grado de precisión y aplicabilidad, especialmente por ser el forense uno de los campos de aplicación.

- Analizar otros factores que influyen en la dinámica de la remodelación ósea (sexo, actividad física, patologías, entre otros) y consecuentemente en la estimación de edad.

- Examinar las implicancias de la aparente diferencia sexual en las relaciones de fragmentos osteonales durante el envejecimiento. 


\section{BIBLIOGRAFÍA CITADA}

Ahlqvist J, Damsten O.

1969. A modification o Kerley's method for the microscopic determination of age in human bone. J Forensic Sci. 14:205-212.

Alfonso M, Powell J.

2005. Ethics of flesh and bone, or ethics in the practice of paleopathology, osteology, and bioarchaeology. En: Biological anthropology and ethics from repatriation to genetic identity. Turner T. (Ed.) State University of New York Press.

An YH, Martin KM.

2003. Handbook of histology methods for bone and cartilage. Humana Press Inc. Totowa, New Jersey.

Antón S.

2005. Commentary: A Discussion of Ethical Issues in Skeletal Biology. En: Biological anthropology and ethics from repatriation to genetic identity. Turner T. (Ed.). State University of New York Press.

Aranda C, Del Papa M.

2009. Avances en las prácticas de conservación y manejo de restos humanos en Argentina. Rev Arg Antrop Biol. 11(1):89-93.

Baccino E, Schmitt A.

2006. Determination of adult age at death in the forensic context. En: Schmitt A, Cunha E, Pinheiro J. (Eds.) Forensic Anthropology and Medicine, Humana Press, New York.

Bednarek J.

2008. Methods of age at death estimation based on compact bone histomorphometry. Arch Med Sad Krym. 58 (4): 197-204.

Beherensmeyer A.

1978. Taphonomic and ecological information from bone weathering. Paleobiology 4: 150-162.

Bekaert B.

2004. Comparison of Two Histomorphometric Methods to Determine Age at Death. B.Sci. Dissertation, University of Central Lancashire, Preston, UK. En Katzenberg MA, Saunders SR (Eds.) 2008. Biological anthropology of the human skeleton. Cap. V: 149-182. New York: Willey Liss. Inc. 
Bernis C.

2004. Envejecimiento, poblaciones envejecidas y personas ancianas. Antropo. 6: 1-14

Bogin B.

1999. Patterns of human growth. 2da. Ed. Cambridge University Press.

Bosio LA, García Guraieb S, Luna L, Aranda CM.

2009. Proyecto Chacarita: conformación y estudio de una osteoteca de referencia para la ciudad de Buenos Aires. Libro de resúmenes de las IX Jornadas Nacionales de Antropología Biológica. Asociación de Antropología Biológica de la Republica Argentina. Pág. 65.

Bouvier M, Ubelaker DH.

1977. A comparison of two methods for the microscopic determination of age at death. Am J Phys Anthropol. 46 (3):391-394

Brickley $\mathrm{M}$, Ives R.

2008. The bioarchaeology of metabolic bone disease. 1ra. Edición. Academic Press Elsevier.

Brothwell DR.

1987. Desenterrando huesos. La excavación, tratamiento y estudio de restos del esqueleto humano. Fondo de Cultura Económica. México D.F.

Brooks ST, Suchey JM.

1990. Skeletal age determination besed on the os pubis: A comparison of Acsádi-Nemeskéri and Suchey-Brooks methods. J Hum Evol. 5: 227-238.

Bruce RM, Burr BN, Sharkey NA.

1998. Skeletal Tissue Mechanics. New York: Springer- Verlag.

Buckberry JL, Chamberlain AT.

2002. Age estimation from the auricular surface of the ilium: a revised method. Am J Phys Anthropol. 119 (3): 231- 239.

Budowle B, Bottrell MC, Bunch SG, Fram R, Harrison D, Meagher S, Oien CT, Peterson PE, Seiger DP, Smith MB, Smrz MA, Soltis GL, Stacey RB.

2009. A perspective on errors, bias, and interpretation in the forensic sciences and direction for continuing advancement. J Forensic Sci. 54 (4): 798-809. 
Buikstra JE, Ubelaker DH.

1994. Standards for Data Collection from Human Skeletal Remains. Arkansas Archeological Survey Research Serie № 44.

Caffell A, Roberts C, Janaway R, Wilson A.

2001. Pressures on osteological collections-the importance of damage limitation. En: Williams E, ed. Conservation, Retrieval and Analysis. British Archaeological Reports, International Series No. 934. Oxford: Archaeopress. pp. 187-197.

Cano -Sánchez J, Campo-Trapero J, Gonzalo Lafuente JC, Moreno López LA, Bascones-Martínez A.

2005. Muestras de hueso sin descalcificar: descripción de técnicas y utilidad basada en la literatura. Med Oral Patol Oral Cir Bucal. 10: 74-87.

Cardoso $\mathrm{H}$.

2006. The collection of identified human skeletons housed at the Bocage Museum (National Museum of Natural History), Lisbon, Portugal. Am J Phys Anthropol. 129 (2):173-176.

Cattaneo C.

2007. Forensic anthropology: developments of a classical discipline in the new millenum. Forensic Sci Int. 165: 185-193.

Cera F, Drusini A.

1985. Analisi critica e sperimentale dei metodi di determinazione dell'eta attraverso le microstructure ossee. Quederni di Anatomia Pratica 41:105-121.

Chiquichano F, Sayhueque C, Dahinten S.

2008. El rescate y relocalización del chenque de Sacanana (Meseta centronorte de la provincia de Chubut, Argentina). Actas de resúmenes del $\mathrm{X}$ Congreso Latinoamericano de Antropología Biológica. La Plata. Formato CDROM.

Christensen AM, Crowder CC. 2009. Evidentiary standards for forensic anthropology. J Forensic Sci. 54 (6): 1211-1216.

Cho H, Stout SD, Madsen RW, and Streeter MA.

2002. Population-specific histological age-estimating method: A model for known African-American and European-American skeletal remains. J Forensic Sci. 47: 12-18. 
Cho H, Stout SD.

2003. Bone remodeling and age-associated bone loss in the past: a histomorphometric analysis of the imperial Roman skeletal populations of Isola Sacra. En Bone loss and osteoporosis: an anthropological perspective. (Eds.) Agarwal SC, Stout SD. Kluwer Academic/Plenum Publishers, New York.

\section{Compston J.}

1998. Bone histomorphometry. En Methods in bone biology. (Eds.) Arnett TR, Henderson B. London, England: Chapman \& Hall. Pp. 177-99

Corsini MM, Schmitt A, Bruzek J.

2005. Aging process variability on the human skeleton artificial network as an appropriate tool for age at death assessment. Forensic Sci Int. 148: 163-167.

Crowder MC.

2005. Evaluating the Use of Quantitative Bone Histology to Estimate Adult Age at Death. Ph.D. Dissertation, University of Toronto, Canada. En Crowder C, Stout S. (Eds.) Bone Histology. An anthropological perspective. CRC Press. Boca Raton. Florida.

Cunha E, Baccino E, Martrille L, Ramsthaler F, Prieto J, Schuliar Y, Lynnerup N, Cattaneo C.

2009. The problem of aging human remains and living individuals: a review. Forensic Sci Int. 193: 1-13.

\section{Currey JD.}

1964. Some effects of ageing in human Haversian systems. J Anat. 98 (1): 6975.

Dayal MR, Kegley DT, Strkay G, Bidmos MA, Kuykendall KL. 2009. The history and composition of the Raymond A. Dart collection of human skeletons at the Witwatersrand, Johannesburg, South Africa. Am J Phys Anthropol. 140 (2): 324-335.

Desántolo, B.

2007. Validación metodológica para la estimación de edad y sexo en restos óseos humanos adultos. Actas del Segundo Encuentro de Becarios de la Universidad Nacional de La Plata. Publicación electrónica.

Desántolo B, García Mancuso R, Plischuk M.

2009. Hacia la búsqueda de estándares osteológicos regionales: poblaciones documentadas versus poblaciones no documentadas. En Bourlot T, Bozzuto D, Crespo C, Hecht AC, Kuperszmit (Eds.) Entre pasado y presente II. Estudios 
contemporáneos en ciencias antropológicas. Buenos Aires: Fundación de Historia Natural Félix de Azara. pp.: 199-206.

Drusini A.

1987. Refinements of two methods for histomorphometric determination of age in human bone. Z Morphol Anthropol. 77: 167-176.

Eliopoulos C, Lagia A, Manolis S.

2007. A modern, documented human skeletal collection from Greece. HOMO 58: 221-228.

Enlow DH.

1982. Handbook of facial growth. 2da. ed. W.B. Saunders Company, Philadelphia.

Ericksen MF.

1991. Histologic estimation of age at death using the anterior cortex of the femur. Am J Phys Anthropol. 84: 171-179.

Ericksen MF.

1997. Comparison of two methods of estimating age at death in a Chilean Preceramic population. Int J Osteoarch. 7: 65-70.

Eynard AR, Valentich MA, Rovasio RA.

2008. Histología y embriología del ser humano. 4ạ ed. Buenos Aires: Médica Panamericana.

Fagan, B.

2007. Foreword. En: Human Remains: A guide for Museum and Academic institutions. AltaMira Press.

Franklin D.

2010. Forensic age estimation in human skeletal remains: current concepts and future directions. Legal Medicine 12: 1-7.

Fangwu Z.

1983. Preliminary study on determination of bone age by microscopic method. Acta Anthropol Sinica 2: 142-151.

Fazekas IG, Kosa F.

1978. Forensic Fetal Osteology. Budapest: Akadémiai Kiadó.

Feik SA, Thomas CDL, Clement JG.

1996. Age trends in remodeling of the femoral midshaft differ between the 
sexes. J Orthop Res. 14: 590-597.

Feik SA, Thomas CDL, Bruns B, Clement JG.

2000. Regional variations in cortical modeling in the femoral mid-shaft: sex and age differences. Am J Phys Anthropol. 112: 191-205.

Ferembach DI, Schwidetzky I, Stloukal M.

1980. Recommendations for age and sex diagnoses of skeletons. Workshop of European Anthropologists. J Hum Evol. 9: 517-549

Ferrante L, Cameriere R.

2009. Statistical methods to assess the reliability of measurements in the procedures for forensic age estimations. Int J legal Med. 123: 277-283

Frost HM.

1958. Preparation of thin, undecalcified bone sections by a rapid manual methods. Stain technol 33: 272-276. En Stout SD. (1989) Histomorphometric analysis of human skeletal remains. En Işcan MY y Kennedy KR (Eds.) Reconstruction of life from the Skeleton. New York: Alan R. Liss, Inc. pp 41-52.

Frost HM.

1985. The "New Bone": some anthropological potentials. Year Am J Phys Anthropol. 28 (S6):211-226.

Frost HM.

1987. Secondary osteon population densities: an algorithm for estimating the missing osteons. Am J Phys Anthropol. 30 (58): 239-254.

García Mancuso R.

2008. Preservación de restos óseos humanos. Análisis de una muestra fetal contemporánea. Zaranda Ideas. 4:43-54.

Gartner LP, Hiatt JL.

2001. Texto Atlas de Histología. 2da. Ed. Mc Graw-Hill Interamericana. México.

González PN.

2008. Morfometría geométrica aplicada al análisis del dimorfismo sexual en restos óseos humanos de individuos adultos y subadultos. Tesis Doctoral. Facultad de Ciencias Naturales y Museo. Universidad Nacional de La Plata. 
Hall BK.

2005. Bones and Cartilage: Developmental and Evolutionary Skeletal Biology. Elsevier Academic Press. USA.

Han S, Kim S, Ahn Y, Huh G, Kwak D, Park D, Lee U, Kim Y.

2009. Microscopic age estimation from the anterior cortex of the femur in Korean adults. J Forensic Sci. 54(3):519-522.

Hauser R, Barres D, Durigon M, Derobert L.

1980. Identification par I'histomorphometrie du femur et du tibia. Acta Medicinae Legalis et Socialis 30:91-97.

Hennig C, Cooper D.

2011. Brief communication: the relation between standard error of the estimate and sample size of histomorphometric aging methods. Am J Phys Anthropol. 16: 658-664.

Hilson S.

2005. Dental Anthropology. Cambridge: Cambridge University

Hoyme, St. L. y M. Iscan

1989. Determination of sex and race: accuracy and assumptions. En: Reconstruction of life from the skeleton. Iscan M, Kennedy K. (comp.). pp. 5393. New York, Alan R. Liss.

Huda, T. y J. Bowman

1995. Age determination from dental microstructure in juveniles. Am J Phys Anthropol. 97:135-50.

Hunt DR, Albanese JA.

2005. History and demographic composition of the Robert J. Terry Anatomical Collection. Am J Phys Anthropol. 127 (4):406-417.

Iwamoto S, Oonuki E, Konishi M.

1978. Study on the age-related changes of the compact bone and the age estimation: On the humerus. Acta Medica Kinki Univ. 3: 203-208. 
Iwamoto S, Konishi M.

1982. Study on the age-related changes of the compact bone and the age estimation: determination of the age limitation. Med J Kinki Uni. 7 (1):33-40.

Jans MM, Kars $\mathrm{H}$.

2002. In situ preservation of archaeological Bone: a histological study within a multidisciplinary approach. Archaeometry 44 (3): 343-352.

Jowsey J.

1960. Age changes in human bone. Clin Orthop Relat Res. 14: 590- 597.

Katzenberg MA, Saunders SR.

2008. Biological anthropology of the human skeleton. New York: Willey Liss. Inc.

Kemkes-Grottenthaler A.

2002. Aging through the ages: historical perspectives on age indicators methods. En Hoppa RD y Vaupel JW. (Eds.). Paleodemography: Age distributions from skeletal sample. Cambridge University Press. Pp. 48-72.

Kerley ER.

1965. The microscopic determination of age in human bone. Am J Phys Anthropol. 23 (2):149-164.

Kerley ER, Ubelaker DH.

1978. Revisions in the microscopic method of estimating age at death in human cortical bone. Am J Phys Anthropol. 49 (4): 545-546.

Keough N.

2007. Estimation of age at death from the microscopic structure of the femur. Thesis the degree of Master of Science in Anatomy. School of Medicine, Faculty of Health Sciences, University of Pretoria, South Africa.

Keough N, L' Abbé EN, Steyn M.

2009. The evaluation of age-related histomorphometric variables in cadaver sample of lower socioeconomic status: implications for estimating age at death. Forensic Sci Int. 191:114-119. 


\section{Krenzer U.}

2006. Compendio de métodos antropológico forenses para la reconstrucción del perfil osteo-biológico. Colombia: Centro de análisis forenses y ciencias aplicadas (CAFCA).

Kosa F.

1989. Age estimation from the fetal skeleton. En Iscan MY. (Ed.). Age markers in the human skeleton. Springfield, Illinois: CC. Thomas, Pub. pp 21-54.

Krogman WE, Işcan MY.

1986. The human skeleton in forensic medicine. Springfield: Charles C. Thomas.

Larsen, C. y P. Walker

2005. The ethics of bioarchaeology. En: Biological anthropology and ethics from repatriation to genetic identity. Turner T. (Ed.). State University of New York press.

L'Abbé EN, Loots M, Meiring JH.

2005. The Pretorian bone collection: A modern South African skeletal sample. HOMO 56: 197-205.

Lazenby RA.

1984. Inherent deficiencies in cortical bone microstructural age estimation techniques. Ossa 9 (11): 95-103.

Lemp Urzúa C, Rodríguez Balboa M, Retamal Yermani R, Aspillaga Lafontaine E. 2008. Arqueología del depósito: manejo integral de las colecciones bioantropológicas en el departamento de Antropología de la Universidad de Chile. Conserva 12:69-96.

Lovejoy CO.

1985. Dental wear in the Libben population: Its functional pattern and role in the determination of adult skeletal age at death. Am J Phys Anthropol. 68: 4756

Lovejoy CO, Meindl RS, Pryzbeck TR, Mensforth RP.

1985. Chronological metamorphosis of the auricular surface of the ilium: A New method for the determination of adult skeletal age at death. Am J Phys Anthropol. 68 (1): 15-28. 
Lynnerup N; B. Frohlich y J. Thomsen.

2006. Assesment of age at death by microscopy: Unbiased quantification of secondary osteons in femoral cross section. Forensic Sci Int. 159: 100-103.

Madeline LA, Elster AD.

1995. Suture closure in the human chondrocranium: CT assessment. Radiology 196 (3): 747-756.

Mandalunis PM.

2006. Remodelación Ósea. Actualiz Osteología 2 (1): 16-18.

Maat GJ, Van den Bos R, Aarents MJ.

2001. Manual preparation of ground sections for the microscopy of natural bone tissue: Update and modification of Frost's "Rapad manual method". Int J Osteoarchaeol. 11: 366-374.

Maat GJ, Maes A, Aarents M, Nagelkerke JD.

2006. Histological age prediction from the femur in a contemporary Dutch sample. The decrease of nonremodeled bone in the anterior cortex. J Forensic Sci. 51 (2): 230-237.

Mays S, Cox M.

2000. Sex determination in the skeletal remains. En: Cox M, Mays S. (Eds) Human osteology in archaeology and forensic sciences: 37 (4): 1068-1075.

Meindl, RS y Lovejoy CO.

1985. Ectocranial Suture Closure: A revised method for the determination of skeletal age at death based on the lateral-anterior sutures. Am J Phys Anthropol. 68 : 57-66.

Meindl RS, Lovejoy CO.

1989. Age changes in the pelvis: Implications for palaeodemography. En: Age Markers in the Human Skeleton, MY Iscan (Ed.) C.C. Thomas, Springfield, III., pp. 137-168.

Meindl RS, Russell KF.

1998. Recent advances in method and theory in paleodemography. Annu Rev Anthropo.l 27:375-399. 
Mulhern DM, Ubelaker DH.

2012. Differentiating human from non human bone microstructure. En Bone Histology: An anthropological perspective. Crowder C., Stout S. (Eds). CRC Press.

Muñoz, C. y J. Gómez Otero

2008. Rescate del enterratorio múltiple de Loma Torta en Gaiman (Provincia de Chubut). Actas de resúmenes del $X$ Congreso Latinoamericano de Antropología Biológica. La Plata. Formato CD-ROM.

Nor FM, Pastor RF, Schutkowski H.

2006. Population specific equation for estimation of age: a model for known Malaysian population skeletal remains. Mal J For Path Sci. 1(1): 15-28.

Ongkana N, Sudwan P.

2009. Gender difference in the Thai mandibles using metric analysis. Chiang Mai Med. J. 48 (2): 43-48.

Ordenanza Municipal 7638/90.

Municipalidad de La Plata. Diciembre de 1990. http://www.concejodeliberante.laplata.gov.ar/digesto.html

Ordenanza Municipal 9471/02.

Municipalidad de La Plata. Octubre de 2002.

http://www.concejodeliberante.laplata.gov.ar/digesto.html

Ortner D.

2003. Identification of pathological conditions in human skeletal remains. Nueva York, Academic Press.

Osborne DL, Simmons TL, Nawrocki SP.

2004. Reconsidering the auricular surface as an indicator of age at death. $J$ Forensic Sci. 49: 905-911.

Paine RR.

2007. How to equip a basic histological lab for the anthropological assessment of human bone and teeth. J Anthropol Sci. 85: 213-219 
Pan F, Verri S.

2002. Histomorfometría aplicada a restos óseos humanos arqueológicos: técnicas de desgaste vs. Meteorización. Ciencias Morfológicas 6 (9):3-16

Paredes C, Hagn J, Constantinescu F.

1997. Estimación de edad en la población chilena actual. Excerpta $N^{\circ} 9$. Facultad de Ciencias Sociales, Universidad de Chile, Chile.

Parfitt AM.

1979. Quantum concept of bone remodeling and turnover: implications for the pathogenesis of osteoporosis. Calcif Tissue Int 28: 1-5.

Parffit AM, Drezner MK, Glorieux H, Kanis JA, Malluche H, Meunier PJ, Ott SM, Recker RR.

1987. Bone Histomorphometry: Standardization of nomenclature, symbols and units. Report of ASBMR histomorphometry nomenclature committee. $J$ Bone Miner Res. 2 (6): 595-610.

\section{Parfitt A.M.}

2002. Targeted and nontargeted bone remodeling: relationship to basic multicellular unit origination and progression. Bone 1:5-7

\section{Pfeiffer S.}

1992. Cortical bone age estimates from historically known adults. Z Morphol Anthropol. 79: 1-10.

Pfeiffer S, Lazenby R, Chiang J.

1995. Brief communication: cortical remodeling data are affected by sampling location. Am J Phys Anthropol. 96: 89-92.

Plischuk M, Desántolo B, García Mancuso R, Salceda S, Costi D, García M, Laguens M, Paggi R, Maliandi N, Prat G, Errecalde A, Inda A.

2007. Age comparision between Prof. Dr. Rómulo Lambre Collection and the death data of Argentina. Revista de la Sociedad de Ciencias Morfológicas de La Plata 9:60

Plischuk M.

2012. Detección y diagnóstico de patologías en restos óseos humanos: aproximación epidemiológica a una muestra documentada. Tesis Doctoral. Facultad de Ciencias Naturales y Museo. Universidad Nacional de La Plata. 


\section{Prieto Carrero JL.}

1993. Parámetros histomorfometricos óseos normales en una población infanto juvenil española. Tesis Doctoral. Facultad de Medicina. Universidad Complutense de Madrid.

Purkait R.

2003. Sex determination from femoral head measurements: a new approach. Legal Medicine 5: 347-350.

Reichs KJ.

1998. Forensic Osteology: Advance in the identification of human remains. Reichs KJ. (Ed.). United States: Charles Thomas, Publisher Ltd.

Restelli MA, Batista SL, Vasallo ML, Maliandi NE, Méndez MG, Salceda SA.

1997. Aportes de las técnicas micro y ultraestructurales sobre restos esqueletarios a la bioantropología. Actas de las II Jornadas Chivilcoyanas en Ciencias Sociales y Naturales de Chivilcoy. pp 123-128.

Riancho JA, Gutierrez GE.

2003. Factores Reguladores de la Resorción Ósea. Rev Metab Óseo Min. 1 (2): 51-66.

Ríos Frutos L.

2003. Brief communication: Sex determination accuracy of the minimum supero-inferior femoral neck diameter in a contemporary rural Guatemalan population. Am J Phys Anthropol. 122 (2): 123-126

Robling AG, Stout SD.

2008. Histomorphometry of human cortical bone: applications to age estimation. En Katzenberg MA y Saunders SR (Eds.). Biological anthropology of the human Skeleton. pp 149-182. New York: Willey Liss. Inc.

Rodríguez Cuenca JV.

1994. Introducción a la antropología forense, análisis e identificación de restos óseos humanos. Departamento de Antropología. Universidad Nacional de Colombia. Bogotá. 
Rojas Alfonso C, Quintero Pardo K.

2011. Condiciones de vida y salud en la Bogotá Republicana. Caracterización paleopatológica de una muestra ósea del Cementerio Central de Bogotá. En Libro de resúmenes de la IV Reunión de la Asociación de Paleopatología en Sudamérica (PAMInSA). Pp. 63.

Ross $\mathrm{MH}$, Pawlina W.

2007. Histología. Buenos Aires: Editorial Médica Panamericana.

Salceda S, Calandra H, De Feo C, Desántolo B, Balbarrey G, Lamenza G, Ramallo V, Silva D, Zapiola L.

2009b. Arqueología pública de pueblos originarios. Atlas de resúmenes de $\mathrm{V}$ Congreso de Antropología Forense. Buenos Aires, Argentina.

Salceda S, Desántolo B, García Mancuso R, Plischuk M, Prat G, Inda AM. 2009. Integración y conservación de la colección osteológica "Profesor Doctor Rómulo Lambre": avances y problemáticas. Revista Argentina de Antropología Biológica 11 (1): 133-141.

Samson C, Branigan K.

1987. A new method of estimating age at death from fragmentary and weathered bone. In: Boddington A, Garland AN, Janaway RC (Eds.) Death Decay and Reconstruction Approaches to Archaeology and Forensic Science. Manchester: Manchester University Press. pp. 101-108. En Katzenberg MA, Saunders SR. (Eds.) 2008. Biological anthropology of the human skeleton. Cap. V. pp. 149-182. New York: Willey Liss. Inc.

Santo M, Lecumberry G.

2005. El proceso de medición: análisis y comunicación de datos experimentales. 1ra. Edición. Río Cuarto: Universidad Nacional de Río Cuarto.

Schaeffer M, Black S, Scheuer L.

2009. Juvenile osteology. A laboratory and field manual. Nueva York: Academic Press.

Scheuer L, Black S.

2000. Developmental Juvenile Osteology. New York: Academic Press. 
Scheuer L.

2002. Application of osteology to forensic medicine. Clinical Anatomy 15: 297312.

Schmeling A, Geserick G, Reinsinger W, Olze A.

2007. Age estimation. F Science Int. 165 (2-3): 178-18.

Schmitt A.

2002. Estimation de l'âge au décès des sujets adultes à partir du squelette : des raisons d'espérer. Age-at-death assessment of adult skeletons: reasons for hope. Bull Mem Soc Anthropol París. 14:51-73.

Schmitt A, Murail P, Cunha E, Rongé E.

2002. Variability of the pattern of aging on the human skeleton: evidence from bone indicators and implications age at death estimation. J Forensic Sci. 47 (6): 1203-1209.

Schulz R, Muhler M, Mutze S, Schmidt S, Reisinger W, Schmeling A.

2005. Studies on the time frame for ossification of the medial epiphysis of the clavicle as revealed by CT scans. Int J Legal Med. 119 (3): 142-145.

Sempé MC, Flores OB.

2011. El cementerio de La Plata y su contexto sociohistorico. 1ra. Edición. Sempé MC. y Flores OB. (Comp.) Municipalidad de La Plata.

Singh IJ, Gunberg DL.

1970. Estimation of age at death in the human males from quantitative histology of bone fragment. Am J Phys Anthropol. 33 (3):373-392.

Stout SD.

1988. The use histomorphology to estimate age. J Forensic Sci. 33 (1): 121125.

Stout SD.

1989. Histomorphometric analysis of human skeletal remains. En Işcan MY y Kennedy KR (Eds.) Reconstruction of life from the Skeleton. New York: Alan R. Liss, Inc. pp 41-52. 
Stout SD.

1998. The application of histological techniques for age determination. En Katzenberg MA y Saunders SR (Eds). Biological anthropology of the human skeleton. New York: Willey Liss. Inc.

Stout SD, Crowder C.

2012. Bone remodeling, histomorphology and histomorphometry. En Crowder C, Stout S. (Eds.) Bone Histology: An Anthropological Perspective.CRC Press.

Stout SD, Gehlert SJ.

1980. The relative accuracy and reliability of histological aging method. Forensic Sci Int. 15: 181- 190.

Stout SD, Paine RR.

1992. Brief communication: histological age estimation using rib and clavicle. Am J Phys Anthropol. 87 (1): 111-115.

Stout SD, Porro MA, Perotti B.

1996. Brief Communication: A Test and Correction of the Clavicle Method of Stout and Paine for Histological Age Estimation of Skeletal Remains. Am J Phys Anthropol 100(1):139-142.

Takahashi H, Frost H.M.

1966. Age and sex related changes in the amount of cortex of normal human ribs. Acta Orthop Scand. 37 (2): 122-30.

Todd TW.

1920. Age changes in the pubic bone: I. The male white pubis. Am J Phys Anthropol. (3): 285-334.

Thompson DD.

1979. The core technique in the determination of age at death of skeletons. $J$ Forensic Sci. 24: 902-915.

Thompson DD.

1981. Microscopic determination of age at death in an autopsy series. $J$ Forensic Sci. 36: 470-475. 


\section{Turner T.}

2005. Introduction: Ethical concerns in biological anthropology. En: Biological anthropology and ethics from repatriation to genetic identity. State University of New York Press.

Ubelaker DH.

1978. Human skeletal remains. Excavation, analysis, interpretation. Chicago: Aldine Publishing Company.

Ubelaker DH.

1986. Estimation of age at death from histology of human bone. En Zimmerman MR, Angel JL (Eds.) Dating and determination of biological materials. Pp. 240-247.

Ubelaker $\mathrm{DH}$.

2000. Methodological Considerations in the Forensic Applications of Human Skeletal Biology. 41-67. En Katzenberg MA, Saunders SR (Eds.) Biological Anthropology of human skeletal. Wuilley-liss, Inc.

Ubelaker DH.

2005. Estimating age at death. En Rich J, Dean DE, Power RH (Eds.). Forensic medicine of the lower extremity: Human identification and trauma analysis of the thigh leg and foot. Human Press Inc.

Ubelaker $\mathrm{DH}$.

2008. Forensic Anthropology: methodology and diversity of applications. En Katzenberg MA y Saunders SR. (Eds.). Biological anthropology of the human skeleton. (2 da. Edición). New York: Willey Liss. Inc. pp. 41-69.

Usher BM.

2002. Reference sample: the first step in linking biology and age in the human skeleton. En Hoppa RD y Vaupel JW. Paleodemography: age distributions from skeletal samples. Cambridge University Press. pp. 29-47.

Vasallo ML, Restelli MA.

2000. Técnica por desgaste de tejidos duros para estudios histomorfométricos. Libro de Resúmenes. IV Congreso de la Sociedad morfológica de La Plata. pp.33 
Vasallo ML; Restelli MA, Salceda SA, Méndez MG, Paggi R, Maliandi N, Batista S, Bruno $M$.

2000. Nueva variable para la determinación de la edad a la muerte por histomorfometría. Libro de Resúmenes del IV Congreso de la Sociedad de Ciencias Morfológicas de la Plata. pp.12.

Vasallo ML, Flores OB, Pan MF.

2001. Estimación de edad en huesos largos humanos mediante análisis escópico e histomorfométrico. Ciencias Morfológicas 5 (8).

Verano J, Ubelaker DH.

1992. Disease and demography in the Americas. Washington DC: Smithsonian Institution Press.

Villa Monroy HN.

2010. Los códigos de ética, una reflexión para el quehacer antropológico en México. Tesis de Maestría. Escuela Nacional de Antropología e Historia. INAH.

Walker RA.

1992. Human variation, cortical bone histology, and determination of skeletal age at death. Am J Phys Anthropol Suppl. 14: 169 (Abstract).

Walker RA, Lovejoy CO, Meindl R.

1994. Histomorphological and geometric: properties of human femoral cortex in individuals over 50: implications for histomorphological determination of age-at-death. Am J Hum Biol. 6:659-667.

Watanabe $\mathrm{Y}$, Konishi M, Shimada M, Ohara H, Iwamoto S.

1998. Estimation of age from the femur of Japanese cadavers. Forensic Sci Int. 98: 55-65.

Welsch U.

2008. Histología/Sobotta. Buenos Aires: Editorial Médica Panamericana.

White TD, Folkens PA.

2005. The Human bone manual. Unite Estate: Elsevier Academic Press. 


\section{Willows ND.}

1991. A comparison of two methods for estimating age at death from bone microstructure. M.A. Thesis, University of Calgary, Alberta, Canada. En Katzenberg MA, Saunders SR (Eds.) 2008. Biological anthropology of the human skeleton. Pp. 149-182. New York: Willey Liss. Inc.

Yoder C, Ubelaker DH, Powell JF.

2001. Examination of variation in sternal rib end morphology relevant to age assessment. J Forensic Sci. 46: 223-227.

Yoshino M, Kazuhiko I, Sachio M, Sueshige S.

1994. Histological estimation of age at death using microradiographs of humeral compact bone. Forensic Sci Int. 64 (2-3): 191-198.

Zavando Matamala DA, Suazo Galdames IC, Smith RL.

2009. Sexual dimorphism determination from the lineal dimensions of Skulls. Int J Morphol. 27 (1): 133-137. 
APENDICES 
Expte. 8209

La Plata, 27 de diciembre de 1990

El concejo Deliberante en su Sesión Ordinaria № 34, celebrada en el día de la fecha, ha sancionado con votación nominal lo siguiente:

\section{ORDENANZA 7638}

\section{I) PRINCIPIOS GENERALES}

ARTíCULO 10: Las tierras que constituyen el Cementerio de la ciudad de La Plata pertenecen al dominio público municipal. En consecuencia los particulares no pueden invocar sobre las sepulturas, otros derechos que los que derivan del acto administrativo que se las otorgó sin que en ningún caso tales actos administrativos puedan importar enajenación.

La Municipalidad ejercerá plenamente el poder de Policía Mortuoria, no sólo dentro del perímetro del Cementerio, sino también respecto de todas aquellas actividades, operaciones 0 servicios que se vinculen de manera directa o indirecta con el Cementerio y el traslado, custodia, conservación y cremación de cadáveres.

ARTícULO 20: Los cementerios serán públicos o privados autorizados por el Departamento Deliberativo de conformidad con las prescripciones del Artículo 28ㅇ inciso 5o de la Ley Orgánica de las Municipalidades. Queda prohibida la cremación de enterratorios particulares.

El traslado de ataúdes con cadáveres a Crematorio u otro Cementerio podrá ser efectuado por Empresas Fúnebres, Crematorios y/o Empresas de traslado radicadas en La Plata y/o Municipios de la provincia de Buenos Aires, las Empresas radicadas en La Plata que deberán cumplimentar los siguientes requisitos:

2.1- Estar autorizada por el Departamento Ejecutivo en concordancia con las normas legales vigentes.

a. Documentación que deben presentar las Empresas encargadas del traslado:

a.1) Autorización Municipal, habilitación de la Empresa Fúnebre, Crematorio y/o empresas de traslado.

a.2) Orden aclaratoria de recepción del Cementerio y/o crematorio con las firmas aclaratorias de los responsables.

a.3) Certificado de defunción o copia autenticado por Escribano Público o Juez de Paz. 
a.4) En los vehículos deberá constar la identificación municipal o de la empresa, crematorio y/o empresa de traslado, dirección y teléfono.

2.2- Los servicios de traslado estarán a cargo de las personas físicas y/o empresas fúnebres que cuenten con la debida autorización otorgada por autoridad competente.

2.3- A los fines de dar cumplimiento con lo dispuesto en la presente Ordenanza las Empresas fúnebres, crematorio o empresa de traslado deberá contar con un furgón con caja cerrada el que no podrá trasladar enfermos- y/o ambulancia debidamente identificada; quedando expresamente prohibida la autorización de otro tipo de vehículo.

2.4- No estarán comprendidas en el cumplimiento de lo establecido en el presente artículo a las personas de escasos recursos económicos las que deberán gestionar la excepción ante el Departamento Ejecutivo.

Modificación efectuada por Ordenanza 10162

ARTíCULO 3o: En el Cementerio de la ciudad de La Plata existe la libertad de cultos.

\section{II) CLASIFICACIÓN - SECCIONES}

ARTíCULO 4: El Cementerio se dividirá en secciones del siguiente modo:
a. Panteones y Bóvedas.
b. Nichos comunes.
c. Nichos para restos reducidos.
d. Sepulturas en tierra arrendada por tiempo determinado.
e. Fosa común.

\section{III) INGRESO - REQUISITOS - HORARIOS DEL ATAÚD Y SUS CONDICIONES}

\section{EXHUMACIONES - REDUCCIONES}

ARTíCULO 5o: La Dirección del Cementerio exigirá ante la presentación de un cadáver para su exhumación, tumulación o cremación:

a. Licencia de inhumación expedida por el Registro Provincial de las Personas.

b. Certificado de Inspección Municipal.

c. Cuando el destino sea panteón o bóveda, el título de las mismos y la autorización por escrito del o los propietarios.

d. Boleta de pago de las contribuciones que al efecto fije la Ordenanza Fiscal Impositiva.

e. Certificado de defunción.

ARTíCULO 6o: Cuando quien pretende introducir restos en el Cementerio no diera cumplimiento a algunos de los requisitos precedentemente anunciados la Dirección los recibirá en depósito provisorios, dando cuenta de tal circunstancia a la Secretaría de Hacienda, debiéndose abonar un derecho por depósito diario del monto que fija la Ordenanza de Contribuciones vigente. Los plazos de permanencia en depósito, para los cadáveres a inhumar, serán de 48 horas y de los cadáveres a tumular, 30 días máximo. Si transcurrido dichos plazos, los deudos no hubieran procedido a completar la documentación, los ataúdes serán inhumados. 
ARTíCULO 70: Las inhumaciones o cremaciones no podrán hacerse antes de las doce horas siguientes a la muerte, ni demorarse más de 36 horas, salvo orden policial o judicial.

ARTíCULO 80: Las tumulaciones en panteones, bóvedas o nichos comunes, se harán en cajas metálicas de cierre hermético, a pestañas soldadas en su interior con estaño y de resistencia suficiente para evitar el escape de gases. Estas cajas deberán ser revestidos de madera u otro material.

Las Empresas de Pompas Fúnebres procederán a clausurar el ataúd, a colocar sobre las abertura cubierta de vidrio, una chapa de metal del mismo material que el de la caja, la que estañarán prolijamente para que reúna las condiciones de cierre y resistencia requeridas. Las inhumaciones en tierra se harán en cajas de madera, que solo podrán ser pintadas, lustradas o forradas en tela.

ARTíCULO 9o: El material a emplearse en las cajas metálicas podrá ser plomo amalgamado de un espesor mínimo de 2 milímetros, zinc, hierro galvanizado o cobre de un espesor mínimo de $1 \frac{1}{2}$ milímetros. El Departamento Ejecutivo podrá, autorizar el uso de otros materiales que reúnan las condiciones necesarias.

ARTíCULO 10: Se inscribirá con pintura al aceite, sobre la caja metálica del ataúd, el nombre de la persona fallecida y la fecha de su defunción.

Estando las cajas revestidas de madera, se repetirá la inscripción sobre una chapa de metal inoxidable, colocada en el exterior en lugar visible.

ARTíCULO 11o: Durante el primer año de efectuada la tumulación, la empresa encargada del servicio fúnebre responderá por las condiciones del cierre y resistencia de las cajas metálicas. Constatada la existencia de escapes de líquidos o gases, la Dirección notificará a la citada empresa, para que proceda a efectuar las reparaciones necesarias dentro del plazo de 24 horas. Vencido dicho término sin que hubiere dado cumplimiento a lo intimado, se sancionará a la empresa ordenándose la ejecución de los trabajos por su cuenta y cargo.

ARTíCULO 12: Transcurrido un año desde la tumulación, la intimación se efectuará al propietario del panteón, bóveda o nicho, a quien se le aplicarán las sanciones establecidas en el Artículo anterior.

ARTíCULO 13:: Prohíbese el uso del material llamado "nylon" y/o cualquiera de sus derivados o similares en los servicios destinados a inhumaciones ya sea en ataúd o en mortaja y/o vestimentas del fallecido. Las empresas que conduzcan cadáveres y no cumplan con este requisito serán sancionadas de acuerdo a lo dispuesto en el capítulo IV, artículo 80 y C.C. de la Ordenanza 6147 - (Código Contravencional).

ARTíCULO 140: Los Cadáveres de fallecidos de enfermedades infecto - contagiosas deberán ser cremados obligatoriamente.

ARTíCULO 15o: El Departamento Ejecutivo podrá conceder permiso para la introducción, inhumación o cremación de cadáveres pertenecientes a personas fallecidas fuera de municipio con sujeción a las disposiciones de la presente Ordenanza y exigiendo previamente se acredite que no procede de región donde existe epidemia ni que el fallecimiento fue ocasionado por enfermedad así calificada. 
Las empresas de Ferrocarriles, de Transporte y los particulares que introdujeran cadáveres al municipio sin el permiso correspondiente serán pasibles de multa.

ARTícULO 16: El certificado establecido en el Artículo 5으, inciso b), deberá referirse al cumplimiento de lo dispuesto en el Artículo 8ㅇ, 9으, 10으 y $13 \%$.

ARTículo 17o: La Dirección del Cementerio en caso de duda sobre la exactitud de los certificados expedidos por la Inspección Municipal requerirá autorización al Departamento Ejecutivo para proceder a su constatación.

ARTíCULO 18: Los cadáveres de las secciones panteones, bóvedas y nichos comunes, podrán ser exhumados para su cremación en cualquier momento. Los de las secciones tierra solo podrán ser exhumados después de cinco año de inhumación (mayores de seis años), o cuatro años (menores de seis años ) cualquiera fuere el destino de los restos.

ARTíCULO 19: Las inhumaciones, reducciones o traslados de restos no serán permitidas desde el 25 de octubre hasta el 5 de noviembre de cada año.

ARTíCULO 20: Los cadáveres tumulados en panteones, bóvedas o nichos comunes, podrán ser reducidos una vez transcurridos 30 años de su tumulación.

ARTíCULO 210: Prohíbese la exhumación de cadáveres en épocas de epidemias.

ARTíCULO 220: Las exhumaciones se autorizarán a pedido de parte que acredite un interes legítimo, el correspondiente vínculo de parentesco y la presentación del último recibo de pago. Los traslados de ataúdes entre panteones, bóvedas y nichos se autorizarán de igual manera.

\section{IV) PANTEONES Y BOVEDAS}

ARTíCULO 23: Los propietarios de panteones, bóvedas y nichos podrán arrendar los mismos o partes determinadas de ellos, con destino a tumular cadáveres o guardar restos en urnas. Los arrendamientos para ser válidos deberán efectuarse con la intervención de la Dirección del Cementerio, la que establecerá un máximo a que podrá ascender el precio del mismo por catre para urna o cadáver. El precio se hará efectivo por un año adelantado a convenirse la locación.

En caso de incumplimiento por parte de los deudos en el pago de la locación o vencido el término del arrendamiento, el propietario de la bóveda podrá exigir el retiro del cadáver o urna dentro del plazo de 60 días de la notificación de los deudos, la que se hará efectiva con la intervención de la Dirección de Cementerio en el domicilio constituido en el momento del ingreso de los restos.

Si no diera cumplimiento a lo conminado o se desconociera el domicilio la Municipalidad intimará a los deudos o interesados por publicación en dos diarios locales durante tres días procedan a su retiro, bajo pena de destinar el cadáver o restos a la fosa común.

Queda prohibida en este tipo de locaciones la actividad de intermediarios.

ARTíCULO 24: En las tumulaciones y colocación de urnas con restos en panteones o bóvedas, la Dirección del Cementerio exigirá la presentación del título de propiedad y autorización del propietario, propietarios y sus representantes legales, que deberán certificar la firma ante escribano, Juez de Paz, autoridad policial o Director de la Dirección del Cementerio, con 
indicación imprescindible del tiempo por el que concede la permanencia del cadáver o urna en sepulcro.

La Dirección registrará y archivará prolijamente dichas autorizaciones.

ARTícULO 250: En los sepulcros no se permitirá mayor número de tumulaciones o colocaciones de urnas con restos, que el de catres o nichos establecidos en el proyecto de construcción aprobado.

Sobre cada catre o nicho se colocará un solo ataúd el que en ningún caso podrá depositarse en otro lugar, como igualmente las urnas, que deberán ser colocadas sobre los mismos catres o nichos.

ARTíCULO 260: Como única excepción de lo dispuesto en el artículo anterior, se permitirá colocar hasta dos ataúdes en el interior del altar de la capilla cuyo frente deberá cubrirse con pares de material, mármol o cristal.

ARTíCULO 270: El Departamento Ejecutivo, procederá a levantar un censo de cadáveres y urnas en los panteones y bóvedas habilitadas a la promulgación de la presente, e intimará por cédula a sus propietarios para que dentro del término de ciento ochenta días, reduzcan el número de ataúdes y urnas al número limitado. Vencido el término del emplazamiento, procederá a la cremación de los excesos, por cuenta y cargo del o los propietarios.

ARTíCULO 280: No podrá obligarse a los deudos o interesados al retiro del cadáver o urna hasta después de vencido el término del permiso acordado, salvo el caso en que la Municipalidad ordenara el desalojo general.

ARTíCULO 290: Vencido el término a que se refiere el artículo 28 el propietario del panteón o bóveda podrá solicitar del Departamento ejecutivo, el retiro del cadáver o urna.

La Municipalidad intimará a los deudos o interesados por publicación en dos diarios locales durante 3 días a costa del solicitante, para que dentro del término de 15 días procedan a su retiro, bajo pena de destinar el cadáver a cremación por cuenta y orden del propietario.

\section{V) NICHOS COMUNES}

ARTíCULO 30: Cada nicho corresponderá para un solo cadáver. En cada nicho podrán colocarse restos reducciones o cenizas de uno o más cadáveres hasta un máximo de cinco (5).

ARTícULO 310: Colocado el ataúd dentro del nicho, se procederá por la Dirección a su clausura, con ladrillo de canto tomadas sus juntas con mezcla fuerte.

ARTíCULO 32:- Dentro de los treinta días de la tumulación el propietario del nicho deberá colocar en su frente una lápida del material que corresponda de acuerdo a la ubicación del mismo, en la que será grabado el nombre de la persona fallecida y la fecha de su defunción.

ARTíCULO 33o: En garantía de lo dispuesto en el artículo anterior el adquirente de nichos depositará previamente en la Tesorería de la Municipalidad la cantidad de , garantía que será devuelta después de verificarse tal cumplimiento. 
ARTíCULO 340: Vencido el término fijado sin haberse colocado la lápida el Departamento Ejecutivo la contratará por licitación y su costo se abonará con el depósito de garantía.

ARTíCULO 350: En el frente de los nichos sólo será permitido colocar ramos de flores naturales o artificiales. Los soportes para ese fin, serán de metal y de acuerdo con las dimensiones que para cada caso establecerá la Dirección.

ARTíCULO 360: Será permitido colocar la lápida en el interior del nicho, hasta treinta centímetros de la línea del frente. En este caso, se colocará en la línea general del frente una puerta de vidrio y con llave o sobre marco de metal. La presente norma regirá únicamente en los nichos de Galería y Bajo Galería .

\section{VI) NICHOS REDUCIDOS}

ARTíCULO 370: Los nichos para restos reducidos, se destinarán a depositar restos exhumados de panteones, nichos comunes, sepulturas en tierra o aquellas que se encuentren en urnas o introduzcan de otros municipios.

ARTíCULO 380: Cada nicho medirá cuarenta centímetros de ancho, cuarenta centímetros de alto y sesenta centímetros de fondo y en cada uno de ellos s permitirá la colocación de restos o cenizas de uno o más cadáveres hasta un máximo de cinco(5).

ARTíCULO 39o: Una vez colocados los restos o cenizas, la Dirección del Cementerio, hará cerrar el nicho con ladrillos de canto y mezcla fuerte, siendo obligatorio la colocación de una lápida del material correspondiente, que cubra todo el frente, e inscripción del nombre, apellido y fecha de defunción. Las lápidas serán uniformes para todos los nichos y no se permitirá la colocación de ningún otro objeto, con excepción de ramos de flores naturales o artificiales y en la forma que establece el artículo 35.

\section{VII) SEPULTURAS}

\section{Tierra Común}

ARTíCULO 40: Las sepulturas en tierra deberán tener una profundidad de un metro cincuenta centímetros, con las dimensiones que se determinan en el plano general del Cementerio. Los cadáveres serán colocados horizontalmente y cubiertos con la misma tierra extraída de la fosa.

ARTíCULO 41:: En cada sepultura no se permitirá más de un cadáver; en la misma se podrá colocar restos reducidos o cremados provenientes de otras sepulturas o nichos que pertenezcan a familiares del ocupante dentro del tercer grado de consanguinidad y segundo de afinidad, lo que será probado administrativamente. Los restos que han de depositarse deberán ser colocados en urnas de mármol, cemento armado $u$ otro material que apruebe el D.E. bajo tierra o en las bases de los monumentos, debiendo indicarse en su exterior y en el de la lápida o monumento del sepulcro, la filiación y fecha de fallecimiento correspondiente a cada resto, pudiendo indistintamente autorizarse el traslado e incorporación de restos hasta un máximo de cinco (5).

Las inhumaciones concedidas gratuitamente se harán en la misma sección de sepulturas arrendadas, sin destinarse tablones especiales que las distingan. 


\section{VIII) CONCESIÓN - ARRENDAMIENTOS - PLAZOS - DURACIÓN}

ARTíCULO 42:: La Municipalidad no se desprende del dominio de las tierras concedidas para panteones, bóvedas y sepulturas, y sus titulares quedan obligados al cumplimiento de las Ordenanzas vigentes o que se dictaren.

ARTíCULO 43::La adjudicación se hará en forma directa por vía administrativa y en la Dirección de Cementerio por los siguientes plazos:

a. Lotes para panteones o bóvedas: límite máximo de cincuenta (50) años. El período de concesión será de veinticinco (25) años con opción a veinticinco años más.

b. Nichos comunes: el límite será de quince (15) años, el primer período de arrendamiento será por diez (10) años, renovables por un período de cinco (5) años.

c. Nichos para restos reducidos: el límite máximo será de treinta (30) años. El primer período de arrendamiento será de diez (10) años, renovable por períodos de cinco (5) años.

d. Sepultura en tierra común:

1. Mayores de seis años, el primer período de arrendamiento será de cinco años con opción a un (1) año más.

2. Menores de seis años, único período de arrendamiento de cuatro años no renovable.

e. En caso de hallarse restos óseos de personas desaparecidas identificadas por la Justicia y que fueran recuperados por la lucha inclaudicable de familiares u Organismos de Derechos Humanos, éstos, podrán ser sepultados en tierra por el período de un (1) año. Vencido dicho plazo serán trasladados a nichos para restos reducidos

Modificación efectuada por Ordenanza 10096

ARTíCULO 44:: Prohíbase acordar tierras o nichos sin que exista el cadáver de la persona a inhumar o tumular. Sólo podrá acordarse la concesión de sepulturas de las mencionadas, sin el cumplimiento de tal recaudo, cuando el peticionante tenga más de sesenta años de edad; en tal circunstancia, la misma sólo podrán ser ocupadas por el titular de la concesión. Queda establecida la intransferibilidad de las sepulturas mencionadas, salvo la transferencias de carácter sucesorio, dispuestas judicialmente, y/o la cesión de derechos realizada a favor de los derechos forzosos del titular, entre cotitulares de la misma

Modificación efectuada por ordenanza 7690

\section{IX) SANCIONES}

ARTícULO 45o: La falta de cumplimiento a cualquiera de las disposiciones de la presente Ordenanza se sancionará con multa de módulos a módulos cuya graduación queda a criterio del Departamento Ejecutivo, el que tendrá en cuenta para regularla la índole de la infracción y el grado de reincidencia. 


\section{X) DISPOSICIONES GENERALES}

ARTíCULO 46: El Cementerio tendrá una fosa común en la que se depositarán toda clase de restos humanos reducidos que no tengan destino especial y lo proveniente de panteones, bóvedas, nichos y sepulturas, conforme a las disposiciones de la presente ordenanza.

ARTíCULO 470: Los ataúdes, urnas o cualquier otro revestimiento de cadáveres exhumados o reducidos serán quemados por la Dirección de Cementerio, prohibiéndose en absoluto otro destino.

Las rejas, mármoles, cruces, lápidas u otro material procedente de sepulturas o nichos desocupados, se entregarán a sus propietarios que los reclamen dentro de término de treinta (30) días.

Vencido dicho plazo perderán todo derecho y la Municipalidad dispondrá su enajenación en la forma que lo disponga en Departamento Ejecutivo.

ARTíCULO 48: El Departamento Ejecutivo podrá autorizar a un capellán católico la atención de la capilla del Cementerio y sus ornamentos, quien prestará gratuitamente los servicios religiosos que le sean requerido por los deudos de los fallecidos.

El capellán deberá permanecer en la capilla, durante las horas hábiles para inhumar.

ARTíCULO 49: Los que pertenezcan a otra religión o secta, podrán hacer las ceremonias con arreglo al rito de su congregación, pudiendo llevar el ministro de su culto.

ARTICULO 50: En el caso que un Panteón o Bóveda requiera reparaciones, se intimará a su propietario por notificación en el domicilio constituido, para que proceda a verificarlas dentro del término que fijará el Departamento Ejecutivo, según importancia de las mismas.

Vencido el término acordado sin haberse efectuado las reparaciones, el D.E. ordenará a la Dirección, tome posesión del sepulcro y contratará por licitación las construcción requerida por cuenta y cargo del propietario. Hasta tanto no se hayan efectuado las reparaciones requeridas, se clausurará el Panteón o bóveda.

ARTíCULO 510: Prohíbese renovar el arrendamiento de las sepulturas comunes, nichos y bóvedas, una vez cumplidos los ciclos máximos dispuestos en el Artículo 43으, inciso a), b) y c), apartado 1 y 2, cuando la reducción no se pueda efectuar; el titular decidirá el destino de los restos, pudiendo retirarlos del cementerio o disponer la cremación.

ARTíCULO 520: Vencido el término por el cual hubiesen sido acordados nichos, sepulturas en tierra y Pabellón Transitorio, el Departamento Ejecutivo intimará mediante notificación fehaciente el titular para que dentro del término de treinta días efectúe la renovación del arrendamiento, en los casos autorizados, o la reducción, cremación o remoción de cadáver. Transcurrido el plazo fijado, la Municipalidad queda facultada para disponer la reducción de los restos, con cargo al responsable, o bien la cremación del cadáver, si resultare imposible la reducción. Los restos reducidos por disposición de la comuna será trasladado a una Fosa común.

ARTíCULO 53: Autorízase a la Dirección del Cementerio a reacondicionar los ataúdes o urnas correspondientes a cadáveres exhumados o destinados a reducción y destinarlos a la 
realización de servicios gratuitos para personas de escasos recursos económicos. En tal supuesto, a los efectos del reacondicionamiento, por intermedio de las áreas pertinentes se realizarán los procedimientos necesarios para preservar la higiene y salubridad.

Modificación efectuada por ordenanza 7690

ARTíCULO 540: El adquirente de concesión de panteón, bóveda, nichos y sepulturas, deberá constituir dentro del Partido de La Plata, su domicilio para todos los efectos que dispone la presente Ordenanza, en el acto de aceptar la concesión

Modificación efectuada por ordenanza 7690

ARTíCULO 550: Los concesionarios de tierras en el Cementerio quedan obligados a todas las disposiciones de la presente Ordenanza.

ARTÍCULO 560: La Municipalidad dispondrá libremente de los nichos y tierra para sepulturas a perpetuidad y arrendamiento, desde el momento en que fueren desocupados por el primer ocupante y los concesionarios o arrendatarios perderán todo derecho a indemnización $o$ devolución. La presente disposición no resultará de aplicación en casos de que se autorice el traslado de los resto antes del vencimiento hacia otro sector del Cementerio General dependiente de la administración del mismo. En tal supuesto, el monto proporcional del período de concesión no utilizado, será descontado de acuerdo a los valores que fije la Ordenanza Impositiva, de la suma a abonar por la nueva concesión.

Modificación efectuada por ordenanza 7690

ARTícULO 57ㅇ: Prohíbese terminantemente el transporte de cadáveres en vehículos no autorizados.

ARTíCULO 58:: Las Empresas de Servicios Fúnebres habilitadas o a habilitarse deberán constituir un depósito de $\$$ de Fianza, para su actuación como tales.

ARTíCULO 59o: Las concesiones actualmente otorgadas en el Cementerio General mantendrán la vigencia de los plazos oportunamente acordados. Vencidos los mismos deberán requerir la renovación de conformidad con las disposiciones del Artículo 44 de la presente Ordenanza

ARTícULO 60: Derógase la Ordenanza 3577 y sus modificatorias, Decreto 8067/69, Decreto 10757/71, Ordenanza 7415 y toda disposición que se oponga a la presente.

ARTíCULO 610: De Forma. 


\section{II- Ordenanza Municipal 9471/02}

Expte. 36423

La Plata, 2 de octubre de 2002

El Concejo Deliberante, en su Sesión Ordinaria $N^{\circ} 25$, celebrada en el día de la fecha, ha sancionado la siguiente:

\section{ORDENANZA 9471}

ARTICULO $1^{\circ}$ : Autorízase al Departamento Ejecutivo a celebrar un Convenio con la Universidad Nacional de La Plata, a los fines de que la Dirección de Cementerio proceda a la entrega de piezas óseas provenientes de cadáveres debidamente identificados, sepultados en el Osario Común, de acuerdo a lo dispuesto en las normas vigentes.

ARTICULO $2^{\circ}$ : Los restos a que se hace referencia en el Artículo $1^{\circ}$, serán destinados a la Facultad de Ciencias Médicas -Departamento de Ciencias Morfológicas- para la creación de una Huesoteca u Osteoteca y a la Facultad de Odontología, las piezas óseas pertinentes a la especialidad para la creación de una Craneoteca para ser utilizados por los estudiantes para su capacitación y a la investigación científica.

ARTICULO $3^{\circ}$ : Las Facultades mencionadas en el Artículo $2^{\circ}$ deberán disponer de un lugar físico acondicionado para el depósito de las piezas óseas. Asimismo, deberán devolver aquellas piezas cuando su utilización no fuera necesaria, para depositarlas en el Osario Común del Cementerio.

ARTICULO $4^{\circ}$ : La Dirección de Cementerio queda autorizada a posteriori de la firma del presente Convenio -previo registro- a la provisión de las piezas óseas.

ARTICULO $5^{\circ}$ : Derógase la Ordenanza 7812 y toda otra norma que se oponga a la presente.

ARTICULO 6 ${ }^{\circ}$ : De forma. 


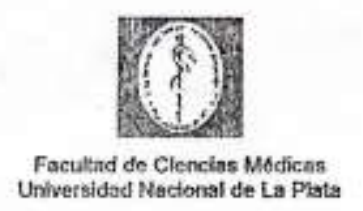

\section{ACUERDO ENTRE LAS FACULTADES DE CIENCIAS MÉDICAS Y DE} CIENCIAS NATURALES Y MUSEO

Entre la FACULTAD DE CIENCIAS MÉDICAS, representada por su Decano, Dr. SALVIOLI con domicilio en la calle 50 y 120 de la ciudad de La Plata, y la FACULTAD DE CIENCIAS NATURALES Y MUSEO, representado por su Decano, Dr. Ricardo Etcheverry, con dornicilio en la calle 60 y 122 , se celebra el presente ACUERDO DE COOPERACIÓN, en el marco del Convenio oportunamente suscripto entre la MUNICIPALIDAD DE LA PLATA Y LA UNIVERSIDAD NACIONAL DE LA PLATA (20/12/2002) y Acta Modificatoria (que como Anexo se incluye), sujeto a las siguientes cláusulas:

PRIMERA: Ambas instituciones favorecerán la concertación de programas de cooperación para la ejecución conjunta y coordinada de proyectos de investigación, docencia y/o extensión entre el Laboratorio de Investigaciones Morfológicas Aplicadas, la Cátedra de Histología, Embriologia y Citologia "A"de la Facultad de Ciencias Médicas y la Cátedra de Métodos y Técnicas de la Investigación Antropobiológica de la Facultad de Ciencias Naturales y Museo.

SEGUNDA: Las acciones a que dé lugar este acuerdo serán instrumentadas en programas de trabajo o de intercambio, según el caso, en los que quedarán formulados los objetivos, las unidades ejecutoras, los detalles op̣erativos y la duración.

TERCERA: Los programas de trabajo o de intercambio serán suscriptos por los

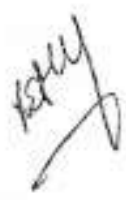
titulares de ambas Cátedras o por quienes cstos designen expresamente. 
CUARTA: Los programas serán desarrollados - cuando fuera el caso - sobre la base de Planes Operativos, en los que se detallarán las acciones del periodo respectivo y los recursos a empiear.

QUINTA: Este acuerdo podrá ser denunciado por cualquicra de las partes mediante comunicación de manera fehaciente a la otra, con seis meses de anticipación. La denuncia no enervará las acciones pendientes de programas que no fueren expresamente rescindidos por los organismos signatarios.

SEXTA: El presente acuerdo tendrá vigencia por el termino de cinco años renovable automáticamente por periodos iguales si las partes no manifiestan fehacientemente su voluntad en contrario.

De conformidad se firman dos (2) ejemplares de un mismo tenor y a un solo efecto en la Ciudad de La Plata a los ...1..... dias del mes deagostade 2005.
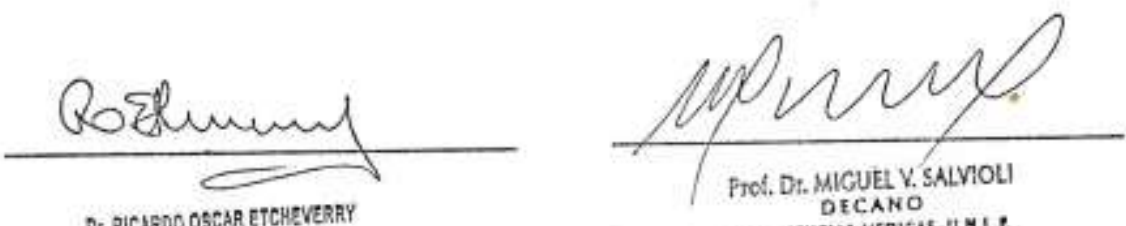

DC. RICHEOD OSTAR ETCHEVERRY DECAND

FAC, CIEKCLIS MEDIES-U.M.C.

fasiltad de Cs, Maturales r Muse:

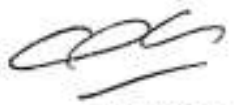

Da ALALLAERACALDE

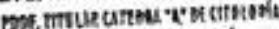

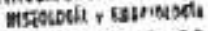
FACULTAD CIENCIAS WR OANS

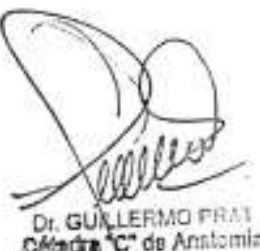

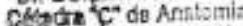

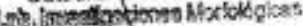

s)

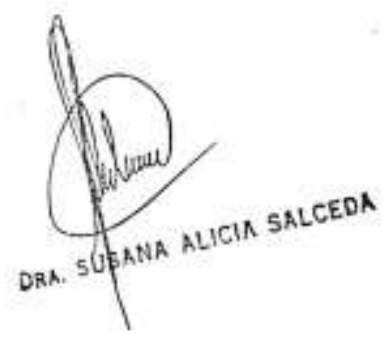




\section{IV- DECLARACIÓN DE HELSINKI}

Adoptada por la 18a Asamblea Médica Mundial Helsinki, Finlandia, Junio 1964 y enmendada por la:

29a Asamblea Médica Mundial Tokio, Japón, Octubre 1975

35a Asamblea Médica Mundial Venecia, Italia, Octubre 1983

41a Asamblea Médica Mundial Hong Kong, Septiembre 1989

48a Asamblea General Somerset West, Sudáfrica, Octubre 1996

y la 52a Asamblea General Edimburgo, Escocia, Octubre 2000

Nota de Clarificación del Párrafo 29, agregada por la Asamblea General de la AMM,

Washington 2002

Nota de Clarificación del Párrafo 30, agregada por la Asamblea General de la AMM, Tokio 2004

\section{A. INTRODUCCION}

1.La Asociación Médica Mundial ha promulgado la Declaración de Helsinki como una propuesta de principios éticos que sirvan para orientar a los médicos y a otras personas que realizan investigación médica en seres humanos. La investigación médica en seres humanos incluye la investigación del material humano o de información identificables.

2.El deber del médico es promover y velar por la salud de las personas. Los conocimientos y la conciencia del médico han de subordinarse al cumplimiento de ese deber.

3.La Declaración de Ginebra de la Asociación Médica Mundial vincula al médico con la fórmula "velar solícitamente y ante todo por la salud de mi paciente", y el Código Internacional de Ética Médica afirma que: "El médico debe actuar solamente en el interés del paciente al proporcionar atención médica que pueda tener el efecto de debilitar la condición mental y física del paciente".

4.El progreso de la medicina se basa en la investigación, la cual, en último término, tiene que recurrir muchas veces a la experimentación en seres humanos.

5.En investigación médica en seres humanos, la preocupación por el bienestar de los seres humanos debe tener siempre primacía sobre los intereses de la ciencia y de la sociedad.

6.El propósito principal de la investigación médica en seres humanos es mejorar los procedimientos preventivos, diagnósticos y terapéuticos, y también comprender la etiología y patogenia de las enfermedades. Incluso, los mejores métodos preventivos, diagnósticos y terapéuticos disponibles deben ponerse a prueba continuamente a través de la investigación para que sean eficaces, efectivos, accesibles y de calidad.

7.En la práctica de la medicina y de la investigación médica del presente, la mayoría de los procedimientos preventivos, diagnósticos y terapéuticos implican algunos riesgos y costos.

8.La investigación médica está sujeta a normas éticas que sirven para promover el respeto a todos los seres humanos y para proteger su salud y sus derechos individuales. Algunas poblaciones sometidas a la investigación son vulnerables y 
necesitan protección especial. Se deben reconocer las necesidades particulares de los que tienen desventajas económicas y médicas. También se debe prestar atención especial a los que no pueden otorgar o rechazar el consentimiento por sí mismos, a los que pueden otorgar el consentimiento bajo presión, a los que no se beneficiarán personalmente con la investigación y a los que tienen la investigación combinada con la atención médica.

9.Los investigadores deben conocer los requisitos éticos, legales y jurídicos para la investigación en seres humanos en sus propios países, al igual que los requisitos internacionales vigentes. No se debe permitir que un requisito ético, legal o jurídico disminuya o elimine cualquiera medida de protección para los seres humanos establecida en esta Declaración.

\section{B. PRINCIPIOS BASICOS PARA TODA INVESTIGACION MEDICA}

10. En la investigación médica, es deber del médico proteger la vida, la salud, la intimidad y la dignidad del ser humano.

11. La investigación médica en seres humanos debe conformarse con los principios científicos generalmente aceptados, y debe apoyarse en un profundo conocimiento de la bibliografía científica, en otras fuentes de información pertinentes, así como en experimentos de laboratorio correctamente realizados y en animales, cuando sea oportuno.

12. Al investigar, hay que prestar atención adecuada a los factores que puedan perjudicar el medio ambiente. Se debe cuidar también del bienestar de los animales utilizados en los experimentos.

13. El proyecto y el método de todo procedimiento experimental en seres humanos debe formularse claramente en un protocolo experimental. Este debe enviarse, para consideración, comentario, consejo, y cuando sea oportuno, aprobación, a un comité de evaluación ética especialmente designado, que debe ser independiente del investigador, del patrocinador o de cualquier otro tipo de influencia indebida. Se sobreentiende que ese comité independiente debe actuar en conformidad con las leyes y reglamentos vigentes en el país donde se realiza la investigación experimental. El comité tiene el derecho de controlar los ensayos en curso. El investigador tiene la obligación de proporcionar información del control al comité, en especial sobre todo incidente adverso grave. El investigador también debe presentar al comité, para que la revise, la información sobre financiamiento, patrocinadores, afiliaciones institucionales, otros posibles conflictos de interés e incentivos para las personas del estudio.

14. El protocolo de la investigación debe hacer referencia siempre a las consideraciones éticas que fueran del caso, y debe indicar que se han observado los principios enunciados en esta Declaración.

15. La investigación médica en seres humanos debe ser llevada a cabo sólo por personas científicamente calificadas y bajo la supervisión de un médico clínicamente competente. La responsabilidad de los seres humanos debe recaer siempre en una persona con capacitación médica, y nunca en los participantes en la investigación, aunque hayan otorgado su consentimiento. 
16. Todo proyecto de investigación médica en seres humanos debe ser precedido de una cuidadosa comparación de los riesgos calculados con los beneficios previsibles para el individuo o para otros. Esto no impide la participación de voluntarios sanos en la investigación médica. El diseño de todos los estudios debe estar disponible para el público.

17. Los médicos deben abstenerse de participar en proyectos de investigación en seres humanos a menos de que estén seguros de que los riesgos inherentes han sido adecuadamente evaluados y de que es posible hacerles frente de manera satisfactoria. Deben suspender el experimento en marcha si observan que los riesgos que implican son más importantes que los beneficios esperados o si existen pruebas concluyentes de resultados positivos o beneficiosos.

18. La investigación médica en seres humanos sólo debe realizarse cuando la importancia de su objetivo es mayor que el riesgo inherente y los costos para el individuo. Esto es especialmente importante cuando los seres humanos son voluntarios sanos.

19. La investigación médica sólo se justifica si existen posibilidades razonables de que la población, sobre la que la investigación se realiza, podrá beneficiarse de sus resultados.

20. Para tomar parte en un proyecto de investigación, los individuos deben ser participantes voluntarios e informados.

21. Siempre debe respetarse el derecho de los participantes en la investigación a proteger su integridad. Deben tomarse toda clase de precauciones para resguardar la intimidad de los individuos, la confidencialidad de la información del paciente y para reducir al mínimo las consecuencias de la investigación sobre su integridad física y mental y su personalidad.

22. En toda investigación en seres humanos, cada individuo potencial debe recibir información adecuada acerca de los objetivos, métodos, fuentes de financiamiento, posibles conflictos de intereses, afiliaciones institucionales del investigador, beneficios calculados, riesgos previsibles e incomodidades derivadas del experimento. La persona debe ser informada del derecho de participar o no en la investigación y de retirar su consentimiento en cualquier momento, sin exponerse a represalias. Después de asegurarse de que el individuo ha comprendido la información, el médico debe obtener entonces, preferiblemente por escrito, el consentimiento informado y voluntario de la persona. Si el consentimiento no se puede obtener por escrito, el proceso para lograrlo debe ser documentado y atestiguado formalmente.

23. Al obtener el consentimiento informado para el proyecto de investigación, el médico debe poner especial cuidado cuando el individuo está vinculado con él por una relación de dependencia o si consiente bajo presión. En un caso así, el consentimiento informado debe ser obtenido por un médico bien informado que no participe en la investigación y que nada tenga que ver con aquella relación.

24. Cuando la persona sea legalmente incapaz, o inhábil física o mentalmente de otorgar consentimiento, o menor de edad, el investigador debe obtener el consentimiento informado del representante legal y de acuerdo con la ley vigente. Estos grupos no deben ser incluidos en la investigación a menos que ésta sea necesaria para promover 
la salud de la población representada y esta investigación no pueda realizarse en personas legalmente capaces.

25. Si una persona considerada incompetente por la ley, como es el caso de un menor de edad, es capaz de dar su asentimiento a participar o no en la investigación, el investigador debe obtenerlo, además del consentimiento del representante legal.

26. La investigación en individuos de los que no se puede obtener consentimiento, incluso por representante o con anterioridad, se debe realizar sólo si la condición física/mental que impide obtener el consentimiento informado es una característica necesaria de la población investigada. Las razones específicas por las que se utilizan participantes en la investigación que no pueden otorgar su consentimiento informado deben ser estipuladas en el protocolo experimental que se presenta para consideración y aprobación del comité de evaluación. El protocolo debe establecer que el consentimiento para mantenerse en la investigación debe obtenerse a la brevedad posible del individuo o de un representante legal.

27. Tanto los autores como los editores tienen obligaciones éticas. Al publicar los resultados de su investigación, el investigador está obligado a mantener la exactitud de los datos y resultados. Se deben publicar tanto los resultados negativos como los positivos o de lo contrario deben estar a la disposición del público. En la publicación se debe citar la fuente de financiamiento, afiliaciones institucionales y cualquier posible conflicto de intereses. Los informes sobre investigaciones que no se ciñan a los principios descritos en esta Declaración no deben ser aceptados para su publicación.

\section{PRINCIPIOS APLICABLES CUANDO LA INVESTIGACION MEDICA SE COMBINA CON LA} ATENCION MEDICA

28. El médico puede combinar la investigación médica con la atención médica, sólo en la medida en que tal investigación acredite un justificado valor potencial preventivo, diagnóstico o terapéutico. Cuando la investigación médica se combina con la atención médica, las normas adicionales se aplican para proteger a los pacientes que participan en la investigación.

29. Los posibles beneficios, riesgos, costos y eficacia de todo procedimiento nuevo deben ser evaluados mediante su comparación con los mejores métodos preventivos, diagnósticos y terapéuticos existentes. Ello no excluye que pueda usarse un placebo, o ningún tratamiento, en estudios para los que no hay procedimientos preventivos, diagnósticos terapéuticos probados. A fin de aclarar más la posición de la AMM sobre el uso de ensayos controlados con placebo, la AMM publicó en octubre de 2001 una nota de clarificación del párrafo 29.

30. Al final de la investigación, todos los pacientes que participan en el estudio deben tener la certeza de que contarán con los mejores métodos preventivos, diagnósticos y terapéuticos probados y existentes, identificados por el estudio.

31. El médico debe informar cabalmente al paciente los aspectos de la atención que tienen relación con la investigación. La negativa del paciente a participar en una investigación nunca debe perturbar la relación médico-paciente.

32. Cuando en la atención de un enfermo los métodos preventivos, diagnósticos o terapéuticos probados han resultado ineficaces o no existen, el médico, con el 
consentimiento informado del paciente, puede permitirse usar procedimientos preventivos, diagnósticos y terapéuticos nuevos o no comprobados, si, a su juicio, ello da alguna esperanza de salvar la vida, restituir la salud o aliviar el sufrimiento. Siempre que sea posible, tales medidas deben ser investigadas a fin de evaluar su seguridad y eficacia. En todos los casos, esa información nueva debe ser registrada y, cuando sea oportuno, publicada. Se deben seguir todas las otras normas pertinentes de esta Declaración.

\section{Nota de Clarificación del Párrafo 29 de la Declaración de Helsinki}

La AMM reafirma que se debe tener muchísimo cuidado al utilizar ensayos con placebo y, en general, esta metodología sólo se debe emplear si no se cuenta con una terapia probada y existente. Sin embargo, los ensayos con placebo son aceptables éticamente en ciertos casos, incluso si se dispone de una terapia probada y si se cumplen las siguientes condiciones:

- Cuando por razones metodológicas, científicas y apremiantes, su uso es necesario para determinar la eficacia y la seguridad de un método preventivo, diagnóstico o terapéutico

- Cuando se prueba un método preventivo, diagnóstico o terapéutico para una enfermedad de menos importancia que no implique un riesgo adicional, efectos adversos graves o daño irreversible para los pacientes que reciben el placebo.

Se deben seguir todas las otras disposiciones de la Declaración de Helsinki, en especial la necesidad de una revisión científica y ética apropiada.

\section{Nota de Clarificación del Párrafo 30 de la Declaración de Helsinki}

Por la presente, la AMM reafirma su posición de que es necesario durante el proceso de planificación del estudio identificar el acceso después del ensayo de los participantes en el estudio a procedimientos preventivos, diagnósticos y terapéuticos que han resultado beneficiosos en el estudio o el acceso a otra atención apropiada. Los arreglos para el acceso después del ensayo u otra atención deben ser descritos en el protocolo del estudio, de manera que el comité de revisión ética pueda considerar dichos arreglos durante su revisión.

La Declaración de Helsinki (Doc. 17.C) es un documento oficial de la Asociación Médica Mundial, organismo representante mundial de los médicos. Fue adoptada por primera vez en 1964 (Helsinki, Finlandia) y revisada en 1975 (Tokio, Japón), 1983 (Venecia, Italia), 1989 (Hong Kong), 1996 (Somerset West, Sudáfrica) y 2000 (Edimburgo, Escocia). Nota de Clarificación del párrafo 29, agregada por la Asamblea General de la AMM, Washington 2002. Nota de Clarificación del párrafo 30, agregada por la Asamblea General de la AMM, Tokio 2004. 


\section{V- DECLARACIÓN DE LA ASOCIACIÓN DE ANTROPOLOGÍA BIOLÓGICA ARGENTINA (AABA) EN RELACIÓN CON LA ÉTICA DEL ESTUDIO DE RESTOS HUMANOS}

En el presente existe un ámbito en el cual han comenzado a surgir, o a hacerse más visibles o explícitos, conflictos de intereses entre antropólogos, fundamentalmente antropólogos biólogos y arqueólogos, y comunidades indígenas. Éste se refiere a la recuperación, conservación y estudio de restos humanos -esqueletizados o momificadoscorrespondientes a poblaciones del pasado, tanto reciente como remoto. En la medida en que tanto el derecho de los Pueblos Originarios o Indígenas a construir su identidad y lograr su reconocimiento y a participar en la toma de decisiones en asuntos que puedan afectar sus intereses, como el derecho de los antropólogos u otros científicos a desarrollar investigaciones en el área de su incumbencia, son igualmente legítimos y amparados por nuestra Constitución Nacional, resulta fundamental la redacción de una declaración que refleje el compromiso de nuestra Asociación por la defensa de los objetivos de la disciplina, al tiempo que reconozca la necesidad de mantener un diálogo responsable con todas las partes interesadas en la gestión del patrimonio biocultural, incluyendo a las comunidades indígenas, a las instituciones públicas y privadas actualmente en posesión o custodia de los restos y a las autoridades legislativas.

En consecuencia, la AABA declara:

1) Adhesión irrestricta a la lucha secular de las comunidades de Pueblos Originarios por la defensa de su identidad y de sus derechos en el marco de una sociedad que pugna por ser, cada día, más plural y democrática.

2) Que el estudio científico de los restos biológicos humanos es de interés para toda la humanidad, independientemente de la nacionalidad, origen, extracción social, credo, etc. y que no puede ser reemplazado por otras aproximaciones científicas y no científicas a la historia de nuestra especie en el ámbito de nuestro territorio nacional.

3) Que este estudio científico requiere una adecuada gestión y manejo de las colecciones de restos humanos actualmente disponibles o que puedan existir en el futuro. En consecuencia, se considera necesario e indispensable que las mismas se encuentren bajo la responsabilidad de curadores profesionales, preferentemente bioantropólogos, que sean catalogadas de modo dinámico y actualizado y que su preservación y acceso estén garantizados por la correspondiente asignación de fondos. 
4) Su derecho a participar, en tanto asociación profesional con personería jurídica, en toda discusión referida a la gestión y manejo del patrimonio biocultural, incluidos los restos humanos. Para que dicha participación sea efectiva, se reconoce la necesidad de promover la formación y actuación de una comisión ad-hoc destinada a la redacción de un Código de Ética para el estudio de restos humanos, a la fijación de criterios básicos para posibilitar un diálogo productivo con los diferentes actores sociales interesados en la protección y manejo del patrimonio y para el asesoramiento de los cuerpos legislativos nacionales y provinciales que así lo requieran.

5) Que resulta necesario y deseable facilitar la restitución de restos de identidad conocida (i.e. cuyo nombre personal esté registrado) a las comunidades de pertenencia que los reclamen, siendo materia de discusión y análisis particular el caso de reclamos de restitución de otros restos. Tal discusión y estudio deben ser efectuados en un marco de mutuo respeto, razonabilidad y acercamiento de perspectivas entre las partes involucradas en la negociación.

6) Que es recomendable atender a reclamos de no exhibición pública de restos humanos realizados por las comunidades de pertenencia que así lo soliciten.

Salta, Argentina, octubre del 2007. 


\section{ASOCIACIÓN DE ANTROPOLOGÍA BIOLÓGICA ARGENTINA (AABA) \\ CÓDIGO DEONTOLÓGICO PARA EL ESTUDIO, CONSERVACIÓN Y GESTIÓN \\ DE RESTOS HUMANOS DE POBLACIONES DEL PASADO}

En cumplimiento de los fines estatutarios de la AABA y del artículo 4 de la Declaración de la Asociación de Antropología Biológica Argentina (AABA) en Relación con la Ética del Estudio de Restos Humanos (2007), se establece el presente Código con el fin de precisar un conjunto mínimo de normas éticas a seguir para el estudio, conservación y gestión de restos humanos correspondientes a poblaciones del pasado ${ }^{16}$.

El mismo deberá ser observado por todos los Asociados, recomendándose su aplicación por parte de otros profesionales o funcionarios eventualmente implicados en tareas o acciones vinculadas con el objeto de este Código. Se espera que este conjunto de normativas y recomendaciones esté sujeto a revisiones periódicas con el fin de asegurar su adecuación a las necesidades y exigencias de la práctica profesional y a la evolución de la sociedad en la cual tal práctica tiene sentido.

En lo general, el presente Código parte de la premisa fundamental de que el antropólogo biólogo, como miembro de la sociedad civil y de una comunidad científica y como formador de futuros profesionales, posee tanto derechos como un conjunto de obligaciones y deberes para con la comunidad, la profesión y su objeto de estudio. En lo particular, el Código se basa en la premisa de que el estudio científico de los restos humanos antiguos es un objetivo legítimo que resulta de interés y beneficio -efectivo o potencial- para toda la humanidad, independientemente de la nacionalidad, origen, extracción social, credo y demás atributos personales o colectivos, y que no puede ser reemplazado -sin costo- por otras aproximaciones a la historia de los grupos humanos en el ámbito de nuestro territorio nacional. Asimismo, parte de la idea de que los objetivos científicos, a pesar de su importancia,

16 En consonancia con el Decreto Reglamentario (1022/2004) de la Ley Nacional $25743 / 2003$ de

Protección del Patrimonio Arqueológico y Paleontológico, se entiende por "poblaciones del pasado" aquellas cuyo lapso de existencia no se encuadra dentro de la definición de "épocas históricas recientes" (Art. 2 de la mencionada Ley), que abarcan los últimos cien años contados, en este caso, a partir de la fecha de realización de un estudio o intervención concretos. 
no pueden ser realizados sin tener en cuenta los derechos, intereses, aspiraciones y percepciones de los distintos sectores de la sociedad con los cuales pudieran, eventualmente, entrar en conflicto. El espíritu del presente Código se basa, ante todo, en la noción de que en una sociedad plural jurídicamente organizada, los conflictos de intereses pueden y deben ser resueltos dentro del marco legal existente pero, fundamentalmente, en un clima de mutuo respeto y buena predisposición al diálogo, atendiendo siempre a un criterio de razonabilidad y acercamiento de perspectivas entre las partes implicadas.

En este marco, la Asociación de Antropología Biológica Argentina ( $A A B A$ ) establece que:

1. Es deber de los antropólogos biólogos no sólo respetar y hacer respetar este Código Deontológico, sino también todas las leyes y disposiciones legales nacionales y provinciales, así como las recomendaciones de instituciones nacionales e internacionales relacionadas con el estudio, la conservación y la gestión de restos humanos antiguos.

2. Es responsabilidad de todos los antropólogos biólogos velar por la conservación de restos humanos, practicando y promoviendo su correcta gestión y estudio.

3. Los restos humanos, en tanto representantes de una multiplicidad de aspectos tangibles e intangibles de personas que vivieron en el pasado, deben ser tratados con dignidad, sensibilidad y respeto, con total independencia de su antigüedad, procedencia y demás atributos personales, étnicos o poblacionales. Teniendo en cuenta que lo que constituye un trato respetuoso o digno varía en diferentes contextos y situaciones, al tiempo que distintas personas pueden manifestar diferentes sentimientos acerca de los restos humanos, los profesionales deben ser particularmente sensibles y atentos al medio sociocultural en el que desarrollan sus tareas de investigación, conservación y/o gestión.

4. Se debe denunciar, ante las autoridades competentes, todo riesgo de alteración o destrucción de sitios de los que se sabe o se presume contienen restos humanos, o de su eventual consumación, debido a acciones tanto públicas como privadas. Esta obligación es válida también para los restos albergados en repositorios públicos y privados.

5. Los antropólogos biólogos no deben involucrarse, bajo ningún concepto, en actos que impliquen la comercialización u otro acto ilegal relacionado con restos humanos y materiales asociados, debiendo denunciar ante las autoridades competentes todo hecho vinculado con esa actividad que sea de su conocimiento. 
6. Toda intervención sobre restos humanos con fines investigativos o de conservación debe ser realizada con una debida justificación observándose, en cada caso, los estándares reconocidos como válidos por la comunidad científica del momento.

7. Se considera una falta a la ética emprender cualquier aspecto de la práctica profesional que involucre el tratamiento de restos humanos, sin estar adecuadamente capacitado desde el punto de vista teórico y técnico en relación con el problema abordado en cada caso.

8. Los resultados de las investigaciones que involucren restos humanos deben ser informados a la comunidad científica en un tiempo razonable y por los medios usuales, al tiempo que deben explorarse las diferentes vías disponibles que aseguren una correcta y efectiva divulgación de los mismos al resto de la sociedad.

9. Debe estimularse y promoverse la realización de debates en diferentes ámbitos (profesionales, académicos, públicos) acerca de la importancia del estudio, conservación y gestión de restos humanos, así como de sus implicancias éticas, con el fin de mejorar la práctica profesional y crear conciencia sobre el problema.

10. Los antropólogos biólogos tienen el deber de asesorar, cuando sea requerido y de manera informada y responsable, a instituciones públicas y privadas, gubernamentales y no gubernamentales, acerca de aspectos vinculados con el estudio, conservación y/o gestión de restos humanos.

11. Se debe mantener y promover una interacción positiva con las comunidades o sectores de la sociedad que reclamen un vínculo de pertenencia con restos humanos específicos, independientemente de su origen étnico, respetando sus preocupaciones, costumbres, credos y valores, en la medida en que esto no implique incurrir en actos ilegales ni contradecir este Código o los derechos humanos fundamentales.

Aprobado por la Asamblea Plenaria de la Asociación de Antropología Biológica Argentina (AABA) del día 27 de octubre de 2011. 


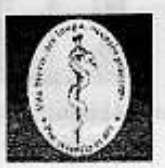

Gacultad da Ciofreiaz Hedicas Univeraidae Nagional de Ea plate

Expediente $\mathrm{N}^{\circ} 800-13597 / 12$.-

La Plata, -6 SET. 2012

Señora Directora del Proyecto

"Análisis Macro y Microscópico de Restos oseos Humanos. Aportes a la Investigación Eorense y Antropológica (Segunda Parte)" de la Facultad de Ciencias Médicas de la UNLP

Prof. Dra, Ana María Inda

$\mathrm{S} / \mathrm{D}$

Ref: Acto Resolutivo $N^{\circ} 376$

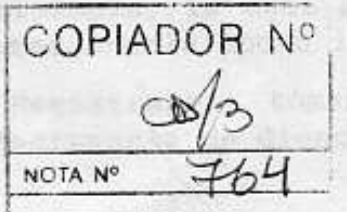

Tengo el agrado de dirigirme a la Señora Profesora, con el objeto de comunicarle que el Consejo Directivo reunido en sesión de fecha 15/08/2012 ha dispuesto, mediante Acto Resolutivo de la referencia -cuya copia se adjunta-, reconocer la existencia de la Colección Osteológica "Profesor Doctor Rómulo Lambre" con sede en la Cátedra "A" de Citología, Histología y Embriología, otorgándole apoyo institucional para su funcionamiento.

Sin otro particular, salúdole muy

atentamente.

mer

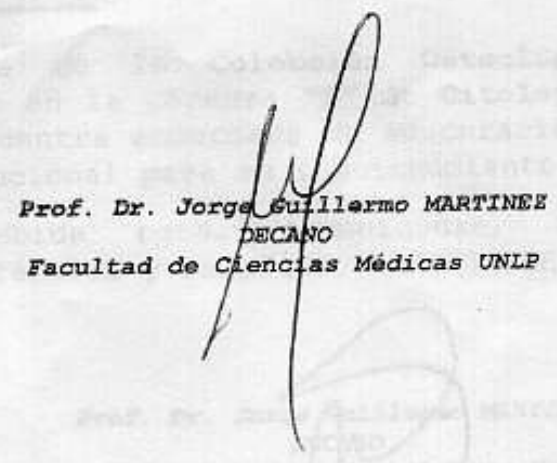



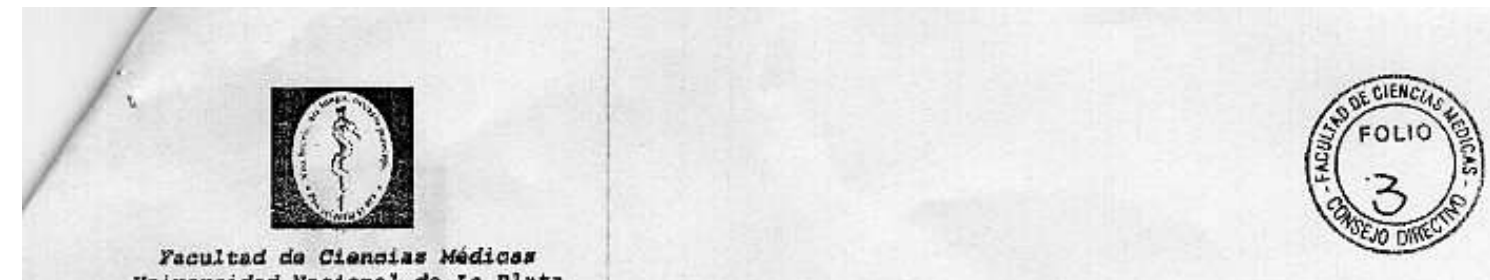

Universidad Nacional de La Plata

- Expediente $\mathrm{N}^{\circ}$ 800-13597/12.-

Ref.: MESA DE ENTRADAS - FAC. CS. MEDICAS - INDA ANA MARIA.-

DEF. TRETORA DEL PROYECTO: "ANALISIS MACRO Y MICROSCOPICO DE RESTOS OSEOS HUKANOS" ELEVA INFORME A LOS EFECTOS DE FORMALIZAR LA PRESENTACION DE LA COLECCIÓN OSTEOLOGICA (PROFESOR DOCTOR ROMULO LAMBRE) A FINES DE UTILIZARSE EN LA DOCENCIA E INVESTIGACION. DETALLES.-

\section{RESOLUCIÓN $\mathbf{N}^{\circ} 376$}

La Plata, -6 SET. 2012

VISTAS las presentes actuaciones, en las cuales la Directora del Proyecto "Análisis Macro y Microscópico de Restos oseos Humanos. Aportes a la Investigación Forense y Antropologica (Segunda Parte)", Profesora Dra. Ana María Inda, eleva propuesta de formalización de la presentación de la colección Osteologica "Profesor Doctor Rómulo Lambre";

en atención al acuerdo de Cooperación firmado en 2005 entre la Facultad de Ciencias Médicas y la Facultad de Ciencias Naturales y Museo de la Universidad Nacional de La Plata, que en la actualidad involucra a las Cátedras " $A$ " de Citología, Histologia y Embriología y de Métodos y Técnicas de la Investigación Antropobiológica, pertenecientes a las Unidades Académicas mencionadas con antelación y a la periódica cooperación brindada por el Cementerio de la Ciudad de la Plata que otorga el material necesario para incrementar dicha colección;

CONSIDERANDO que con base en este material se han desarrollado proyectos de Investigación colectivos e individuales, acreditados por Instituciones del Sistema Cientifico Nacional y vinculados con la caracterización biológica individual, cuyos resultados parciales han sido volcados en tesis Doctorales, Articulos publicados en Revistas periódicas y Encuentros Académicos de la Especialidad;

y teniendo en cuenta que los análisis realizados por los distintos investigadores redundarán en una mayor comprensión de la Histología y Anatomía Osea, asi como también en el desarrollo y aplicación de métodos y técnicas vinculados a las ciencias Forenses;

\section{EL CONSEJO DIRECTIVO DE LLA FACULTAD DE CIENCIAS MÉDICAS} - en sesión de fecha 15/08/2012 -

R E S U E L V E:

ARTICULO $1^{\circ}$.- RECONOCER la existencia de la Colécción Osteológica "Profesor Doctor Rómulo Lambre" con sede en la Cátedra "A" de Citología, Histología y Embriología, la cual se encuentra encargada de su curación y administración, otorgándole apoyo institucional para su funcionamiento.

ARTICULO $2^{\circ}$.- Registrese, tómese debida nota, comuniquese, tome conocimiento la secretaría de Ciencia y 'técnica y cumplido, ARCHIVESE. mer

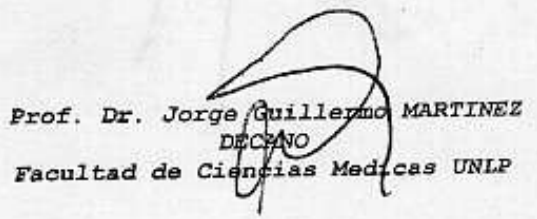




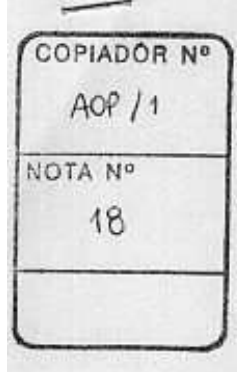

LA PLATA, 29 de agosto de 2012.-

Expediente № $800-13.812 / 12$.-

Señor Profesora

Dra. Ana María INDA

S/D

Tengo el agrado de dirigirme a Usted, con el objeto de enviarle -adjunto a la presente-, el Formulario de Aprobación de Protocolo del Comité de Bioética de esta Facultad, sobre el Protocolo titulado "Integración y Análisis de la Colección Osteológica Profesor Doctor Rómulo Lambre".

atentamente.

Sin otro particular, saludo a Usted muy

Acc

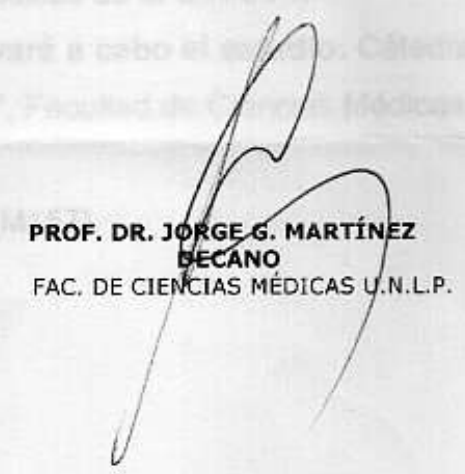




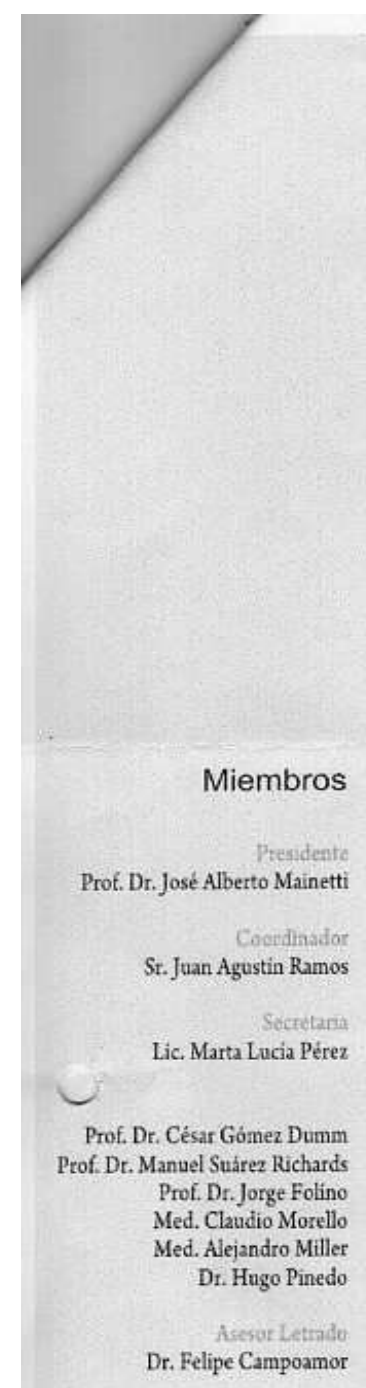

Prof. Dr. César Gómez Dumm Prof. Dr. Jorge Folino Med. Claudio Morello d. Alejandro Mille Dr. Felipe Campoamor
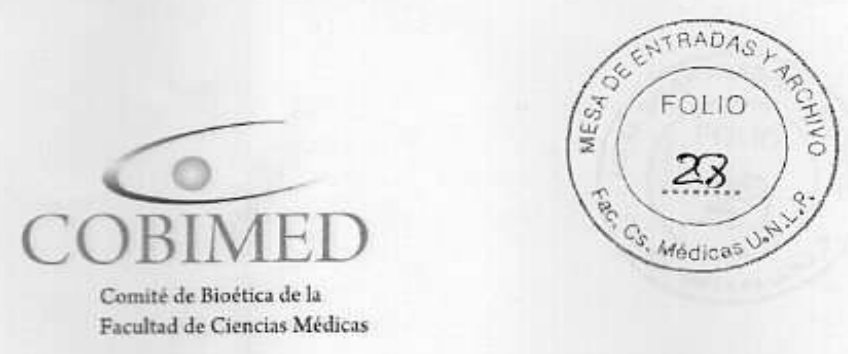

\section{FORMULARIO DE APROBACIÓN DE PROTOCOLO}

A los efectos del cumplimiento de las Buenas Prácticas Clínicas, el Comité de Bioética (COBIMED) / Comité Institucional de la Facultad de Ciencias Médicas de la Universidad Nacional de La Plata aprueba según consta en Acta $N^{\circ} 17$ y autoriza el desarrollo del estudio a realizarse en esta Facultad a cargo de la Prof. Dra. Inda Ana María, solicitándole un informe de seguimiento cada seis meses hasta la culminación del proyecto.

Título del Protocolo: "INTEGRACIÓN Y ANÁLISIS DE LA COLECCIÓN OSTEOLÓGICA PROF. DR. RÓMULO LAMBRE." (EXP.: $N^{\circ}$ 0800-013812/12-000).

Nombre del Investigador responsable: Dra. Inda, Ana María (Profesora de la Facultad de Ciencias Médicas de la U.N.L.P.).

Nombre de la Institución donde se llevará a cabo el estudio: Cátedra de Citología, Histología y Embriología "A", Facultad de Ciencias Médicas, Universidad Nacional de La Plata.

Financiamiento: Proyecto de Incentivo (M157)

Tipo de Comité: Independiente

FACUltad de Ciencias Medicas, Unlp

Avenida 60 y 120 | La Plata | Buenos Aires | Argentina | Tel +54 2214275022 | covimed@atas.med.unlp.edu.ar 


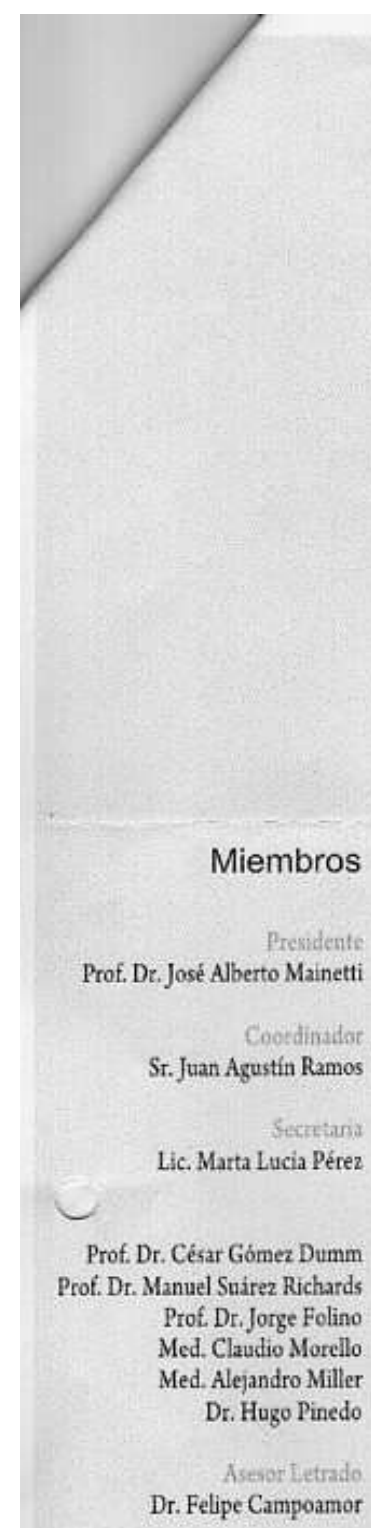

Nombre y sello del Comité:

Aclaración de Firma:

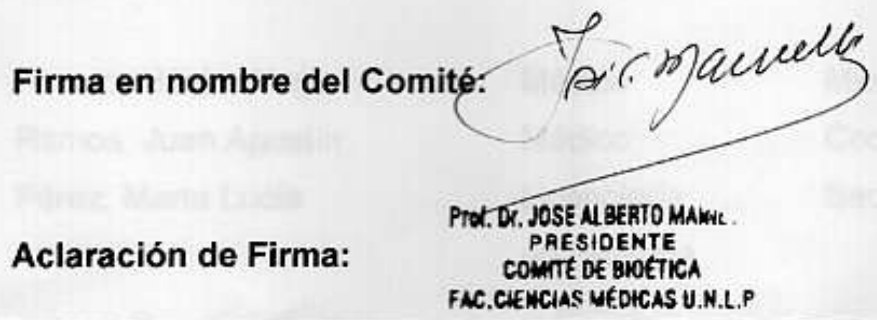

Comité de Bioética de 1 .

Facultad de Ciencias Médicas

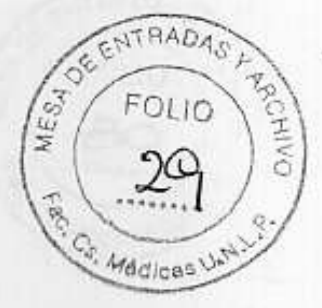

Lugar y fecha: La Plata, 21 de Agosto de 2012.

Integrantes del Comité:
Apellido y Nombre

Mainetti, José Alberto

Suárez Richards, Manuel

Folino, Jorge

Campoamor, Felipe

Morello, Claudio

Miller, Alejandro

$\begin{array}{ll}\text { Ocupación } & \text { Cargo en el Comité } \\ \text { Doctor } & \text { Presidente } \\ \text { Doctor } & \text { Miembro } \\ \text { Doctor } & \text { Miembro } \\ \text { Abogado } & \text { Miembro } \\ \text { Médico } & \text { Miembro } \\ \text { Médico } & \text { Miembro }\end{array}$

FACULTAD DE CIENCIAS MEdicas, UNLP

Avenida 60 y 120 | La Plata | Buenos Aires |Argentina | Tel +54 2214275022 | covimed@atas.med.unlp.eduar 


\section{ANEXO DE RESULTADOS -TABLAS}

Tabla I. Matriz Básica de Datos

\begin{tabular}{|c|c|c|c|c|c|c|c|c|c|c|}
\hline Individuo & edad & sexo & lat. & Can.Hav & OC & OF & N.On & N.On.Fg & \%On.Fg & OPD \\
\hline CMLP.036 & 22 & $M$ & $\mathrm{D}$ & 40,96 & 36 & 12 & 9 & 3 & 25,00 & 10,91 \\
\hline CMLP.053 & 25 & $M$ & 1 & 38,39 & 36 & 12 & 9 & 3 & 25,00 & 10,91 \\
\hline CMLP.0120 & 26 & $F$ & 1 & 46,39 & 48 & 24 & 12 & 6 & 33,33 & 16,36 \\
\hline CMLP.043 & 33 & $M$ & D & 45,11 & 44 & 20 & 11 & 5 & 31,25 & 14,55 \\
\hline CMLP.0228 & 35 & $M$ & 1 & 49,98 & 40 & 20 & 10 & 5 & 33,33 & 13,64 \\
\hline CMLP.017 & 40 & $M$ & D & 49,74 & 28 & 32 & 7 & 8 & 53,33 & 13,64 \\
\hline CMLP.0179 & 40 & $M$ & 1 & 47,80 & 45 & 8 & 11 & 2 & 15,09 & 12,05 \\
\hline CMLP.07 & 41 & $M$ & $D$ & 44,59 & 49 & 40 & 12 & 10 & 44,94 & 20,23 \\
\hline CMLP.01 & 42 & $M$ & $D$ & 49,85 & 54 & 36 & 14 & 9 & 40,00 & 20,45 \\
\hline CMLP.014 & 43 & $M$ & $D$ & 44,82 & 60 & 20 & 15 & 5 & 25,00 & 18,18 \\
\hline CMLP.O23 & 43 & $M$ & $D$ & 42,30 & 55 & 16 & 14 & 4 & 22,54 & 16,14 \\
\hline CMLP.042 & 44 & $M$ & $D$ & 54,63 & 40 & 28 & 10 & 7 & 41,18 & 15,45 \\
\hline CMLP.0219 & 45 & $F$ & 1 & 48,20 & 55 & 12 & 14 & 3 & 17,91 & 15,23 \\
\hline CMLP.0119 & 46 & $F$ & 1 & 52,35 & 79 & 8 & 20 & 2 & 9,20 & 19,77 \\
\hline CMLP.0190 & 46 & $M$ & 1 & 48,98 & 53 & 8 & 13 & 2 & 13,11 & 13,86 \\
\hline CMLP.O27 & 47 & $M$ & $D$ & 47,28 & 67 & 28 & 17 & 7 & 29,47 & 21,59 \\
\hline CMLP.0223 & 48 & $\mathrm{~F}$ & 1 & 43,33 & 55 & 8 & 14 & 2 & 12,70 & 14,32 \\
\hline CMLP.037 & 48 & $M$ & $D$ & 45,84 & 47 & 24 & 12 & 6 & 33,80 & 16,14 \\
\hline CMLP.063 & 49 & $M$ & 1 & 42,15 & 51 & 4 & 13 & 1 & 7,27 & 12,50 \\
\hline CMLP.081 & 49 & $M$ & 1 & 44,46 & 53 & 16 & 13 & 4 & 23,19 & 15,68 \\
\hline CMLP.0212 & 50 & $\mathrm{~F}$ & 1 & 44,24 & 44 & 68 & 11 & 17 & 60,71 & 25,45 \\
\hline CMLP.0220 & 50 & $\mathrm{~F}$ & 1 & 43,75 & 48 & 20 & 12 & 5 & 29,41 & 15,45 \\
\hline CMLP.072 & 50 & $\mathrm{~F}$ & 1 & 43,13 & 60 & 52 & 15 & 13 & 46,43 & 25,45 \\
\hline CMLP.0114 & 50 & $M$ & 1 & 40,58 & 60 & 48 & 15 & 12 & 44,44 & 24,55 \\
\hline CMLP.059 & 50 & $\mathrm{M}$ & I & 49,70 & 44 & 48 & 11 & 12 & 52,17 & 20,91 \\
\hline
\end{tabular}




\begin{tabular}{|c|c|c|c|c|c|c|c|c|c|c|}
\hline CMLP.0227 & 51 & $M$ & 1 & 44,52 & 48 & 48 & 12 & 12 & 50,00 & 21,82 \\
\hline CMLP.0160 & 52 & $M$ & 1 & 43,34 & 56 & 28 & 14 & 7 & 33,33 & 19,09 \\
\hline CMLP.0117 & 53 & $\mathrm{~F}$ & 1 & 49,06 & 32 & 44 & 8 & 11 & 57,89 & 17,27 \\
\hline CMLP.064 & 53 & $M$ & 1 & 48,84 & 36 & 52 & 9 & 13 & 59,09 & 20,00 \\
\hline CMLP.040 & 54 & $M$ & $\mathrm{D}$ & 44,80 & 40 & 48 & 10 & 12 & 54,55 & 20,00 \\
\hline CMLP.0206 & 57 & $M$ & 1 & 44,79 & 44 & 56 & 11 & 14 & 56,00 & 22,73 \\
\hline CMLP.0225 & 57 & $M$ & 1 & 50,07 & 68 & 52 & 17 & 13 & 43,33 & 27,27 \\
\hline CMLP.06 & 57 & $M$ & $\mathrm{D}$ & 51,47 & 68 & 44 & 17 & 11 & 39,29 & 25,45 \\
\hline CMLP.0149 & 58 & $\mathrm{~F}$ & $\mathrm{D}$ & 41,61 & 56 & 44 & 14 & 11 & 44,00 & 22,73 \\
\hline CMLP.0199 & 58 & $\mathrm{~F}$ & 1 & 44,25 & 44 & 48 & 11 & 12 & 52,17 & 20,91 \\
\hline CMLP.0224 & 58 & $M$ & 1 & 53,56 & 44 & 36 & 11 & 9 & 45,00 & 18,18 \\
\hline CMLP.O29 & 58 & $M$ & $\mathrm{D}$ & 58,44 & 48 & 56 & 12 & 14 & 53,85 & 23,64 \\
\hline CMLP.0204 & 59 & $M$ & 1 & 42,12 & 44 & 60 & 11 & 15 & 57,69 & 23,64 \\
\hline CMLP.0159 & 60 & $F$ & D & 51,88 & 60 & 44 & 15 & 11 & 42,31 & 23,64 \\
\hline CMLP.0229 & 60 & $M$ & 1 & 48,25 & 100 & 56 & 25 & 14 & 35,90 & 35,45 \\
\hline CMLP.O26 & 60 & $M$ & $\mathrm{D}$ & 54,46 & 40 & 28 & 10 & 7 & 41,18 & 15,45 \\
\hline CMLP.0205 & 61 & $M$ & $\mathrm{D}$ & 49,05 & 36 & 32 & 9 & 8 & 47,06 & 15,45 \\
\hline CMLP.O25 & 62 & $M$ & $\mathrm{D}$ & 42,68 & 44 & 52 & 11 & 13 & 54,17 & 21,82 \\
\hline CMLP.038 & 62 & $M$ & $\mathrm{D}$ & 43,39 & 44 & 96 & 11 & 24 & 68,57 & 31,82 \\
\hline CMLP.031 & 63 & $\mathrm{~F}$ & $\mathrm{D}$ & 58,28 & 56 & 56 & 14 & 14 & 50,00 & 25,45 \\
\hline CMLP.0185 & 63 & $M$ & 1 & 45,06 & 52 & 32 & 13 & 8 & 38,10 & 19,09 \\
\hline CMLP.019 & 64 & $M$ & 1 & 41,68 & 48 & 32 & 12 & 8 & 40,00 & 18,18 \\
\hline CMLP.0183 & 65 & $M$ & 1 & 46,64 & 56 & 56 & 14 & 14 & 50,00 & 25,45 \\
\hline CMLP.0132 & 66 & $M$ & $\mathrm{D}$ & 49,70 & 40 & 52 & 10 & 13 & 56,52 & 20,91 \\
\hline CMLP.0134 & 67 & $\mathrm{~F}$ & 1 & 42,67 & 44 & 52 & 11 & 13 & 54,17 & 21,82 \\
\hline CMLP.0196 & 67 & $\mathrm{~F}$ & $\mathrm{D}$ & 41,03 & 40 & 76 & 10 & 19 & 65,52 & 26,36 \\
\hline CMLP.056 & 67 & $F$ & 1 & 45,84 & 40 & 48 & 10 & 12 & 54,55 & 20,00 \\
\hline CMLP.09 & 67 & $M$ & 1 & 47,66 & 48 & 44 & 12 & 11 & 47,83 & 20,91 \\
\hline CMLP.0130 & 68 & $\mathrm{~F}$ & 1 & 49,34 & 48 & 68 & 12 & 17 & 58,62 & 26,36 \\
\hline CMLP.0207 & 68 & $M$ & 1 & 46,40 & 60 & 72 & 15 & 18 & 54,55 & 30,00 \\
\hline
\end{tabular}




\begin{tabular}{|c|c|c|c|c|c|c|c|c|c|c|}
\hline CMLP.051 & 68 & $M$ & 1 & 41,11 & 36 & 52 & 9 & 13 & 59,09 & 20,00 \\
\hline CMLP.021 & 73 & $M$ & 1 & 49,30 & 40 & 76 & 10 & 19 & 65,52 & 26,36 \\
\hline CMLP.066 & 74 & $M$ & 1 & 58,48 & 44 & 40 & 11 & 10 & 47,62 & 19,09 \\
\hline CMLP.0177 & 76 & $\mathrm{~F}$ & 1 & 43,98 & 48 & 68 & 12 & 17 & 58,62 & 26,36 \\
\hline CMLP.04 & 76 & $M$ & 1 & 40,34 & 64 & 52 & 16 & 13 & 44,83 & 26,36 \\
\hline CMLP.055 & 77 & $\mathrm{M}$ & 1 & 50,69 & 48 & 60 & 12 & 15 & 55,56 & 24,55 \\
\hline CMLP.075 & 78 & $M$ & 1 & 47,47 & 96 & 76 & 24 & 19 & 44,19 & 39,09 \\
\hline CMLP.058 & 80 & $F$ & $\mathrm{D}$ & 45,76 & 48 & 52 & 12 & 13 & 52,00 & 22,73 \\
\hline CMLP.0135 & 81 & $F$ & 1 & 46,60 & 44 & 56 & 11 & 14 & 56,00 & 22,73 \\
\hline CMLP.O10 & 81 & $M$ & 1 & 40,51 & 68 & 96 & 17 & 24 & 58,54 & 37,27 \\
\hline CMLP.050 & 82 & $F$ & $\mathrm{D}$ & 53,74 & 56 & 76 & 14 & 19 & 57,58 & 30,00 \\
\hline CMLP.034 & 85 & $M$ & 1 & 58,32 & 72 & 60 & 18 & 15 & 45,45 & 30,00 \\
\hline CMLP.O22 & 88 & $\mathrm{~F}$ & 1 & 42,73 & 48 & 108 & 12 & 27 & 69,23 & 35,45 \\
\hline CMLP.032 & 88 & $M$ & 1 & 46,80 & 60 & 92 & 15 & 23 & 60,53 & 34,55 \\
\hline CMLP.O2 & 90 & $M$ & $\mathrm{D}$ & 50,90 & 76 & 72 & 19 & 18 & 48,65 & 33,64 \\
\hline CMLP.O24 & 91 & $M$ & 1 & 45,65 & 48 & 84 & 12 & 21 & 63,64 & 30,00 \\
\hline
\end{tabular}

OC: total de osteonas completas, OF: total de osteonas fragmentarias, N.On: número de osteonas completas por campo, N.On.Fg: número de osteonas fragmentarias por campo, \% On.Fg: porcentaje de osteonas fragmentarias por campo, OPD: densidad poblacional osteonal. 
Tabla II. Comparaciones múltiples - HSD de Tukey (N.On.Fg.)

\begin{tabular}{|c|c|c|c|c|c|c|}
\hline \multirow{2}{*}{$\begin{array}{l}\text { (I) Edad } \\
\text { (agrupado) }\end{array}$} & \multirow{2}{*}{$\begin{array}{l}(J) \quad \text { Edad } \\
\text { (agrupado) }\end{array}$} & \multirow{2}{*}{$\begin{array}{c}\text { Diferencia de } \\
\text { medias (I-J) }\end{array}$} & \multirow[b]{2}{*}{ Error típico } & \multirow[b]{2}{*}{ Sig. } & \multicolumn{2}{|c|}{ Intervalo de confianza al 95\% } \\
\hline & & & & & Límite inferior & Límite superior \\
\hline \multirow[t]{4}{*}{$20-29$} & $30-39$ & $-2,000$ & 3,940 & 986 & $-13,05$ & 9,05 \\
\hline & $40-49$ & $-4,467$ & 2,966 & ,562 & $-12,79$ & 3,85 \\
\hline & $50-59$ & $-8,833^{*}$ & 2,936 & ,030 & $-17,07$ &,- 59 \\
\hline & $60+$ & $-12,273^{*}$ & 2,869 & 001 & $-20,32$ & $-4,22$ \\
\hline \multirow[t]{4}{*}{$30-39$} & $20-29$ & 2,000 & 3,940 & 986 & $-9,05$ & 13,05 \\
\hline & $40-49$ & $-2,467$ & 2,966 & 920 & $-10,79$ & 5,85 \\
\hline & $50-59$ & $-6,833$ & 2,936 & 150 & $-15,07$ & 1,41 \\
\hline & $60+$ & $-10,273^{*}$ & 2,869 & ,006 & $-18,32$ & $-2,22$ \\
\hline \multirow[t]{4}{*}{$40-49$} & $20-29$ & 4,467 & 2,966 & ,562 & $-3,85$ & 12,79 \\
\hline & $30-39$ & 2,467 & 2,966 & 920 & $-5,85$ & 10,79 \\
\hline & $50-59$ & $-4,367^{*}$ & 1,377 & ,019 & $-8,23$ &,- 50 \\
\hline & $60+$ & $-7,806^{*}$ & 1,227 & ,000 & $-11,25$ & $-4,36$ \\
\hline \multirow[t]{4}{*}{$50-59$} & $20-29$ & $8,833^{*}$ & 2,936 & 030 & ,59 & 17,07 \\
\hline & $30-39$ & 6,833 & 2,936 & 150 & $-1,41$ & 15,07 \\
\hline & $40-49$ & $4,367^{*}$ & 1,377 & 019 & ,50 & 8,23 \\
\hline & $60+$ & $-3,439^{*}$ & 1,154 & ,032 & $-6,68$ &,- 20 \\
\hline \multirow[t]{4}{*}{$60+$} & $20-29$ & $12,273^{*}$ & 2,869 & ,001 & 4,22 & 20,32 \\
\hline & $30-39$ & $10,273^{*}$ & 2,869 & ,006 & 2,22 & 18,32 \\
\hline & $40-49$ & $7,806^{*}$ & 1,227 & ,000 & 4,36 & 11,25 \\
\hline & $50-59$ & $3,439^{*}$ & 1,154 & ,032 & 20 & 6,68 \\
\hline
\end{tabular}

*. La diferencia de medias es significativa al nivel 0.05 .

Grupo menores o iguales de 49 años

Tabla III. Resumen del modelo ${ }^{c, d}$

\begin{tabular}{|c|c|c|c|c|}
\hline Modelo & $\mathrm{R}$ & $\mathrm{R}^{2}$ & $\mathrm{R}^{2}$ corregida & $\begin{array}{c}\text { Error típico de la } \\
\text { estimación }\end{array}$ \\
\hline 1 &, $845^{a}$ & 715, & 686 & 1,800 \\
\hline 2 &, $915^{\mathrm{b}}$ & ,837 & 801 & 1,433 \\
\hline \multicolumn{5}{|c|}{ a. Variables predictoras: (Constante), N.On } \\
\hline \multicolumn{5}{|c|}{ b. Variables predictoras: (Constante), N.On, OPD } \\
\hline \multicolumn{5}{|c|}{ c. Edad (agrupado) = Menores de 50} \\
\hline \multicolumn{5}{|c|}{ d. Variable dependiente: Edad } \\
\hline
\end{tabular}


Tabla IV. Análisis de la varianza - ANOVA ${ }^{c, d}$

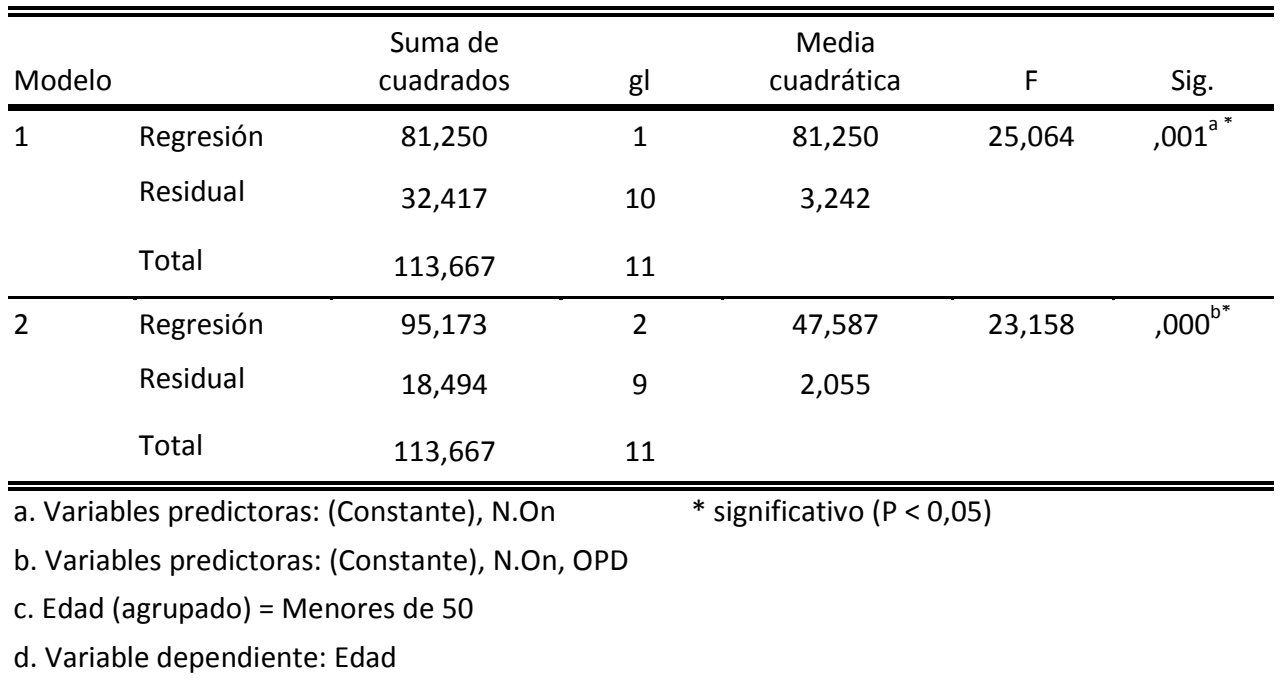

Tabla V. Coeficientes de la ecuación de regresión a,b

\begin{tabular}{|c|c|c|c|c|c|c|}
\hline \multirow{2}{*}{\multicolumn{2}{|c|}{ Modelo }} & \multicolumn{2}{|c|}{ Coeficientes no estandarizados } & \multirow{2}{*}{$\begin{array}{c}\begin{array}{c}\text { Coeficientes } \\
\text { tipificados }\end{array} \\
\text { Beta }\end{array}$} & \multirow[b]{2}{*}{$\mathrm{t}$} & \multirow[b]{2}{*}{ P-valo } \\
\hline & & B & Error típico & & & \\
\hline \multirow[t]{2}{*}{1} & (Constante) & 31,417 & 2,795 & & 11,239 & ,000 \\
\hline & N.On & 1,250 & ,250 & ,845 & 5,006 & ,001 \\
\hline \multirow[t]{3}{*}{2} & (Constante) & 27,229 & 2,746 & & 9,915 & ,000 \\
\hline & N.On & 818 & 259 &, 554 & 3,162 & 012 \\
\hline & OPD & ,549 & 211 & ,456 & 2,603 & ,029 \\
\hline
\end{tabular}

a. Edad (agrupado) $=$ Menores de 50

b. Variable dependiente: Edad

\section{Análisis de Residuos}

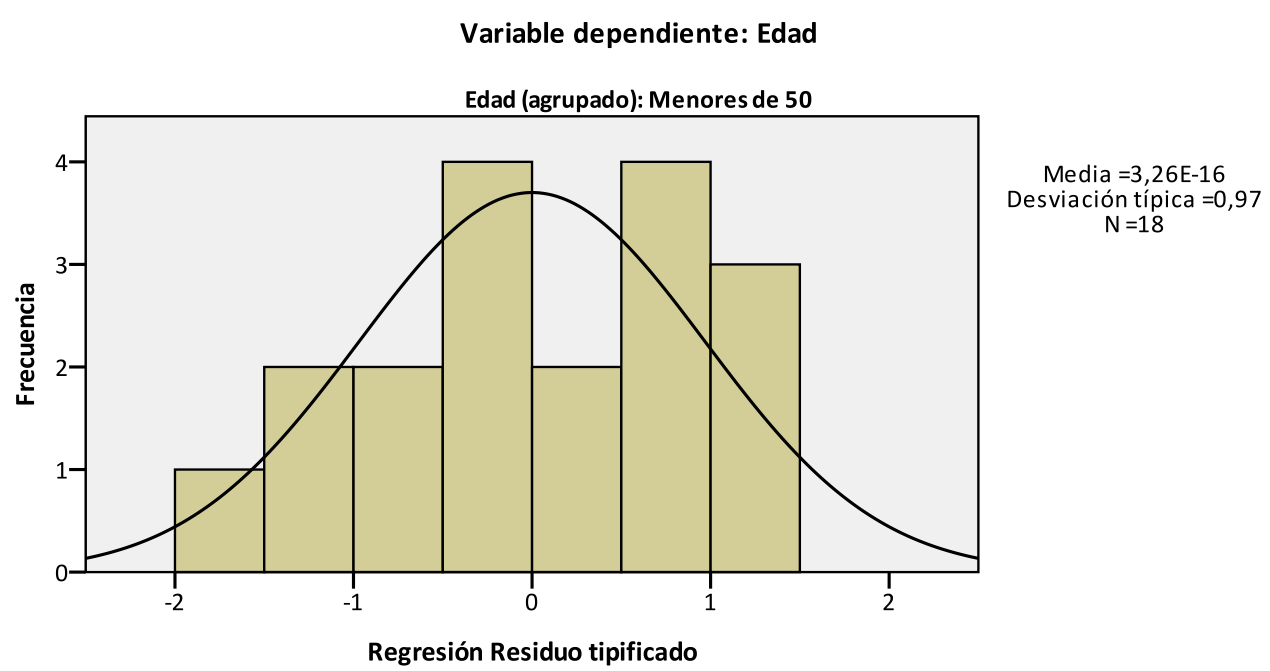


Gráfico P-P normal de regresión Residuo tipificado

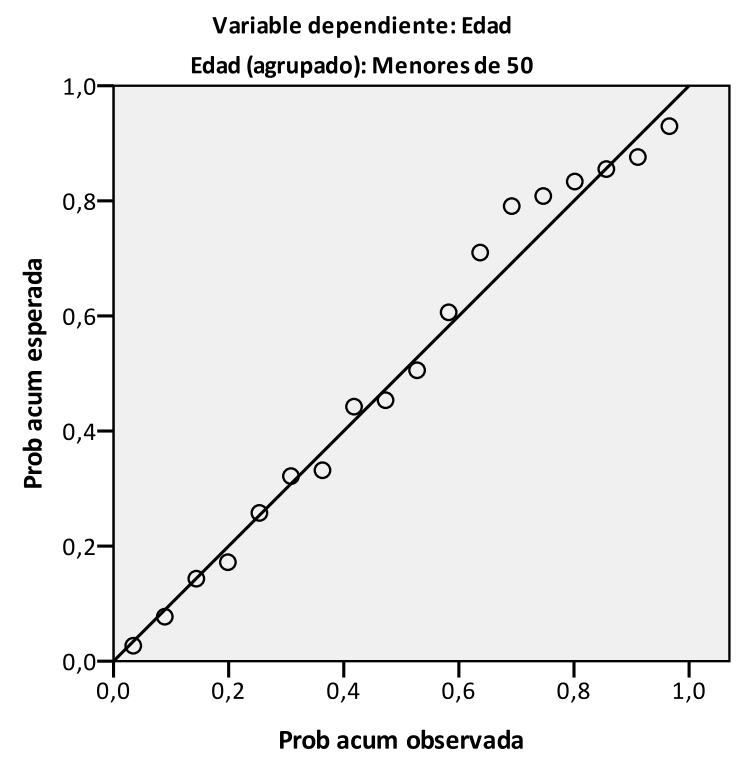

\section{Grafico de dispersión}

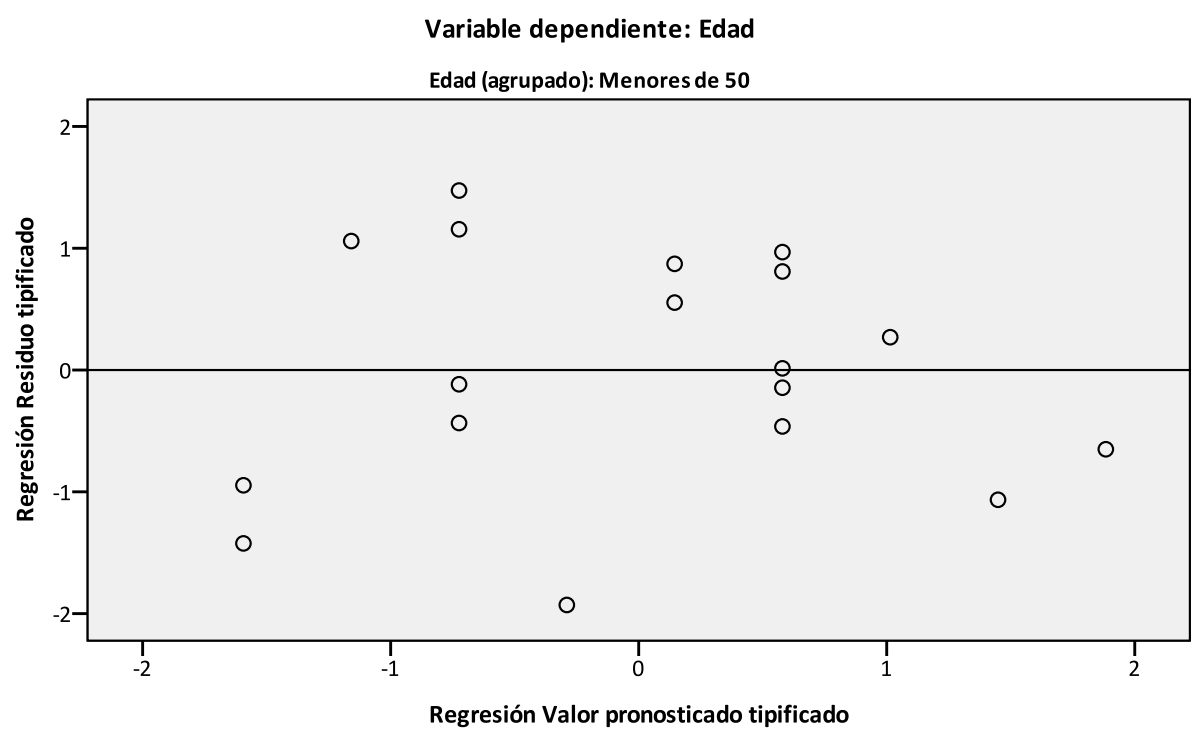


Grupo mayores de 50 años

Tabla VI. Resumen del modelo ${ }^{b, c}$

\begin{tabular}{lcccc}
\hline \hline \begin{tabular}{l} 
Modelo \\
\hline 1
\end{tabular}$\quad \mathrm{R}^{2}$ & $\mathrm{R}^{2}$ corregida & $\begin{array}{c}\text { Error típico de la } \\
\text { estimación }\end{array}$ \\
\hline \hline a. Variables predictoras: (Constante), N.On.Fg &, 484 & 8,557 \\
b. Edad (agrupado) = Mayores de 50 & & \\
c. Variable dependiente: Edad
\end{tabular}

Tabla VII. Análisis de la varianza ANOVA ${ }^{\mathrm{b}, \mathrm{c}}$

\begin{tabular}{|c|c|c|c|c|c|c|}
\hline Modelo & & $\begin{array}{l}\text { Suma de } \\
\text { cuadrados }\end{array}$ & $\mathrm{gl}$ & $\begin{array}{c}\text { Media } \\
\text { cuadrática }\end{array}$ & $F$ & P-valor \\
\hline \multirow[t]{3}{*}{1} & Regresión & 3230,844 & 1 & 3230,844 & 44,128 & $000^{*}$ \\
\hline & Residual & 3441,156 & 47 & 73,216 & & \\
\hline & Total & 6672,000 & 48 & & & \\
\hline
\end{tabular}

a. Variables predictoras: (Constante), N.On.Fg $*$ significativo $(P<0,05)$

b. Edad (agrupado) $=$ Mayores de 50

c. Variable dependiente: Edad

Tabla VIII. Coeficientes de la ecuación de regresión a,b

\begin{tabular}{|c|c|c|c|c|c|c|}
\hline \multirow{2}{*}{\multicolumn{2}{|c|}{ Modelo }} & \multicolumn{2}{|c|}{ Coeficientes no estandarizados } & \multirow{2}{*}{$\begin{array}{c}\begin{array}{c}\text { Coeficientes } \\
\text { tipificados }\end{array} \\
\text { Beta }\end{array}$} & \multirow[b]{2}{*}{$\mathrm{t}$} & \multirow[b]{2}{*}{ P - valor } \\
\hline & & B & Error típico & & & \\
\hline \multirow[t]{2}{*}{1} & (Constante) & 40,781 & 4,009 & & 10,173 & $000^{*}$ \\
\hline & N.On.Fg & 1,838 & 277 & ,696 & 6,643 &, $000 *$ \\
\hline
\end{tabular}

a. Edad (agrupado) $=$ Mayores de $50 *$ significativo $(P<0,05)$

b. Variable dependiente: Edad 


\section{Análisis de los residuos}

\section{Variable dependiente: Edad}

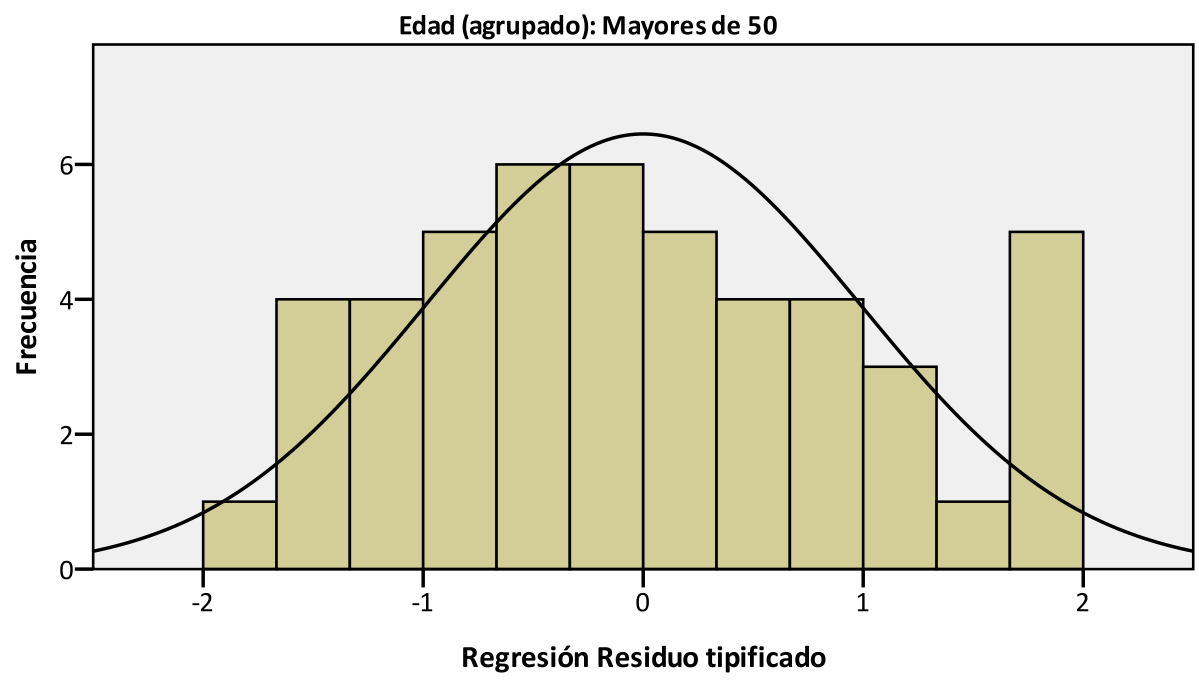

Gráfico P-P normal de regresión Residuo tipificado

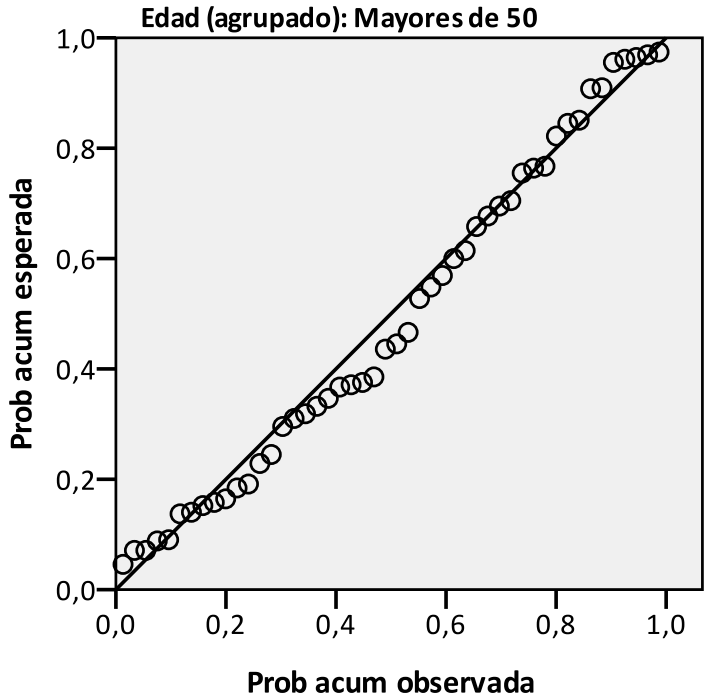




\section{Gráfico de dispersión}

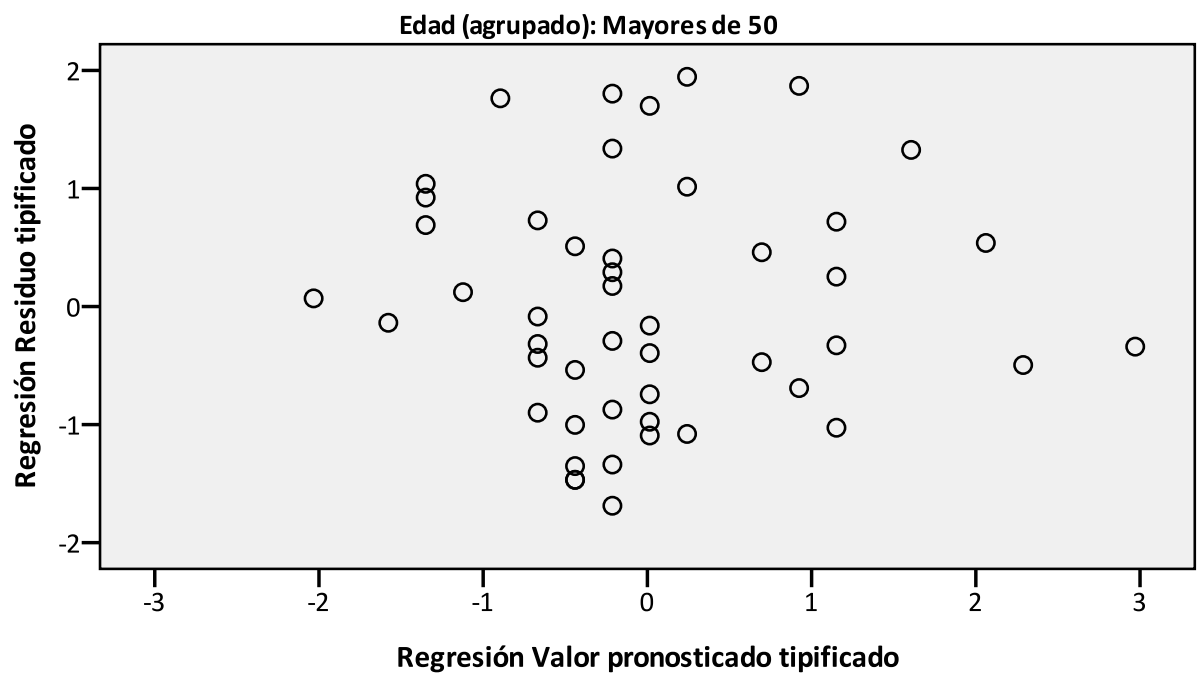


Tabla IX. Edades estimadas a partir de los diferentes métodos

Individuo edad sexo Vasallo SyG K1

\begin{tabular}{|c|c|c|c|c|c|c|}
\hline CMLP.036 & 22 & $M$ & 35,87 & 25,23 & 4,45 & 6,77 \\
\hline CMLP.053 & 25 & $M$ & 35,87 & 25,95 & 3,96 & 6,77 \\
\hline CMLP.0120 & 26 & $\mathrm{~F}$ & 45,18 & 26,08 & 4,52 & 8,31 \\
\hline CMLP.043 & 33 & $M$ & 42,85 & 25,65 & 4,34 & 7,79 \\
\hline CMLP.0228 & 35 & $M$ & 45,18 & 23,50 & 4,15 & 7,79 \\
\hline CMLP.017 & 40 & $M$ & 67,52 & 21,19 & 3,59 & 9,33 \\
\hline CMLP.0179 & 40 & $M$ & 45,18 & 22,53 & 3,77 & 7,28 \\
\hline CMLP.07 & 41 & $M$ & 54,49 & 28,16 & 4,90 & 10,36 \\
\hline CMLP.01 & 42 & $M$ & 48,56 & 26,69 & 4,90 & 9,33 \\
\hline CMLP.014 & 43 & M & 57,59 & 24,94 & 4,15 & 9,33 \\
\hline CMLP.O23 & 43 & $M$ & 45,18 & 25,65 & 4,15 & 7,79 \\
\hline CMLP.042 & 44 & $M$ & 53,94 & 22,19 & 4,15 & 8,82 \\
\hline CMLP.0219 & 45 & $\mathrm{~F}$ & 38,97 & 26,36 & 4,71 & 7,79 \\
\hline CMLP.0119 & 46 & $F$ & 50,31 & 29,15 & 5,65 & 10,87 \\
\hline CMLP.0190 & 46 & $M$ & 49,10 & 25,36 & 4,52 & 8,82 \\
\hline CMLP.O27 & 47 & $M$ & 53,64 & 26,62 & 4,71 & 9,85 \\
\hline CMLP.0223 & 48 & $\mathrm{~F}$ & 52,62 & 26,94 & 4,52 & 9,33 \\
\hline CMLP.037 & 48 & $M$ & 66,45 & 24,65 & 4,15 & 10,87 \\
\hline CMLP.063 & 49 & $M$ & 27,66 & 28,85 & 4,90 & 6,77 \\
\hline CMLP.081 & 49 & $M$ & 50,50 & 27,41 & 4,71 & 9,33 \\
\hline CMLP.O212 & 50 & $\mathrm{~F}$ & 75,76 & 25,89 & 4,34 & 13,98 \\
\hline CMLP.0220 & 50 & $\mathrm{~F}$ & 40,80 & 26,82 & 4,52 & 7,79 \\
\hline CMLP.072 & 50 & $\mathrm{~F}$ & 59,80 & 29,36 & 5,08 & 11,91 \\
\hline CMLP.0114 & 50 & $M$ & 57,59 & 30,08 & 5,08 & 11,39 \\
\hline
\end{tabular}




\begin{tabular}{|c|c|c|c|c|c|c|}
\hline CMLP.059 & 50 & $M$ & 66,22 & 24,36 & 4,34 & 11,39 \\
\hline CMLP.O227 & 51 & $M$ & 63,79 & 26,60 & 4,52 & 11,39 \\
\hline CMLP.0160 & 52 & $M$ & 45,18 & 28,51 & 4,90 & 8,82 \\
\hline CMLP.0117 & 53 & $\mathrm{~F}$ & 72,61 & 22,17 & 3,77 & 10,87 \\
\hline CMLP.064 & 53 & $M$ & 73,95 & 23,02 & 3,96 & 11,91 \\
\hline CMLP.040 & 54 & $M$ & 68,87 & 24,95 & 4,15 & 11,39 \\
\hline CMLP.0206 & 57 & $M$ & 70,50 & 25,74 & 4,34 & 12,42 \\
\hline CMLP.O225 & 57 & $M$ & 56,35 & 29,00 & 5,46 & 11,91 \\
\hline CMLP.06 & 57 & $M$ & 51,83 & 28,61 & 5,46 & 10,87 \\
\hline CMLP.0149 & 58 & $\mathrm{~F}$ & 57,09 & 29,00 & 4,90 & 10,87 \\
\hline CMLP.0199 & 58 & $\mathrm{~F}$ & 66,22 & 25,89 & 4,34 & 11,39 \\
\hline CMLP.O224 & 58 & $M$ & 58,21 & 23,28 & 4,34 & 9,85 \\
\hline CMLP.O29 & 58 & $M$ & 68,09 & 22,71 & 4,52 & 12,42 \\
\hline CMLP.0204 & 59 & $M$ & 72,39 & 26,49 & 4,34 & 12,94 \\
\hline CMLP.0159 & 60 & $\mathrm{~F}$ & 55,20 & 26,91 & 5,08 & 10,87 \\
\hline CMLP.O229 & 60 & $M$ & 48,04 & 35,83 & 6,96 & 12,42 \\
\hline CMLP.026 & 60 & $M$ & 53,94 & 22,24 & 4,15 & 8,82 \\
\hline CMLP.0205 & 61 & $M$ & 60,51 & 22,97 & 3,96 & 9,33 \\
\hline CMLP.O25 & 62 & $M$ & 68,45 & 26,33 & 4,34 & 11,91 \\
\hline CMLP.038 & 62 & $M$ & 84,54 & 26,13 & 4,34 & 17,62 \\
\hline CMLP.031 & 63 & $\mathrm{~F}$ & 63,79 & 24,33 & 4,90 & 12,42 \\
\hline CMLP.0185 & 63 & $M$ & 50,50 & 27,24 & 4,71 & 9,33 \\
\hline CMLP.019 & 64 & $M$ & 52,62 & 27,40 & 4,52 & 9,33 \\
\hline CMLP.0183 & 65 & $M$ & 63,79 & 27,59 & 4,90 & 12,42 \\
\hline CMLP.0132 & 66 & $M$ & 71,08 & 23,57 & 4,15 & 11,91 \\
\hline CMLP.0134 & 67 & $F$ & 68,45 & 26,33 & 4,34 & 11,91 \\
\hline
\end{tabular}




\begin{tabular}{|c|c|c|c|c|c|c|}
\hline CMLP.0196 & 67 & $\mathrm{~F}$ & 81,13 & 26,00 & 4,15 & 15,02 \\
\hline CMLP.056 & 67 & $\mathrm{~F}$ & 68,87 & 24,65 & 4,15 & 11,39 \\
\hline CMLP.09 & 67 & $M$ & 61,37 & 25,73 & 4,52 & 10,87 \\
\hline CMLP.0130 & 68 & $\mathrm{~F}$ & 73,42 & 25,25 & 4,52 & 13,98 \\
\hline CMLP.0207 & 68 & $M$ & 68,87 & 28,45 & 5,08 & 14,50 \\
\hline CMLP.051 & 68 & $M$ & 73,95 & 25,19 & 3,96 & 11,91 \\
\hline CMLP.021 & 73 & $M$ & 81,13 & 23,69 & 4,15 & 15,02 \\
\hline CMLP.066 & 74 & $M$ & 61,13 & 21,91 & 4,34 & 10,36 \\
\hline CMLP.0177 & 76 & $\mathrm{~F}$ & 73,42 & 26,76 & 4,52 & 13,98 \\
\hline CMLP.O4 & 76 & $M$ & 58,02 & 30,93 & 5,27 & 11,91 \\
\hline CMLP.055 & 77 & $M$ & 70,00 & 24,88 & 4,52 & 12,94 \\
\hline CMLP.075 & 78 & $M$ & 57,30 & 35,26 & 6,77 & 15,02 \\
\hline CMLP.058 & 80 & $F$ & 66,03 & 26,26 & 4,52 & 11,91 \\
\hline CMLP.0135 & 81 & $\mathrm{~F}$ & 70,50 & 25,23 & 4,34 & 12,42 \\
\hline CMLP.010 & 81 & $M$ & 73,33 & 31,68 & 5,46 & 17,62 \\
\hline CMLP.050 & 82 & $\mathrm{~F}$ & 72,26 & 25,60 & 4,90 & 15,02 \\
\hline CMLP.034 & 85 & $M$ & 58,72 & 27,48 & 5,65 & 12,94 \\
\hline CMLP.O22 & 88 & $\mathrm{~F}$ & 85,27 & 27,11 & 4,52 & 19,19 \\
\hline CMLP.032 & 88 & $M$ & 75,55 & 28,34 & 5,08 & 17,10 \\
\hline CMLP.O2 & 90 & $M$ & 62,28 & 30,35 & 5,83 & 14,50 \\
\hline CMLP.024 & 91 & $\mathrm{M}$ & 79,03 & 26,29 & 4,52 & 16,06 \\
\hline
\end{tabular}

Método de Vasallo y Colaboradores, S y G: Método de Singh y Gunberg, K1: Método de Kerley para osteonas completas, K2: Método de Kerley para osteonas fragmentarias. 